UC-NRLF

||| || || || |||||||||||||||-||||||-|||||||||||

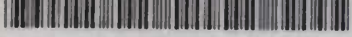

B $3349 \quad 372$ 


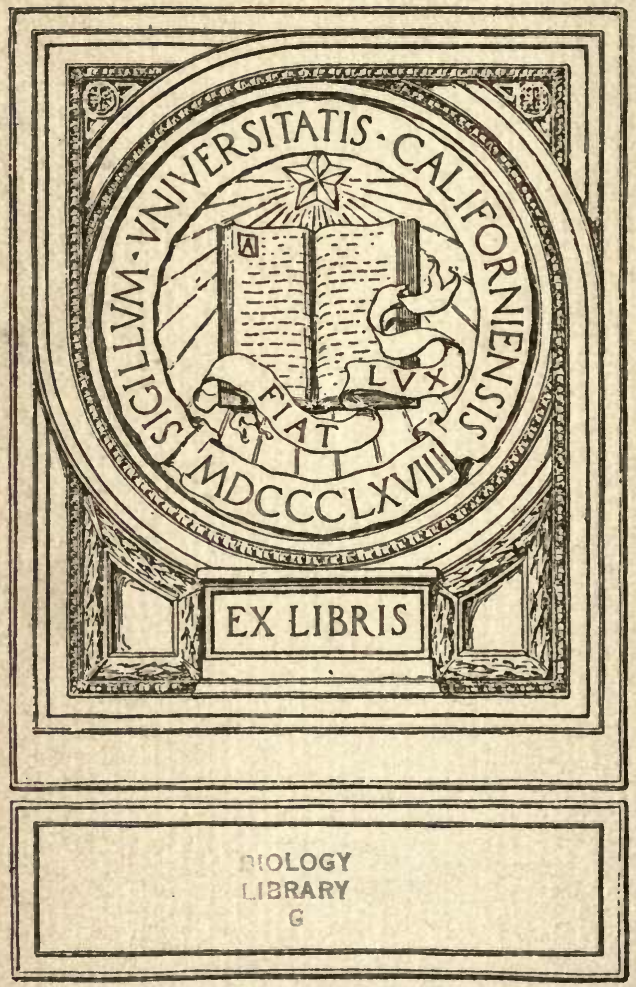







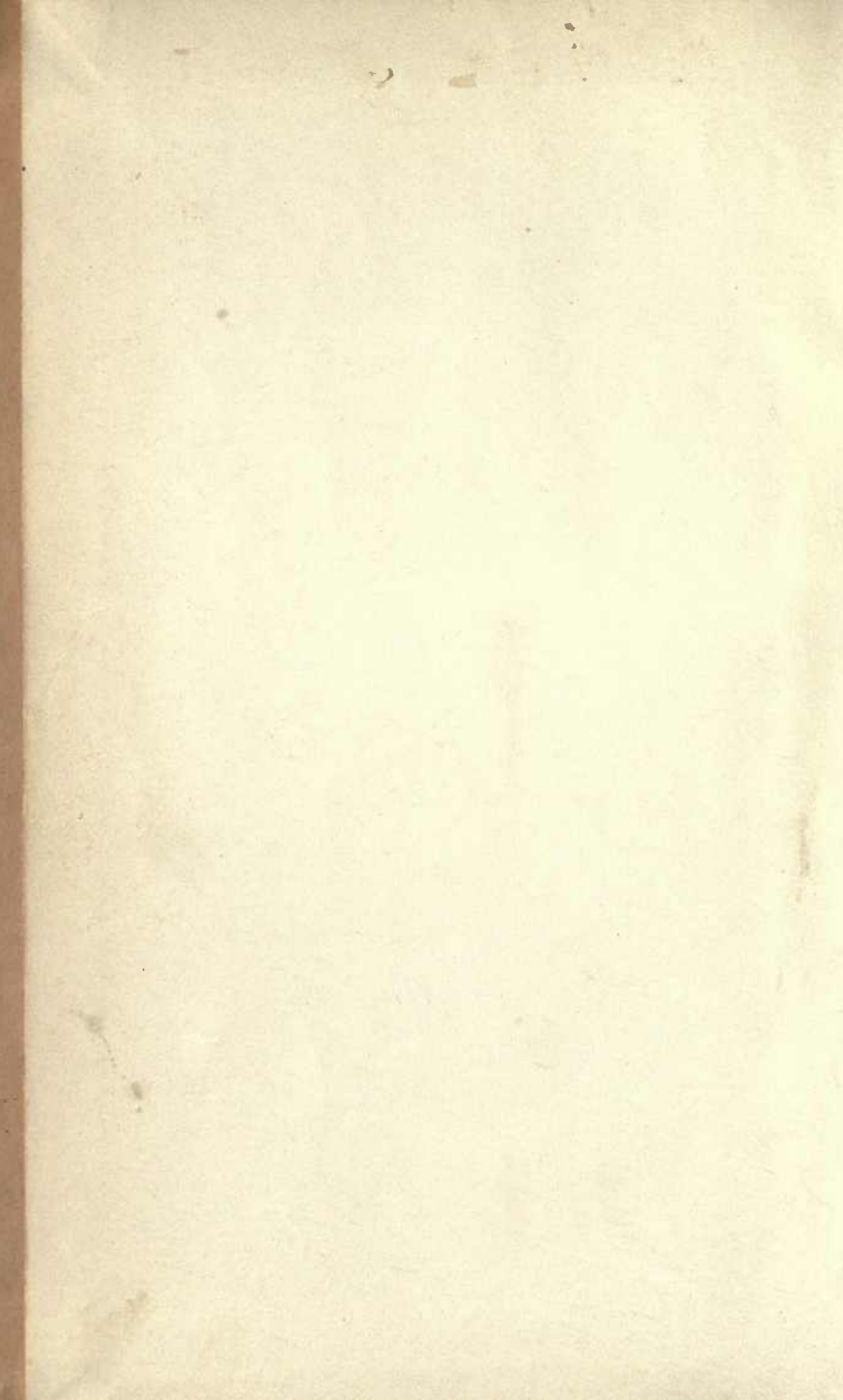

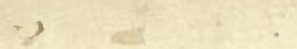
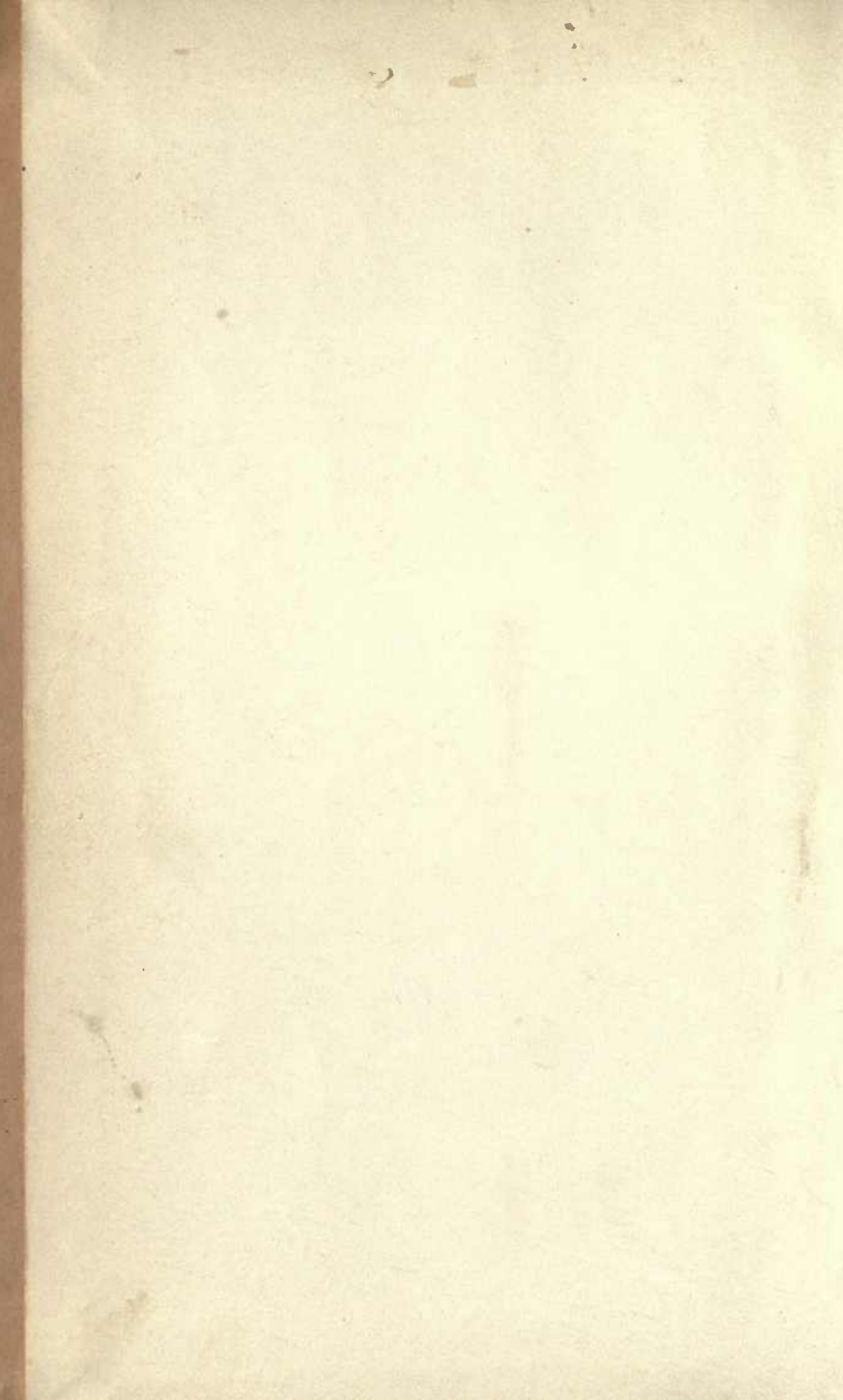

\section{.} (

.




\title{
THE UNIVERSITY OF CHICAGO SCIENCE SERIES
}

\author{
Editorial Committee \\ ELIAKIM HASTINGS MOORE, Chairman \\ JOHN MERLE COULTER \\ ROBERT ANDREWS MILLIKAN
}


The University of Chicago Science Series, established by the Trustees of the University, owes its origin to a feeling that there should be a medium of publication occupying a position between the technical journals with their short articles and the elaborate treatises which attempt to cover several or all aspects of a wide field. The volumes of the series will differ from the discussions generally appearing in technical journals in that they will present the complete results of an experiment or series of investigations which previously have appeared only in scattered articles, if published at all. On the other hand, they will differ from detailed treatises by confining themselves to specific problems of current interest, and in presenting the subject in as summary a manner and with as little technical detail as is consistent with sound method. 
A CHEMICAL SIGN OF LIFE 
THE UNIVERSITY OF CHICAGO PRESS CHICAGO, ILLINOIS

\section{Agents}

THE BAKER \& TAYLOR COMPANY NEW YORK

THE CUNNINGHAM, CURTISS \& WELCH COMPANY LOS ANGELES

THE CAMBRIDGE UNIVERSITY PRESS

LONDON AND EDIYBUEOH

THE MARUZEN-KABUSHIKI-KAISHA

TOKYO, OSAKA, TYOTO, YUXUOKA, SEMDAI

THE MISSION BOOK COMPANY

SHANeHAI

KARL W. HIERSEMANN

LEIP2I0 
'A CHEMICAL SIGN OF LIFE'

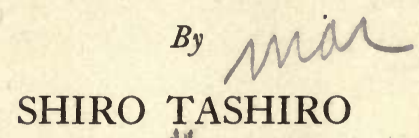

Instructor in Physiological Chemistry in the University of Chicago
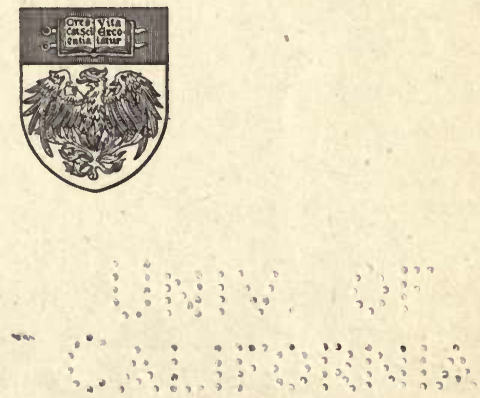

THE UNIVERSITY OF CHICAGO PRESS CHICAGO, ILLINOIS 
Copyright igI7 By

The University of Chicago

\section{All Rights Reserved}

Published March I9I7

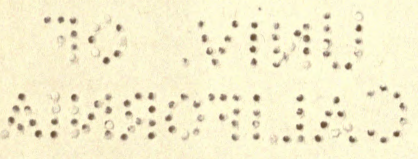




\section{PREFACE}

The present work is an attempt to apply facts discovered during the study of the physiology of nerves to living processes in general. That mechanism characteristic of all living matter which enables it to respond to the external world is best developed in the nervous system. This mechanism may be called the most characteristic thing in life. The chemical accompaniment, or basis, of this mechanism, discovered by the author in nerve fibers, he has hoped to show exists also in all forms of living matter, both of plants and of animals. It gives a chemical method of distinguishing living from dead tissue, and of measuring the quantity of life.

This book, therefore, contains somewhat in detail all the essential facts which he with his students has discovered from studies of the chemical changes in nerves accompanying functional change. In the presentation of this work, however, many important references and discussions have been omitted in order that the reader may not lose the main trend of the argument. The facts themselves are nevertheless given in the form of accurate numerical data so that the book may be useful also to the specialist whose interest lies more directly in the general physiology of the nervous system.

In an appendix the detailed method for the use of the biometer is added in response to frequent requests of many friends and students who wish to use it for various biological and chemical researches.

The author is deeply indebted to Professor A. P. Mathews for his criticism, scientific and literary, during the preparation of the work.

January, I9I7

Shiro TASHIRo 


\section{CONTENTS}

Chapter

I. IRritability AS A Sign OF Life . . . . . . I The Characteristics of Living Matter. Irritability.

- Functional Changes as a Sign of Irritability. Functional Changes in the Nerve Fiber.

II. Chemical Signs of Irritability in the Nerve FIBER

Signs of Metabolic Activities in a Tissue. Indirect Evidence for Presence of Metabolic Activity in the Nerve Fiber. Direct Evidence. Experimental Methods with NonMedullated Nerve Fiber. Medullated Nerve Fiber. Is Carbon Dioxide Produced by Living Processes? Discussion.

III. Chemical Signs of Irritability in the Nerve FIBER-Continued

Increased Metabolism on Stimulation. Experimental. Electrical Stimulation. Other Stimulations. Discussion.

IV. Excitation and Conduction

Excitability and Metabolism. Degree of Excitability Compared with Metabolism. Effects of Narcotics. Lower Concentration. Higher Concentration. Direction of the Nerve Impulse and Metabolic Gradient. Velocity of the Nerve Impulse and Carbon Dioxide Production.

V. Chemical Signs of Life .

Resting Metabolism in Seeds. Increased Metabolism in Seeds on Injury. Other Tissues. A Chemical Sign of Life.

VI. Conclusions

Summary. Other Criteria of Life. Functions of Resting Metabolism. Metabolism and Irritability. Chemical Conditions in the Living Processes. Quantity of Life.

Appendix. The Biometer: How to Use It Io9 



\section{CHAPTER I}

\section{IRRITABILITY AS A SIGN OF LIFE}

In the pages which follow we shall consider particularly the question of the chemical processes which take place in nerves when nerve impulses pass over them. There is scarcely a subject in the world more interesting than this one, for the question of what is the nature of that disturbance in nerve tissue which shows itself in our thoughts has attracted men from the earliest days. We must first find out the changes of a material kind-if there are any such changeswhich occur in the brain when we think before we can form any probable idea of the relation of these changes to the psychical changes which accompany them. Obviously, we must first try to solve the simplest problem in this field and discover what are the changes of a chemical or physical kind when a nerve impulse flashes over a nerve before we can form any conception of the relation of the material to the psychic world. The following pages do not contain, of course, the solution of this problem of such absorbing interest, but they do present the first accurate information we have had of the chemical changes which accompany the nerve impulse; they have in them, therefore, the foundation upon which a solid structure of fact can be based.

The observations which we have to present are not confined to nerves, however, for psychic phenomena are 
not confined, we believe, to animals which have welldeveloped nerves. The course of evolution from the simplest to the most complex shows us very clearly that the complex psychic life of man and the higher animals did not suddenly spring fully formed into existence. In every child, in fact, it can be seen to appear very slowly and gradually and to increase as the child develops. We cannot say at what point psychic life begins, for the simplest organisms show some signs of it. Indeed, as living originates from lifeless, we are led to conclude that the simplest rudiments of psychic life must be found also in the lifeless. And perhaps the universe as a whole, inert as it appears to us to be, may have a psychic life of its own. So it is not necessary to confine our studies to nerves, for we find the same phenomena which nerves show, phenomena corresponding to those of nerve impulses, even in plants, and indeed in the simplest kinds of plants. The differences between animals and plants are superficial differences. Plants, in general, are sessile; they cannot move freely from place to place as animals do; and they have a green pigment in them-chlorophyll-while most animals have a red pigment in their blood. This green pigment enables plants to make their food from simpler substances than can be done by animals. But these differences are superficial, and fundamentally plants and animals are alike. We must suppose, therefore, that even so humble a living form as a small plant seed has a psychic life of its own. Impulses pass through it like nerve impulses; it may be anesthetized as in the case of man; it sleeps as does man; and, indeed, many of the fundamental properties it shows resemble those which 
we possess. Thus a part of the study which follows has been made upon such simple things as seeds and garden peas. It is surprising how closely the results obtained with these parallel those obtained from nerves.

The really important and peculiar property of living things is the psychic life they show. And if we actually had an accurate means of testing the degree or amount of life, it would be some kind of a reagent or instrument for testing "psychism," as we may call it. But unfortunately we cannot at present find any means of testing this property. We do not know what its physical basis is, and, until we discover that, we cannot make a psychometer which we can apply to all kinds of living and non-living things, and thus measure the amount of psychism, and hence of life, which they possess. In the absence of any such psychometer we have to do the best we can, and take as a measure of this property those physical and chemical changes which experience or experiment demonstrates to us always accompany the psychic change. The situation is very much as it was in the realm of electricity before the galvanometer was invented; an idea of the quantity of electricity produced by a battery could be obtained only indirectly by measuring the amount of chemical change which the current produced, since Faraday found that that amount was always a measure of the amount of electricity.

There are material changes which occur in living things as long as they are alive and show psychic life of any kind. The changes which we may rely upon to measure the amount of life, and thus indirectly the amount of psychism, are partly visible changes, but in 
part they are invisible and have to be detected by special apparatus. The visible changes consist in some reaction of the organism when its surroundings change. If it moves when it is touched, the degree of movement not being related to the impulse given it; if it breathes; if it changes its rate of growth under changing conditions, we say that it is alive. It is irritable, and it has the property of irritability. Another thing noticed in a living thing is that the impulse which arouses it to action may cause reaction in a part of the organism distant from the point of stimulation. In other words, the change, whatever its nature, set up in the organism by the stimulus is propagated to a distance from the point of irritation. We can see the results of this propagation. All things which show this conduction and response we say are living things. These are physical processes which apparently always accompany the psychic process. But sometimes these changes, although they occur, produce no visible result; consequently we must have methods which will detect conduction and irritability, even though there are no visible signs of them. One cannot see, for example, that anything has happened to a seed when it is pricked by a pin; it does not say "ouch!" loud enough for us to hear it, or in a language we understand; but nevertheless it jumps when it is pricked as if it did say "ouch!" as we can show by appropriate methods.

There are two signs, or tests, which all living things show and which are an index of life. One of these is an electrical disturbance. This was discovered a very long time - a hundred years-ago, and its discovery was the basis of the development of knowledge of electricity. The 
other is a chemical sign, which has just been discovered and which will be discussed in this book. The electrical sign of life was discovered by Galvani when he found that animal tissues are a source of electricity. He discovered animal electricity. It is now certain that whenever the response to a stimulus takes place in animals or plants - the response which is the sign of life-an electrical change accompanies it. By placing a galvanometer on the animal or plant we can study this electrical response. Life and electricity are thus shown to be related. Electricity and psychism have something in common, although just what the connection is cannot at present be said. The English physiologist Waller has recently introduced as a measure of life a particular kind of electrical response which he has discovered and which he calls the "blaze" current, because it is as if the electrical display suddenly blazed up when the living matter was disturbed; this he calls an electrical sign of life. By it he can tell whether a dry seed is alive or not without putting it in the ground and letting it sprout. It is very hard to know whether this electrical disturbance which living things show is due to physical or to chemical changes in their substances.

- It is therefore a matter of very great interest that I have recently found that there is always and everywhere an accompanying chemical change of a particular kind which is as sure a sign of life and as invariable an accompaniment of the vital reaction as the electrical change. This chemical sign is the sudden outburst of carbon dioxide which all living things show-plants as well as animals, dry seeds as well as the nerve tissues of the highest mammals - when they are stimulated in any 
way. The instrument which I have made to detect this carbon dioxide I have called a "biometer" because, as will be appreciated from this short discussion, it is an apparatus for measuring or detecting the amount of life possessed by different things. I shall show in the following pages that the increment of carbon dioxide produced by living things when they are irritated, or stimulated in any way, is a sure measure of the amount of life they have; and we may hope that it is to be an indirect measure of the amount of psychism they possess, although of course we cannot be sure of this as yet. It will be noticed that it is not the absolute amount of carbon dioxide which is the measure of life, but the increase above the usual production which occurs when a definite amount of stimulus is applied to the living thing, which is the real measure of life. Anesthetized or sick things do not show the normal increase; those abounding in life show a remarkable increase.

The first results to be presented will be the proof that carbon dioxide production is the sign of life of a nerve fiber. And it will be well before going into this to say a few words about the scientific opinion concerning the nature of the nerve impulse generally prevailing before the work recorded here was done.

The main function of a nerve fiber is to transmit a state of excitation from one place to another. It serves for the conduction of the nerve impulse, which it transmits in the most efficient manner. The nerve is also excitable at all points, since it can be stimulated by a variety of methods at any point along the fiber. When physiologists investigated what takes place in nerve fibers during the passage of nerve impulses, many 
peculiar results were brought out. In the first place, if there are no other organs attached to the nerve it is impossible to determine by casual observation whether or not the nerve has been stimulated, for there is positively no visible physical sign of the vitality in it." Not even with a microscope can any structural change in the tissue be seen. There is, also, no heat change detected with a method which is sensitive to a millionth of a degree Centigrade. There was, before this work was published, no apparent production of carbon dioxide, or any other chemical change in the tissue. These facts seemed to indicate that the functional activity of nerve fibers was in no way associated with any chemical change. This failure of a nerve to show any chemical or structural changes similar to those of muscles had a decisive influence in the formation of ideas concerning, not only the nature of the nerve impulse, but also the nature of irritability in general. For nerve fibers not only show the highest type of irritability of protoplasm, but they also possess, as stated before, the power of transmitting the state of excitation in the most perfect manner. And all attempts to explain the nature of irritability in general must necessarily account for the peculiarities of the nerve fiber where we find that property in its highest development. If irritability, excitation, and conduction do not involve chemical changes in nerves, it may be concluded that neither do they in any other tissues. Thus, on account of the absence of evidence of any chemical changes accompanying irritability in nerves, we have gradually drifted away from the notion that the fundamental condition for protoplasmic activity is chemical. 
When it was found that an electrical change occurred in a nerve when it conducted an impulse, the problem was considered to be settled. The nerve impulse was supposed to be electrical in nature. This idea was soon questioned, however, when the speed of the conduction of a nerve impulse was found to be so slow in comparison with that of an electrical current. The speediest nerves, such as those of human beings, conduct impulses only at the rate of a hundred meters per second, whereas electricity travels in a wire at a speed of thousands of kilometers per second. One thing seemed to be certainthat the nerve impulse can pass through a fiber without consuming any material. It was found that some nerves could not be fatigued even on prolonged stimulation. This fact supported the idea that certain quickly reversible physical conditions must exist in the nerve, and that the changes in these conditions, rather than chemical changes, must determine the phenomena of irritability and conductivity. Ultimately physiologists settled down to the view that the physical and fundamental changes concerned in irritability were either a change of colloidal state, of surface tension, or in the permeability of the nerve to salt, or changes in the distribution of electrically charged particles in the nerve.

- Although such physical changes as these in nerves have never been demonstrated experimentally, biologists generally have tried to explain the nature of a nerve impulse and the phenomena of excitation purely on the basis of these hypothetical physical changes; and they have neglected the chemical changes. They have also attributed many other important physiological functions, such as secretion and contractility, to these 
purely physical conditions, and this in spite of the fact that this point of view is obviously incomplete, if not fundamentally erroneous, because the source of all energy of living things is chemical. The chief reason, as has been stated, for the adoption of this hypothesis was the fact that the most irritable tissue-nervous tissue-had shown no sign of chemical changes when it functioned, and also the fact that some other living tissues, such as seeds, seemed to maintain their vitality without any chemical change. The erroneous character of this view will be apparent from what follows, where it is shown that chemical changes are, indeed, an invariable accompaniment of nervous activity, and of all life. 


\section{CHAPTER II}

\section{CHEMICAL SIGNS OF IRRITABILITY IN THE}

NERVE FIBER

- There are various chemical processes which occur in all forms of living matter and which we might examine in order to see whether they are associated with the property of irritability, but we naturally seek to make use of that one which is the easiest to detect. Among these chemical processes there are, in the first place, the processes concerned in growth. All living matter has the power of building up complex proteins, fats, and carbohydrates as long as it is vigorously alive. But it is clear that this process would be very hard to measure quantitatively without killing the living matter and determining how much substance it has produced. And there are also other objections to using growth as a measure of vitality. Another chemical process found in all, or nearly all, forms of matter is respiration. By respiration we mean the gaseous exchange of living matter with its environment: the taking on of oxygen and the production of carbon dioxide. This is a very much more promising line of experiment to follow in measuring life and metabolism, for, in the first place, it is universal, as I shall presently show, and, in the second place, the oxygen may be measured, or the carbon dioxide given off may be determined, without injuring the living matter. It was for this reason that the carbon dioxide was selected for study as probably 
being the easiest of quantitative determination and undoubtedly correlated with the most fundamental vital processes.

The idea that respiration is one of the most fundamental of vital phenomena is by no means a novel view. Even in the earliest times breathing was supposed to be the process most intimately connected with life. When a man stopped breathing he died. As early as the second century Galen had the notion that there must be a pneumatic spirit in the air which kept up life, and he predicted that some day it would be discovered. It was after the lapse of fifteen hundred years that this prediction was verified or fulfilled when Mayow, an English physician, discovered that there was a gas, or spirit, in the air which was essential to life and combustion. Later, oxygen was discovered by Priestly, and it was Lavoisier who first showed that this oxygen after entering the lungs came out again as carbon dioxide; and he proved that animal heat was due to the combustion of the materials of the body by the oxygen to form water and carbon dioxide, and that the sole source of energy of living things was this combustive change. In selecting respiration as the chemical test of life we are, therefore, selecting that most fundamental reaction by virtue of which living things get their energy. It is clear that it is this reaction, rather than any other chemical reaction, which touches most closely the phenomena of irritability; for, to move or to think, we must have energy. It is much better to take this reaction, rather than those chemical changes which are related to growth or the repair of waste, as a criterion of living, for the very essence of a living thing 
is that by chemical transformations it sets free energy and moves itself.

It is much better, too, to take the carbon dioxide produced, rather than the oxygen consumed, as the measure of the metabolism associated with irritability, for the reason that sometimes organisms get their oxygen from sources other than the air, whereas their carbon dioxide production is always something positive and universal.

Indirect evidence of the presence of metabolic activity in the nerve fiber. - The search for some kind of metabolism, such as the production of carbon dioxide, in nerves had been made by many physiologists on many occasions, but it was impossible for them to discover this substance because their methods were not sufficiently delicate. No carbon dioxide could be found, and for this and other reasons the conclusion was incorrectly drawn that there was none produced, or that, if it were produced, it had no connection with the vital functions of the nerve. Most physiologists were accordingly of the opinion that the conduction of the nerve impulse was a physical process and involved no transformation of energy and no consumption of material. There was one exception to this rule. Professor A. D. Waller, the eminent English physiologist, maintained that, because of their electrical behavior, nerves certainly produced carbon dioxide. In 1896 he showed that carbon dioxide when applied to a nerve produced a very characteristic change in the electrical response which a nerve exhibits when it is irritated. It will be remembered that when a nerve or, in fact, any kind of protoplasm is irritated in any way, if one applies two electrodes to the living tissue in such a way that one electrode is on 
a part which is in activity and the other on a part which is less active, it will be found that there is a current which flows in the tissue from the more active to the less active part, from the more to the less excited, and outside in the galvanometer from the less to the more excited part. This electrical current was discovered by Galvani and is called the current of action, or the action current. Generally, when an impulse sweeps along a nerve to which two electrodes are applied, first one electrode and then the other becomes negative, so that the current is diphasic, running first in one direction and then in the other. Now, Waller observed that when a nerve was exposed to carbon dioxide this diphasic current showed a characteristic changè, the negative phase being first increased by small amounts of carbon dioxide and then diminished. He then discovered that just the same kind of a change occurred in the electrical response if he stimulated a nerve repeatedly at very short intervals of time. $\mathrm{He}$ concluded from this that on stimulation of the nerve carbon dioxide was produced, and that this caused the characteristic alteration of the electrical response which occurred in the tetanized or repeatedly stimulated nerve. This conclusion was not generally accepted by physiologists for the reason that it was possible that the same change in the electrical response might be produced in other ways than by carbon dioxide, and while the experiments were regarded as circumstantial evidence of value, showing that a chemical change accompanied the nerve impulse, they were not regarded as conclusive.

Waller supported this conclusion by another discovery, namely, that when he stimulated the nerve at regular intervals, not too long or too short, by a strong 
induction shock, he obtained a series of electrical responses, each of which is the greatest the nerve can give at the time, but each of which is a little greater than its predecessor. Such a series of increasing responses is known as a staircase, the negative phase increasing steadily while the positive phase decreases. This Waller explained by supposing that small amounts of carbon dioxide were formed by each nerve activity, and that this augmented the negative response and diminished the positive response, just as does carbon dioxide applied to the outside of the fiber. He considered that our failure to find the gas was due to the inadequacy of the chemical methods then in existence. That this criticism of Waller's was a just one and that there may be carbon dioxide produced by nerves, but too small in amount to be measured by the ordinary chemical method, is shown by the following calculation: A frog (Rana temporaria) gives off $0.355 \mathrm{~g}$. of carbon dioxide per kilogram per hour at $19^{\circ}$ to $20^{\circ} \mathrm{C}$. A small piece of the nerve fiber of the same animal, say I cm., or threeeighths of an inch, in length, will weigh, probably, not more than Io $\mathrm{mg}$. Now, if this mass of the nerve fiber respires at the same rate as the whole animal, it will not give off more than about $0.000,000,7 \mathrm{~g}$. of carbon dioxide during ten minutes. This calculation at once suggested that the failure to detect the evolution of carbon dioxide in nerves was very probably due to the limitation of the methods for the estimation of the carbon dioxide, and that it was not at all conclusive evidence that carbon dioxide was not produced. It was evidently necessary to devise methods for the detection of very minute quantities of carbon dioxide. 
- In order to study the whole of the respiratory metabolism of a tissue, we should at least determine the oxygen consumption as well as the carbon dioxide production, and also generally the heat production. Inasmuch as the present problem, however, is concerned only with presenting direct evidence for the existence of metabolic activity in nerve fibers, we shall attempt to measure the carbon dioxide production alone; for while the lack of consumption of atmospheric oxygen may not necessarily indicate the absence of chemical changes, the production of carbon dioxide will surely prove the presence of metabolism, provided, of course, that we can prove that such carbon dioxide is formed by physiological processes. Furthermore, as carbon dioxide is the only universal expression of the respiratory activity in almost all anaërobic and aërobic plant and animal tissues in normal condition, metabolic activity is probably better represented by carbon dioxide production than by oxygen consumption, although we must restate here, of course, that the study of carbon dioxide alone will never reveal completely the nature of the metabolic activity.

Method.-The method which was finally devised to detect and measure quantitatively the very minute amounts of carbon dioxide which it might be expected ${ }^{\circ}$ would be formed consisted essentially in determining the amount of carbon dioxide which was just sufficient to produce a deposit of barium carbonate in a film of half-saturated barium hydroxide solution. Barium carbonate is almost entirely insoluble in such a barium hydroxide solution, and a very small amount of precipitate can be detected with the aid of a small lens. The 
method is described in detail in the Appendix. The special apparatus, the biometer, as I have named it, which was constructed for the investigation, is shown in Fig. I, and its use is detailed in the Appendix. It will detect one ten-millionth of a gram of carbon dioxide and estimate it with accuracy.

As is shown in the figure, the biometer has two respiratory chambers each provided with a small tube, at the top of which the hemispherical drop of barium hydroxide can be formed. Exceedingly minute amounts of carbon dioxide produced in the chamber by the small piece of nerve will be precipitated as barium carbonate on the surface film of these hemispherical drops and may be seen with a lens. As the apparatus has two chambers, not only can we detect very small amounts of carbon dioxide which the nerve may produce, but we can also compare the output of carbon dioxide of different tissues under the same conditions, by placing one tissue in one respiratory chamber and another in the other.

To discover whether nerve fibers, as distinct from nerve cells, respire, particular care was taken to select at first those nerves which are known to be free from such cells and, as far as possible, free also from connective tissue. It was necessary to do this because the work of several investigators seemed to indicate that tissue oxidation was in some way dependent on the cell nucleus. Certain biologists even went so far as to believe that a nerve fiber ought not to respire at all, since it contained no nucleus. The fact that the blood supply to the brain, where most of the nerve cells are located, is so copious, whereas the blood supply to the nerve fibers is 


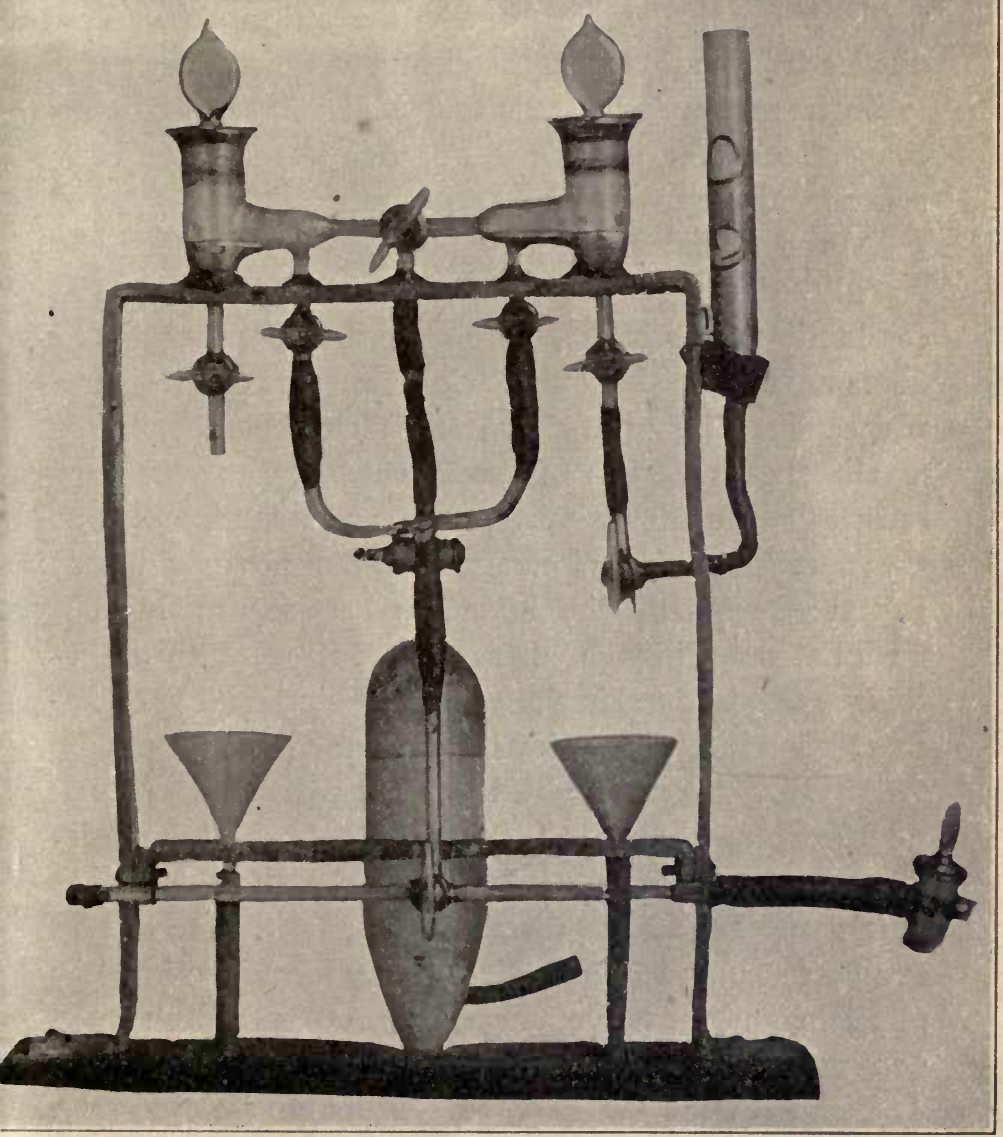

FIG. I.-The Biometer. One-fourth actual size 
so scanty, was partly responsible for this conclusion. ${ }^{x}$ In order to test the correctness of such an assumption, we have studied quantitatively the output of carbon dioxide from various lengths of nerves which are known to be free from nerve cells and which have almost no connective tissue in them. For this purpose the claw nerve from the spider crab was selected.

Nerve fibers are of two kinds, called respectively medullated and non-medullated nerves. The essential conducting parts of these are alike, but the medullated fibers have lying about the conducting core of the fiber a white, glistening, fatty matter called the medulla, or myelin sheath. Most of the nerves going to voluntary muscle in the higher vertebrates are medullated; but the nerves to the viscera are often non-medullated and the nerves of the invertebrates are usually nonmedullated. $\rightarrow$ This medullary sheath is evidently something which is found in those nerves which it is important should conduct very quickly and which should not be fatigued by conduction, and it is clear that the medullation is an improvement which has not yet been universally introduced. The function of this sheath is probably nutritive. But in any case it is important, if we wish to avoid any complication which it may introduce into the physiology of the nerve, to examine both medullated and non-medullated nerves. And that we have done.

Non-medullated nerve fibers. - When an isolated claw nerve of the spider crab is placed in the right chamber

I Indeed, Bayliss attributes our results, which are soon to be detailed, to the presence of the connective tissue cells around the fiber, so firmly convinced does he appear to be that only nucleated parts of cells respire. For further consideration of this objection see p. 33 . 
of 'the biometer and no nerve in the left, the biometer being properly sealed with mercury and filled with air which is free from carbon dioxide, and if barium hydroxide is allowed to rise to the top of each tube in such a way as to form hemispherical drops of approximately equal size in both chambers, we observe that the drop in the right chamber, where the nerve is, will soon be coated with a white precipitate of barium carbonate, but that no precipitate whatever can be seen, even with a lens, in the left chamber. Carbon dioxide is thus shown to be produced by this resting nerve of the spider crab. By interchanging the nerve from the right to the left chamber, no nerve being now put in the right, we find that the precipitate is now in the left-hand side of the biometer, and we have no difficulty in convincing ourselves that the carbon dioxide has come from the nerve, for we have thus eliminated any technical error which might have produced the different results in the different chambers. The rate at which the precipitate appears and its quantity depend on the size of the nerve and the length of time we leave it in the chamber. That an unstimulated nerve gives off carbon dioxide is a fact which can thus be demonstrated easily to anyone if the proper apparatus is at hand. The rate of production of carbon dioxide by the normal resting nerve of the spider crab is found to be proportional to its weight, other things being equal, and is fairly constant. The quantitative determination shows that for $10 \mathrm{mg}$. of nerve per ten minutes it gives off $6.7 \times 10^{-7} \mathrm{~g}$. of carbon dioxide at $15^{\circ}$ to $16^{\circ} \mathrm{C}$.

The quantitative determination of this amount is made in the following manner: The claws of the crab are carefully removed 
from the body, and by gentle cracking the long fiber of the nerve trunk is easily. isolated. After the last drop of water is removed by a filter paper, the nerve, with the aid of glass chopsticks, is carefully placed on the glass plate (Fig. 2) and quickly weighed. The glass plate with the nerve is now hung on the platinum hooks in the right respiratory chamber, and the chamber is then sealed with mercury. The left, or analytic chamber, is now partially filled with mercury in the manner described elsewhere, and then the apparatus is washed as usual by air free from carbon dioxide. The time at which barium hydroxide is introduced into the top of the tube in the left chamber is recorded and the stopcock between the two chambers is closed. When at the end of ten minutes the drop on the tube in the left chamber is perfectly clear, having not a single granule of the precipitate visible to a lens, thus insuring that the air used for washing is absolutely free from carbon dioxide, a known amount of the gas from the .right respiratory chamber is introduced into the left chamber in which the clear drop of barium hydroxide has been exposed, and it is determined whether or not the amount of the gas taken contains enough carbon dioxide to give a precipitate in several minutes. Usually ten minutes will be sufficient for the reaction. ${ }^{x}$. If it does not give a precipitate in this time, a larger volume should be taken until the precipitate appears within ten minutes. If it does, the apparatus is washed, dried, and with a fresh nerve the procedure is repeated, but a less volume of the gas than the amount which before gave the precipitate is withdrawn into the left chamber from the right. ${ }^{2}$

In this way, by the use of several fresh nerves, a minimum volume of the gas for a known weight of the nerve which gives a precipitate is determined. This minimum volume should contain a definite quantity of carbon dioxide, namely, I.0X IO $^{-7} \mathrm{~g}$., the amount carefully determined previously (taking known amounts of the exceedingly diluted gas) to be just sufficient to produce a noticeable precipitate.

The weight of this plate is known, hence the weight of the nerve can be determined very quickly (see p. 38 ).

${ }^{2}$ See footnote, p. I 26. 
- Thus, since we know the original volume of the chamber in which the respiration took place and from which this minimum volume is withdrawn, and since we know the quantity of carbon dioxide contained in this volume, it is easily calculated how much carbon dioxide is given off by the nerve during the known period. It should be understood that, in determining the minimum volume of gas taken from the respiratory chamber, a series of experiments was conducted in order to calculate both the minimum volume which just gives the precipitate and the maximum volume which does not give the precipitate for a known weight of the nerve for a known period of respiration. In Table I, in the Appendix (p. 128), columns 8 and 9 refer to these volumes calculated from experiments for to $\mathrm{mg}$. of the nerve, for ten minutes.

Medullated nerve fibers.-We have repeated this experiment with the sciatic nerve of the frog, this nerve being a typical medullated nerve. The result showed, not only that medullated nerves also give off carbon dioxide, but that they give a quantity of about $5.5 \times$ I0 $\rightarrow \mathrm{g}$. for each Io $\mathrm{mg}$. of the nerve for the first ten minutes, which is a little less than was obtained from the non-medullated nerve.

A large variety of nerves was tested to see whether or not all resting nerves give off carbon dioxide. As a result, we found no exception in any of them, although they vary quite widely in the rate at which they produce carbon dioxide. The following nerves were examined, and it will be noticed that the list includes all varieties, such as sensory, motor, vertebrate and invertebrate, medullated and non-medullated nerves.

I. Motor Nerve: Oculomotor nerve of the skate (Raia ocallata).

2. SENSORY Nerve: Olfactory nerve of the same. 
3. Medullated Nerves: Sciatic nerve of the dog, frog, turtle, mouse, guinea-pig; optic nerve of the skate (both Raia ocallata and Raia erinecia).

4. Non-Medullated Nerves: Nerves of the spider crab, olfactory nerve of the skate (Raia ocallata).

5. Nerves of INVERTEbrates: Nerves of the spider crab, Limulus, Limax.

6. Nerves of Vertebrates: Nerves of frog, dog, mouse, squiteague (Cynoscion regalis), and skate (both Raia ocallata and Raia erinecia).

7. Nerves of Warm-Blooded Animals: Those of dog, rat, rabbit, guinea-pig.

8. Nerves of Cold-Blooded Animals: Those of frog, squiteague (Cynoscion regalis), catfish, carp, and skate.

9. Sensory Dendrite: Lateral line nerve (ramus lateralis vagi) of carp and catfish, and ramus lateralis accessorius of catfish.

This is a partial list of the many nerves examined and it is given only to show that we are justified in making the generalization that all freshly isolated nerves of all animals, regardless of the kind of nerve or of the kind of animal, produce carbon dioxide. It is thus certain that chemical changes of a very vigorous kind are going on constantly in this tissue without any visible results. Nerves respire; they are not chemically inert. It remains now for us to establish the fact that this carbon dioxide is a product of normal metabolic activity and is not due to a disintegration involved in the process of dying on the part of the tissue, or to a lifeless fermentation, and that it is not simply gas which had happened to be absorbed by the nerve from the atmosphere or the blood.

Is this carbon dioxide produced by living processes?Since there are many organic compounds, as well as dead 
tissues, which produce carbon dioxide either by direct oxidation, by fermentation, or by the decomposition of carbonates by acids, the possibility that this carbon dioxide which we have detected is not a product of vital activity cannot be so easily disproved. Inasmuch as our apparatus detects such a small amount of the gas as that which is contained in one-sixth of a cubic centimeter of the purest air, we cannot accept the results just cited as certain proof that the normal nerve undergoes metabolic changes. We must inquire, therefore, whether this carbon dioxide is produced by living processes. In the first place, as the biometer in its present form cannot examine the carbon dioxide production of a nerve in its normal position and with its muscle attached to it, we have to use an isolated nerve. Certain experimental factors are thus introduced which must be carefully considered before we interpret our observations. It is first necessary to be sure that this isolated nerve lives and remains excitable for a considerable period after it has been removed from the body. We can be quite certain that this is the case because of the fortunate circumstance that the passage of the nerve impulse through such an isolated nerve produces a characteristic electrical disturbance, which we may detect by a sensitive galvanometer. As long as this electrical disturbance occurs and the nerve is excited, we may be perfectly sure that the nerve is living. It is as certain a sign of the passage of the nerve impulse, and consequently as sure an evidence of the vitality of the nerve, as would be the contraction of the muscle which the nerve supplies, had this remained attached to it. By thus testing with a galvanometer isolated nerves, such 
as we have examined, it has been found by Waller that the vitality persists even as long as nineteen hours after removal from the body. These facts are proof, therefore, that the observations made on the carbon dioxide production of isolated nerves are really made on active living nerves, and they may be regarded as qualitatively similar to what would happen in the normal nerve in situ were we able to measure its carbon dioxide production.

\section{TABLE I}

Comparison between Normal and Krlled (by Steam) Nerves of Spider Crab

\begin{tabular}{|c|c|c|c|c|c|c|}
\hline Date & $\begin{array}{c}2 \\
\text { Tempera- } \\
\text { ture of } \\
\text { Room } \\
\text { Degrees C. }\end{array}$ & $\begin{array}{c}3 \\
\text { Weight of } \\
\text { Nerve in } \\
\text { Milligrams }\end{array}$ & $\underset{\text { tion }}{\text { Stimula- }}$ & $\begin{array}{l}\text { Cubic } \\
\text { Centime- } \\
\text { ters of Gas } \\
\text { Taken } \\
\text { from Res- } \\
\text { piratory } \\
\text { Chamber }\end{array}$ & $\begin{array}{c}6 \\
\text { Duration } \\
\text { of Respira- } \\
\text { tion } \\
\text { Minutes }\end{array}$ & $\begin{array}{c}7 \\
\text { Ppt. of } \\
\left.\text { Ba(CO } \mathrm{CO}_{3}\right) \\
\text { after Ten } \\
\text { Minutes }\end{array}$ \\
\hline $\begin{array}{l}\text { November } 4 \ldots \\
\text { November } 4 \ldots \\
\text { November } 5 \ldots \\
\text { November } 6 \ldots \\
\text { November } 7 \ldots\end{array}$ & $\begin{array}{l}13 \\
13 \\
15 \\
15 \\
16\end{array}$ & $\begin{array}{l}40 \text { (killed) } \\
40 \text { (killed) } \\
\text { I6 (normal) } \\
\text { I6 (killed) } \\
\text { I6 (normal) }\end{array}$ & $\begin{array}{l}\text { No } \\
\text { Yes } \\
\text { No } \\
\text { No } \\
\text { No }\end{array}$ & $\begin{array}{l}0.5 \\
0.5 \\
1.0 \\
1.0 \\
1.0\end{array}$ & $\begin{array}{l}\text { 10 } \\
\text { 10 } \\
\text { 10 } \\
\text { I2 } \\
\text { 10 }\end{array}$ & $\frac{\bar{t}}{\bar{t}}$ \\
\hline
\end{tabular}

If the carbon dioxide is produced by vital activity, its production should be diminished when the nerve is killed. This we can demonstrate by placing a nerve killed by steam in one chamber of the biometer and an equal weight of a normal living nerve in the other chamber and then comparing simultaneously the output of carbon dioxide in the living and dead nerves. It is found that the living nerve continues to give off carbon dioxide, while the dead gives off extremely little, the difference between the two becoming more marked as time goes on. Such a comparison between two nerves of the spider crab is given in Table I, from which it 
will be seen, if the experiments on November 6 and 7 are compared, that I c.c. of gas taken from the respiratory chamber in which the dead nerve had been for a certain length of time contained not enough carbon dioxide to produce a precipitate, while I c.c. of gas from the chamber in which the living nerve had been for the same time did produce a precipitate and consequently contained more carbon dioxide. It is clear, then, that a dead nerve gives off less carbon dioxide than the living.

Comperison of anesthetized and normal nerves.-By the use of anesthetics we can diminish the irritability, or, as we may say, the vitality, of the nerve without abolishing it altogether, The nerve, although anesthetized, is still alive, but in a condition of suspended animation. When the anesthetic escapes from it, it recovers its normal vitality. If the carbon dioxide has been produced by a vital process and is at all correlated with the state of irritability of the nerve, we should expect that a diminution of that irritability by anesthetics would produce a diminution in the carbon dioxide output. If, on the other hand, this carbon dioxide is the result, not of a vital process, but of a fermentation, or of an acid production of some sort, then we should expect that it would be little, if at all, affected by the anesthetic. Accordingly, nerves were anesthetized in various ways, for example, by placing them in a solution of urethane, or they were treated with the vapors of ether, or the nerve was isolated from a deeply anesthetized frog, and the quantity of carbon dioxide produced by such nerves was compared with the quantity produced by normal nerves of the same animals. It was found always that the anesthetized nerve gave off 
decidedly less carbon dioxide than the nerves of normal frogs or nerves taken from frogs whose circulation had been suspended for a period of time equal to that of etherization. A perfect parallelism was found to exist between the carbon dioxide production and the state of excitability of the nerve. Thus small quantities of anesthetics have often the effect of increasing at first the excitability of the nerve, and it was found that such quantities also produced at first an increase in the carbon dioxide. A further consideration of the effects of anesthetics on the metabolism of the claw nerve of the spider crab will be found in chapter iv. The important fact is that since these agents are known to affect the normal uncut nerve in situ and also to modify carbon dioxide production in an isolated nerve, and in a manner parallel with their known actions on irritability, it is certain that at least the larger part of the carbon dioxide we measure in an isolated resting nerve must have been produced by a physiological process.

Carbon dioxide production in a hydrogen atmosphere.Although many nerves remain alive for a long time in an atmosphere free from oxygen, they generally exhibit a lowered irritability when compared with nerves in normal air. It has been found, for example, that if nerves remain in the body after the circulation of a frog has ceased, so that they have not been supplied with oxygen for some time, they are by no means so easily stimulated by a salt solution as are normal nerves. Their vitality is reduced. A similar change occurs in nerves taken out of the body and put in hydrogen gas. In them, also, irritability is decidedly diminished. If, now, carbon dioxide is produced in these nerves by a vital process, 
we should expect to find that less carbon dioxide was produced by nerves in an atmosphere of hydrogen than in normal air. On the other hand, if the carbon dioxide was due to some fermentation, or non-vital process, then it should not be influenced by the absence of oxygen.

When, with Dr. Adams, we determined the rate of carbon dioxide production in nerves placed in an atmosphere of hydrogen gas, care having been taken to insure the gas being perfectly pure, we found that the rate was only about half that of the normal nerve. It appears from this determination that in a medium deficient in oxygen the claw nerve of the spider crab gives off less carbon dioxide than in an ordinary atmosphere. The effect cannot be due to the hydrogen, since that gas has no physiological action, but is quite inert, and we may conclude that the lowering of the carbon dioxide is due to the lack or absence of oxygen. This is additional evidence that the lowering of the gaseous output is a physiological phenomenon, and that the carbon dioxide measured in normal isolated nerves is a product of normal metabolism, and is not the mere diffusion outward of the gas which is present in the tissue, being produced there by other than living processes.

Carbon dioxide production of the isolated nerve at successive time intervals. - If the carbon dioxide production is due to a vital process, it might be expected to diminish gradually in the isolated nerve as its vitality diminishes. On the other hand, there was a possibility that the isolated nerve had become infected with bacteria and that the carbon dioxide might be due to their action. If this were the case, it would be expected that the carbon dioxide would gradually increase. Accordingly, experi- 
ments were tried to discover how the carbon dioxide production behaved at successive time intervals after the nerve was removed from the body. A number of sciatic nerves were isolated from several frogs of the same size and sex and were left for varying periods of time in Ringer's salt solution, in which they live well. The rate of the gas production was then determined in the nerves when removed from the Ringer solution after one hour, two hours, and at other intervals up to twenty-five hours. The interesting results given in Table II make it clear that the fresh nerve produces the

TABLE II

Showing Decreased CO 2 Production by Long Standing (Frog's Sciatic)

\begin{tabular}{|c|c|c|c|}
\hline $\begin{array}{l}\text { Temperature } \\
\text { of Room } \\
\text { Degrees C. }\end{array}$ & $\begin{array}{l}\text { Time Elapsed } \\
\text { after Isolation }\end{array}$ & $\begin{array}{c}3 \\
\text { Minimum Cubic } \\
\text { Centimeters Neces- } \\
\text { sary to Give } \downarrow \\
\text { Calculated for } \\
\text { ro mg. for ro } \\
\text { Minutes }\end{array}$ & $\begin{array}{l}\text { Total Amount of } \\
\mathrm{CO}_{2} \text { Produced by } \\
\text { Io mg. of Nerve in } \\
\text { Io Minutes }\end{array}$ \\
\hline 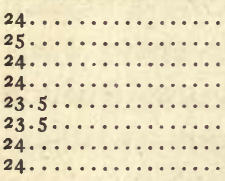 & $\begin{array}{l}\text { Immediately } \\
\text { I hour } \\
2 \text { hours } \\
5.5 \text { hours } \\
7 \text { hours } \\
\text { I0. } 5 \text { hours } \\
26 \text { hours } \\
27.4 \text { hours }\end{array}$ & $\begin{array}{l}2.7 \text { c.c. } \\
7.08 \text { c.c. } \\
\text { I0.8 c.c. } \\
\text { I } 2.8 \text { c.c. } \\
\text { I5.3 c.c. } \\
21.0 \text { c.c. } \\
9 \text { c.c. } * \\
1.8 \text { c.c. }\end{array}$ & $\begin{array}{l}5.5 \times 10^{-7} \text { g. } \mathrm{CO}_{2} \\
2.1 \times 10^{-7} \text { g. } \mathrm{CO}_{2} \\
1.4 \times 10^{-7} \text { g. } \mathrm{CO}_{2} \\
1.1 \times 10^{-7} \text { g. } \mathrm{CO}_{2} \\
0.9 \times 10^{-7} \text { g. } \mathrm{CO}_{2} \\
0.6 \times 10^{-7} \text { g. } \mathrm{CO}_{2} \\
1.6 \times 10^{-7} \text { g. } \mathrm{CO}_{2} \\
8.1 \times 10^{-7} \text { g. } \mathrm{CO}_{2}\end{array}$ \\
\hline
\end{tabular}

* The gradual increase at this point should be noted (after 26 hours, it is clear that bacterial decomposition sets in).

most carbon dioxide and that the amount produced per unit of time interval decreases rapidly up to about twenty-three hours and from then on suffers a very rapid increase. These facts show that the carbon dioxide output diminishes as the vitality of the nerve diminishes, and that as bacterial decomposition sets in there is a sudden and rapid increase. There is, therefore, a 
parallelism between the decrease in metabolism and decrease of irritability in the nerve. The gas production slows up as the nerve approaches death. This indicates, also, that the carbon dioxide is formed by a vital process.

Comparison between the metabolism of resting nerves and other tissues.-While a comparison of the rate of the metabolism of the nerve with that of other tissues is subject to a good many limitations, since there are so many and great variations in conditions which do not affect all tissues similarly, it is nevertheless interesting to note whether the nerve respires relatively more or less than most other tissues. In order to give a better numerical picture of the amount of metabolism in the resting nerve, as compared with other tissues, we have set down in Table III the figures for carbon dioxide production in various animals. Since there are no exact determinations made of the carbon dioxide production of the spider crab as a whole, or of its tissues, we have used for comparison various other crustacea where these data have been determined. It will be noticed from an inspection of this table that the spider crab nerve produces, weight for weight, carbon dioxide at a rate three to four times that of the whole body of crabs, and almost as much in proportion to weight as a human being at rest. Recently Bayliss, in his admirable book entitled Principles of General Physiology, expressed a doubt of our figures. He thinks that the gas we measured must be due to some cause other than the metabolic activity of the nerve, because, he says, the data show that it is greater than that of an equal weight of muscle. It is rather difficult for us to understand the force of this 
criticism, since there are many other evidences that the metabolism of the nervous system is more intense than that of any other tissue of the body. There is, as far as we know, no physiological reason for assuming a priori that the nerve has a lower metabolism than other tissues, but, on the contrary, the direct and indirect

TABLE III

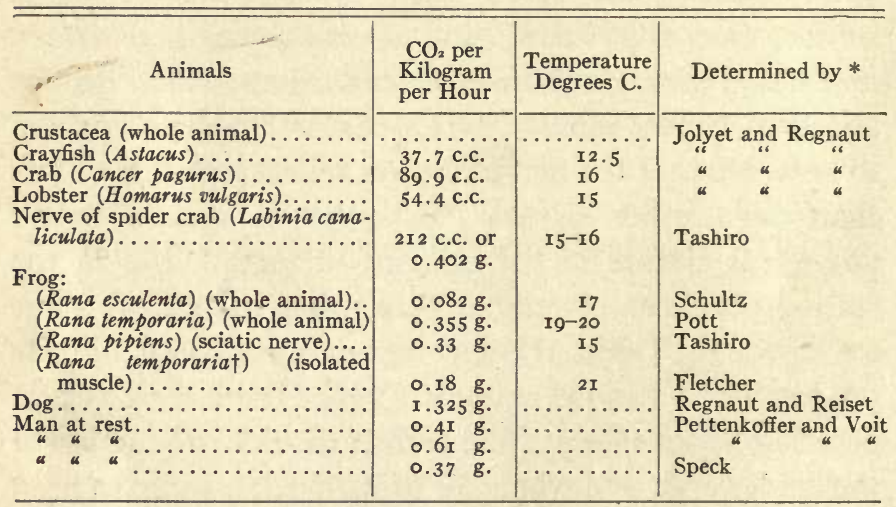

* All the figures are quoted from Schäfer's Text Book of Physiology, I, 702, 707, and 708 , except that of the isolated muscle, which I calculated from Fletcher (op. cit.). Fletcher fails to state the weight of a leg, but gives the value 0.2 c.c. for one-half hour. Hill believes that if we take each leg as $6 \mathrm{~g}$. in average, the value will not be far from the truth.

† Fletcher fails to state the species of the frog, but it is inferred from Hill's paper.

evidence shows that it has a more intense metabolism. It is no doubt true, however, that an isolated nerve, such as we have used, respires somewhat faster than the same nerve intact in the body, because the effect of cutting the nerve is to act as a stimulant. But, even allowing for this effect, the metabolism still remains markedly higher than that of most other tissues. We may add here, however, that the hourly rate of output of carbon dioxide from the resting nerve of a frog is 
at a maximum only about 0.03 per cent of the wet weight of the tissue.

Comparison of carbon dioxide output of nerve fibers and nerve ganglia.-From the table already presented it is clear that the living nerve trunk containing no nerve cells gives off carbon dioxide at a rapid rate. It is interesting to see whether nerve tissues containing ganglion cells produce more or less carbon dioxide per gram per hour than the nerve fibers. For this purpose we studied the ganglionated nerve cord on the back of the heart of the king crab (Limulus polyphemus). This is an elongated automatic ganglion which has been shown to be the direct cause of the heart-beat. It was isolated carefully from the heart, the operation taking but a few minutes, placed in the biometer, and its carbon dioxide output measured. It was found to give $2.3 \times \mathrm{IO}^{-7}$ to $4.7 \times 10^{-7} \mathrm{~g} . \mathrm{CO}_{2}$ per centigram per ten minutes at $22.8^{\circ}$ to $23^{\circ} \mathrm{C}$. The rate was somewhat lower in the larger individuals, which were usually females. This amount of carbon dioxide is very small when compared with the output of the claw nerve of the spider crab, which without stimulation gives off from an equal weight of tissue $6.7 \times 10^{-7} \mathrm{~g}$. If, however, the comparison be made with the claw nerve or with the optic nerve of Limulus itself - the same animal as that from which the ganglion was taken - the rate in the ganglion is found to be about the same as that in the fibers. The claw nerve of Limulus gives only about $2.6 \times 10^{-7} \mathrm{~g}$. of carbon dioxide, while the optic nerve gives somewhat more, namely, 2.6 to $5 \times 10^{-7} \mathrm{~g}$., depending on what portion of the optic nerve is taken (see p. 76). Limulus is a very sluggish, slowmoving animal, whereas the spider crab is more active. 
It appears from these determinations that the heart ganglion gives off about the same amount of carbon dioxide per gram of its substance as the nerve fibers of the same animal. Certainly there is no marked superiority of carbon dioxide output by the ganglion. If anything, its rate is a little lower. This is very interesting because, as already stated, this ganglion is

TABLE IV

Summary of Carbon Dioxide Production from Various Nerve Tissues

\begin{tabular}{|c|c|c|c|c|c|}
\hline Animal & Sex & Nerve & $\begin{array}{c}\text { Temper- } \\
\text { ature } \\
\text { Degrees C. }\end{array}$ & $\begin{array}{l}\text { Amount of } \\
\mathrm{CO}_{2} \text { Given } \\
\text { Off by ro mg. } \\
\text { of Nerve in } \\
\text { Io Minutes }\end{array}$ & $\underset{\mathrm{By}}{\text { Estimated }}$ \\
\hline $\begin{array}{l}\text { Limulus } \\
\text { polyphemus }\end{array}$ & 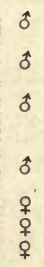 & 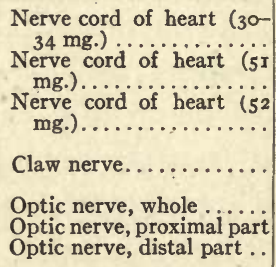 & $\begin{array}{c}23-23 \cdot 5 \\
23 \\
23 \\
23 \\
17 \cdot 8 \\
22.5 \\
22\end{array}$ & $\begin{array}{l}4.7 \times 10^{-7} \mathrm{~g} . \\
2.4 \times 10^{-7} \mathrm{~g} . \\
2.3 \times 10^{-7} \mathrm{~g} . \\
2.6 \times 10^{-7} \mathrm{~g} . \\
2.6 \times 10^{-7} \mathrm{~g} . \\
3.0 \times 10^{-7} \mathrm{~g} . \\
5.0 \times 10^{-7} \mathrm{~g} .\end{array}$ & $\begin{array}{c}\text { Tashiro, } \\
\text { Adams } \\
\text { Tashiro, } \\
\text { Adams } \\
\text { Tashiro, } \\
\text { Adams } \\
\text { Tashiro, } \\
\text { Adams } \\
\text { Tashiro } \\
\text { Tashiro } \\
\text { Tashiro }\end{array}$ \\
\hline & & $\begin{array}{l}\text { Claw nerve, whole } \\
\text { Claw nerve, whole....... }\end{array}$ & $\begin{array}{l}15-16 \\
20.2\end{array}$ & $\begin{array}{l}6.7 \times 10^{-7} \mathrm{~g} \\
7.9 \times 10^{-7} \mathrm{~g}\end{array}$ & $\begin{array}{l}\text { Tashiro } \\
\text { Tashiro, }\end{array}$ \\
\hline $\begin{array}{l}\text { Labinia } \\
\text { canaliculata }\end{array}$ & & $\begin{array}{l}\text { Claw nerve, proximal part } \\
\text { Claw nerve, distal part.... } \\
\text { Claw nerve, whole, when } \\
\text { stimulated ............ }\end{array}$ & $\begin{array}{r}2 I .4 \\
23.2 \\
I 4-I 6\end{array}$ & $\begin{array}{r}8.0 \times 10^{-7} \mathrm{~g} . \\
3.7 \times 10^{-7} \mathrm{~g} \\
16.0 \times 10^{-7} \mathrm{~g} .\end{array}$ & $\begin{array}{l}\text { Adams } \\
\text { Tashiro } \\
\text { Tashiro }\end{array}$ \\
\hline Rana pipiens & & $\begin{array}{l}\text { Sciatic, resting ........... } \\
\text { Sciatic, stimulated ...... }\end{array}$ & $\begin{array}{l}19-20 \\
20-22\end{array}$ & $\begin{array}{r}5.5 \times 10^{-7} \mathrm{~g} \\
14.2 \times 10^{-7} \mathrm{~g}\end{array}$ & $\begin{array}{l}\text { Tashiro } \\
\text { Tashiro }\end{array}$ \\
\hline
\end{tabular}

automatically active all the time and is constantly discharging nerve impulses. Of course this result may be due either to an equality of the metabolism in cells and fibers, or the injury may have raised the rate more in the nerve than in the ganglion, or in the ganglion the amount of non-nervous tissue may be somewhat greater than in the nerve trunk, so that the carbon dioxide pro- 
duction per gram is reduced thereby. But one thing seems to be certain, i.e., that to attribute the carbon dioxide production in the nerve fiber to the connective tissue cells surrounding the nerve trunk, as Bayliss does, is rather ridiculous. Nerve cells evidently breathe at about the same rate as nerve fibers, and not faster, as one might suppose. Table IV summarizes the carbon dioxide production by various nervous tissues, some of which contain cells and others only fibers.

Summary.-We have thus far shown, then, that the living nerve fiber is no exception to the rule that all living matter undergoes chemical changes. It respires. There is a chemical sign of irritability in the nerve. By the use of a proper apparatus of sufficient delicacy we can demonstrate experimentally the formation of carbon dioxide in all nerves; and by estimating the amount produced under various conditions-conditions which we know affect the state of irritability of the normal nerve in the body -we find a very close parallelism between the amount of carbon dioxide produced and the state of irritability. We are justified, therefore, in concluding that the gas thus measured is the expression of the metabolic activity of the nerve. We may now pass on to discover whether this carbon dioxide is increased in case of stimulation. 


\section{CHAPTER III}

CHEMICAL SIGNS OF IRRITABILITY IN THE NERVE FIBER-Continued

Increased metabolism on stimulation.-We have already stated that all living matter, whether it is an organism or an isolated tissue, normally undergoes chemical changes and produces carbon dioxide as one of the final products of its metabolic activity, and that the nerve fiber is no exception to this rule. In other words, respiration is one of the unfailing signs of life and is a necessary condition for living processes. But carbon dioxide production from a tissue is not by itself a sufficient sign of life. For there are many chemical compounds which spontaneously give off carbon dioxide, among others sea-water, bicarbonate solutions, as well as organic materials which are unstable. It would obviously be a mistake to call these compounds living because of the fact that they give off this gas. This criterion alone, therefore, cannot be used for detecting the vitality of the tissues.

Not only is it common for many non-living matters to give off carbon dioxide spontaneously, but there are also some whose mode of gaseous exchange is remarkably similar to that of the living process. Among these substances there is none in which the parallelism to vital respiration is more detailed and interesting than ordinary linseed oil. The many curious resemblances of the chemical processes involved in painting to proto- 
plasmic respiration and growth have already been pointed out. ${ }^{1}$ It is unnecessary to go into this more fully than to call attention to the facts that linseed oil takes up oxygen, that it gives off carbon dioxide, that it is stimulated by light, that it undergoes also other phases of metabolism common to living matter, and that, very singularly, it exhibits many of the phenomena of memory, learning, and forgetting. It is striking, too, that this respiration is of an autocatalytic naturethat is, it becomes more rapid as it progresses and in this respect resembles the psychic phenomena of memory and learning. Thus we see that respiration alone cannot be taken as a criterion of life; and, furthermore, that even the characteristic features of protoplasmic respiration itself cannot be said to be peculiar to living things. A more certain criterion of life is the increase of respiration on stimulation.

It is well known that contracting muscle produces more carbon dioxide than resting muscle. We breathe faster when we run. We can measure the irritability of the muscle by its increased metabolism occurring on stimulation. Is it possible to increase the metabolism of the nerve also by stimulation? Can the nerve, one of the most irritable tissues of all, perform its function without consuming any material? Is the nerve impulse something similar to an electrical current passing through a rather imperfect conductor? How is the electromotive force created in the nerve fiber when the impulse passes through it? Is it simply the equivalent of the energy we put in at the initial stimulation? These questions cannot be considered unless we first

${ }^{x}$ Mathews, Textbook of Physiological Chemistry, 1915, p.67. 
determine positively whether or not nervous functions involve metabolic change.

As far as the brain - the master nervous tissue of the body-is concerned, it is perfectly obvious that its action involves a very intense chemical activity. This is shown by various circumstances. It is made evident in the first place by the fact that the brain has an extremely abundant blood supply and that the blood returning from the brain has lost a considerable part of its oxygen. Direct measurement of the amount of oxygen actually consumed by the brain shows that it is greater than that of any other tissue in the body relative to its weight. The carbon dioxide production is also greater. Everyone knows, also, that keen intellectual work depends on a plentiful blood supply to the head. When one works hard intellectually the face flushes; often the hands and feet become cold, owing to concentration of the blood in the head. If this increase of blood does not occur, keen intellectual effort is impossible. If the circulation stops, or even if the blood pressure becomes low, we become unconscious or faint. These facts are sufficient to prove that the functions of the brain, at any rate, involve oxygen and are expressed in its respiration. The attempt to measure the amount of heat produced in the brain during intellectual effort has thus far been unsuccessful, owing in part to the fact that it is impossible ever to get the brain in a state of rest. It is always in partial activity. In the second place, the brain makes only a small portion of the total weight of the body, so that its heat makes but a small fraction of that of the whole body, and it is this which we have to measure. It has been observed, also, that 
if Ehrlich's method of staining tissues with methylene blue is used, a spot of the surface of the brain loses its blue color when it is stimulated, owing to the consumption of oxygen and the resulting decolorization of the blue.

We may now consider the carbon dioxide output of nerves on stimulation.

Non-medullated nerves. - The biometer is so delicate that in trying these experiments many precautions had to be taken to make certain that the experimental conditions themselves did not produce an increase of carbon dioxide independent of the change in the metabolism of the nerve. If we stimulate with an electrical current, we have to be on our guard lest there should be direct decomposition of some substances at the electrodes, resulting in more production of carbon dioxide. But by trying various kinds of stimulation, mechanical and chemical as well as electrical, we can throw out these possible sources of error. We found, in the first place, that there was no appreciable increase of carbon dioxide due to any direct electrical decomposition by stimulating a dead nerve. In all the quantitative experiments which follow, the current for stimulating was so small as to be barely perceptible to the tongue. The heating effect was, therefore, practically negligible.

A nerve of the claw of the spider crab was isolated as before. A comparative estimate was first made. Two pieces of the nerve of equal weights and lengths were placed separately on the glass plates, each nerve being laid across the electrodes of the plate, in the manner shown in Fig. 2. In this way either nerve can be stimulated at will. These glass plates are hung upon the 
platinum wires fused into the side of the apparatus (see p. II3), these wires being connected in turn with the induction coil. Under this condition, when neither nerve is stimulated, the amount of the precipitate is equal in the two chambers. However, when one of the nerves is electrically stimulated with a weak induction current, the distance between the primary and second-

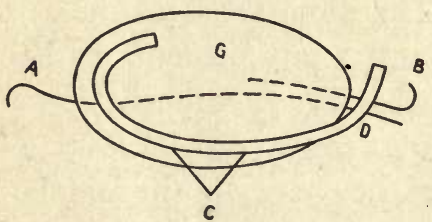

FIG. 2.-Glass weighing plate. $A, B$, platinum wires fused in the rear of the glass plate, with hooks; $C$, the nerve which is stimulated at $D ; G$, the plate proper. Another piece of glass, exactly counterbalanced with this plate, is used, so that any wet tissue can be weighed very quickly.

in the manner described above.

ary coils being more than ro $\mathrm{cm}$., an ordinary dry battery being used, not only does the precipitate appear sooner in the chamber containing the stimulated nerve, but the quantity of the carbonate is much greater. This difference in carbon dioxide production can be brought out better in the quantitative estimate made As shown in Table $\mathrm{V}$, a stimulated nerve fiber of the spider crab gave $16 \times 10^{-7} \mathrm{~g}$. of carbon dioxide for

TABLE V

\begin{tabular}{|c|c|c|c|}
\hline Nerve & $\begin{array}{l}\text { Amount of } \mathrm{CO}_{2} \text { Pro- } \\
\text { duced by ro mg. of } \\
\text { Resting Nerve in } \\
\text { ro Minutes }\end{array}$ & $\begin{array}{c}\text { Amount of } \mathrm{CO}_{2} \text { - Pro- } \\
\text { duced by ro mg. of } \\
\text { Stimulated Nerve in } \\
\text { ro Minutes }\end{array}$ & $\begin{array}{l}\text { Rate of } \\
\text { Increase } \\
\text { of } \mathrm{CO}_{2}\end{array}$ \\
\hline $\begin{array}{l}\text { Non-medullated (spider } \\
\text { crab) } \ldots \ldots \ldots \ldots \\
\text { Medullated (frog)........ }\end{array}$ & $\begin{array}{l}6.7 \times 10^{-7} \text { g. }\left(15^{\circ}-16^{\circ}\right) \\
5.5 \times 10^{-7} \text { g. }\left(19^{\circ}-20^{\circ}\right)\end{array}$ & $\begin{array}{l}\text { I6. } \times 10^{-7} \text { g. }\left(14^{\circ}-16^{\circ}\right) \\
\text { I4. } 2 \times 10^{-7} \text { g. }\left(20^{\circ}-22^{\circ}\right)\end{array}$ & $\begin{array}{l}2.4 \text { times } \\
2.6 \text { times }\end{array}$ \\
\hline
\end{tabular}

Io $\mathrm{mg}$. of the nerve for ten minutes, while a fresh unstimulated nerve of the same animal gave only 
$6.7 \times 10^{-7} \mathrm{~g}$. for the same units. In other words, the output was increased between I00 and 200 per cent by the tetanization of the nerve.

Electrical stimulation of medullated nerves. -The fact that the increased production of carbon dioxide on stimulation is not limited to the non-medullated nerve is shown by our quantitative determination on the sciatic nerve of the frog. Ten milligrams of frog's nerve gave $14.2 \times 10^{-7} \mathrm{~g}$. of the gas during ten minutes of stimulation as compared with $5.5 \times 10^{-7} \mathrm{~g}$., the amount produced by the resting nerve of the same animal. Here again stimulation increased the output from 200 to 300 per cent.

Other stimulation.-We have now established the fact that when a nerve is stimulated by an electrical current it gives off more carbon dioxide. In order to test whether this increased production of the gas on electrical stimulation is due to the direct decomposing influence of the current or to the state of excitation produced by the stimulus, many additional facts must be sought. In the first place, if the increased gas production is not due to a change in rate of metabolism, but to the current itself, then we should expect that the stimulation of a killed nerve ought also to cause more gas production, provided, of course, that we may assume that the conditions under which electrical decomposition takes place are the same in the living and in the dead.

When we place two nerves killed by steam, one in each chamber of the biometer, and stimulate one of them, the stimulated nerve does not give off more carbon dioxide than the unstimulated when the same strength of current is employed as was used in the other experiments. 
In the next place, it was thought possible that our assumption that the condition under which an electrical decomposition takes place is the same in a living and dead nerve may not be strictly true, but that an electrical current can in some way drive away carbon dioxide more quickly in the living nerve. Since killing by steam may also drive out the gas already present in the tissue, the apparent indifference of the dead nerve toward electrical stimulation may not prove that the increased carbon dioxide accompanying stimulation in the living nerve is really a direct result of a change in its vitality, rather than an indirect result of the passage of the electrical current. If, however, this increased gas production were due to the mere electrical decomposition, which was not limited to the point of contact with the electrode, we ought in the living nerve to get a proportional increase of carbon dioxide by increasing the length of nerve through which the current directly passes. The fact is, however, that we can produce an increase of carbon dioxide by stimulating with electrodes $2 \mathrm{~mm}$. apart, so that only a small portion of the nerve is traversed by the current, as well as by electrodes $15 \mathrm{~mm}$. apart. It makes no difference how much of the nerve is traversed by the current. But it does make a difference how much of the nerve is traversed by the nerve impulse. These experiments suggest very strongly that the increase of carbon dioxide on electrical stimulation is due to the increased metabolic activity during functional activity in the nerve, and is not due to the influence of the electrical current as such. With the aid of other means of stimulation we shall now proceed to prove that all stimulation is accompanied by an increase of 
metabolic activity, as shown by the output of carbon dioxide.

Mechanical stimulation.-Since the ordinary method for mechanical stimulation cannot be used directly on the nerve in the biometer in its present form, in view of the fact that the chamber has to be kept shut, we used a different method, namely, that of injuring the nerve by crushing. That when protoplasm is smashed vigorous chemical changes result is well established. Fletcher reports that injured muscle gives off more carbon dioxide than normal muscle; later he and Hopkins discovered that muscle under a similar condition is richer in lactic acid. Mathews observed a similar increase in carbon dioxide in the crushed eggs of Arbacia. We have discovered that if a nerve is crushed with a rough edge of a glass rod it gives off more carbon dioxide than the normal one; that is, an injury increases the carbon dioxide output of the nerve. Since this increase of carbon dioxide cannot be produced by crushing an unexcitable nerve, we consider this injury to be a form of mechanical stimulation. (For further consideration of this subject see p. 9r.)

Chemical stimulation.- The study of the nature of chemical stimulation has been so thoroughly made that it might seem ideal to study quantitatively the increased production of the gas following the stimulation of the nerve by various salt solutions. But there are complications which seriously interfere with the use of this method. We found, for instance, that the presence of minute quantities of a foreign liquid is a seriously disturbing factor for a quantitative estimate of carbon dioxide. Qualitatively, however, we found various 
evidences which establish the fact that the nerve chemically stimulated gives off more carbon dioxide, and that when rendered less excitable by reagents it produces less carbon dioxide than the normal resting nerve.

When the two sciatic nerves of a frog are isolated and one is left in physiological salt solution- 0.75 per cent sodium chloride - and the other in the body of the frog for the same length of time, and when they are transferred to the two chambers of the apparatus, it is found, if the quantities of the carbonate precipitates are compared, that the nerve which has been in the saline solution produces more carbon dioxide than that which has remained in the body. It is known that such a saline solution raises irritability and ultimately stimulates the frog's sciatic nerve.

The different rates at which carbon dioxide is produced from different nerves treated by various concentrations of potassium chloride are equally instructive. When a nerve is placed in a molecular solution of potassium chloride, stimulation takes place for a considerable time. Then finally the nerve becomes inexcitable. But if the nerve is put in 0.2 mol. solution of the same salt, nervous excitability is abolished in a short time without any primary stimulation. The carbon dioxide production follows exactly analogously to this. The nerve treated with the stronger solution gives off more carbon dioxide than the one treated with the weaker solution. This was true even after the nerve became inexcitable, showing that the nerve must still be giving off more carbon dioxide while being stimulated by the stronger solution. Mr. Riggs is making an extensive study of the effect of various 
sodium salt solutions of varying concentrations and has already discovered confirmatory evidence for the increase of metabolism during chemical stimulation. It may be added here in passing that the different solubility of carbon dioxide in these salt solutions cannot alone explain our results, for there is not enough difference in solubility of this gas in such dilute equimolecular solutions of potassium and sodium chloride whose effects on carbon dioxide production are so divergent, the former salt diminishing, the latter increasing, it.

The fact that during chemical stimulation the nerve gives off more carbon dioxide is made evident, also, by the use of low concentrations of anesthetics. If the concentration is so low as to give a primary stimulation to the nerve, the production of this gas is greatly accelerated at the beginning of immersion of the nerve in the narcotics. This is an additional evidence that there is a relation between excitation and metabolic activity.

Stimulation in hydrogen.-The last experiment which we shall describe in this connection is on the quantitative estimation of the carbon dioxide production in a nerve when the latter is in an atmosphere of hydrogen and when it is being stimulated by an electrical current. We expected to find here one of two things. First, there is evidence, to which reference has already been made, that nerves left in hydrogen gas show diminished irritability and that they give off smaller amounts of carbon dioxide than do the same nerves in air. This fact led us to anticipate that these nerves, being thus less irritable than normal nerves, would produce less than the usual increment of carbon dioxide on excitation. This would be the case if the increment were a proper measure of the 
state of excitability. On the other hand, if this carbon dioxide increment were not correlated with the vitality of the nerve, and if nerve activity did not involve respiration, we expected to find that putting the nerve in hydrogen gas would not affect the output on stimulation. For this experiment the claw nerve of a spider crab was used, and stimulation was effected in the usual manner by a tetanizing induced current of the same strength as that which had been used before and found to increase the output in normal nerves. The results are given in Table VI. It will be seen in this table that the production of carbon dioxide by this nerve was reduced

\section{TABLE VI}

Comparative Rates of $\mathrm{CO}_{2}$ Production in the Nerve with and without Oxygen

\begin{tabular}{|c|c|c|c|}
\hline Nerve & Medium & $\begin{array}{l}\text { Amount of } \mathrm{CO}_{2} \\
\text { Produced by } \\
\text { 1o mg. of Resting } \\
\text { Nerve in Io } \\
\text { Minutes }\end{array}$ & $\begin{array}{l}\text { Amount of } \mathrm{CO}_{2} \\
\text { Produced by } \\
\text { ro mg. of Stimu- } \\
\text { lated Nerve in } \\
\text { ro Minutes }\end{array}$ \\
\hline $\begin{array}{l}\text { Claw nerve of spider crab.. } \\
\text { Claw nerve of spider crab.. } \\
\text { Claw nerve of spider crab.. }\end{array}$ & $\begin{array}{l}\mathrm{CO}_{2} \text { free air } \\
\mathrm{CO}_{2} \text { free air } \\
\mathrm{CO}_{2} \text { free } \\
\text { hydrogen }\end{array}$ & $\begin{array}{l}6.7 \times 10^{-7} \mathrm{~g} .\left(15^{\circ}-16^{\circ}\right) \\
7.9 \times 10^{-7} \mathrm{~g} .\left(20^{\circ} .2\right) \\
3.4 \times 10^{-7} \mathrm{~g} .\left(23^{\circ} \cdot 0\right)\end{array}$ & $\begin{array}{l}16 \times 10^{-7} \text { g. }\left(14^{\circ}-16^{\circ}\right) \\
\cdots \cdots \cdots \cdots \cdots \cdots \cdots \cdots \\
3.6 \times 10^{-7} \text { g. (21.०o) }\end{array}$ \\
\hline
\end{tabular}

almost exactly 50 per cent when the nerve was in hydrogen, as compared with when the nerve was in the air; and still more remarkable is the fact that stimulation in the hydrogen atmosphere produced practically no change in the carbon dioxide output. We interpret this to mean that the excitability of the nerve had been so reduced by the lack of oxygen that this strength of stimulus was unable to cause any excitation in the nerve. We base this conclusion on the known fact that lack of oxygen lowers considerably the irritability of the nerve 
and also reduces the time during which a current of any strength can stimulate the nerve. Exhaustion comes on much more rapidly in a hydrogen atmosphere. Fröhlich found that when a sciatic nerve of a frog is deprived of atmospheric oxygen its irritability, measured by the threshold of stimulation for muscular contraction, decreases more and more, until after the lapse of some hours the stimulation required is so strong as to approach the region where electrical currents spreading down the nerve stimulate the muscle directly. If such is the case in a frog's nerve, the claw nerve, too, left in hydrogen may in reality not be stimulated by such a weak current. Thörner, also, taking the action current as an index, found that a nerve continuously stimulated in an atmosphere deficient in oxygen was quickly exhausted. It is remarkable that the action current of a nerve in nitrogen gas falls to two-thirds of its original value within the first ten minutes. Fatigue of the nerve by continuous stimulation during the first few minutes of our experiments with hydrogen may then have been brought about.

Whatever interpretation we take -and, as a matter of fact, both factors doubtless enter here the fact that there is no decided increase of carbon dioxide on weak electrical stimulation in hydrogen points inevitably to the view that oxygen is a primary factor in the excitability of the nerve, as well as in the conduction of the nerve impulse.

Recently Bayliss has pointed out what he considers a probable error in our experiments. To him it seems that the increased production of carbon dioxide on electrical stimulation may be due, in consequence of the 
heat produced by the exciting current itself, to the escape of carbon dioxide which had been dissolved in the living cells in the connective tissue around the nerve fiber. We have cited several experiments the results of which exclude this possibility. In addition to these, the apparent lack of any increase of this gas on application of induction shocks to a nerve in an oxygen-free medium like hydrogen should be taken as conclusive evidence that the increased gas production by a nerve when stimulated in the air is due to physiological processes, and not to experimental errors.

Lack of fatigue. - If the chemical change of the nerve tissue is as active as the observations just cited indicate, one naturally asks how we can explain the fact that the nerve impulse can pass continuously through the fiber without any measurable sign of fatigue. There is no doubt that this apparent lack of fatigue of medullated nerves is a very remarkable and striking phenomenon. Nerves can be stimulated for many hours continuously without marked fatigue. But it does not at all mean that there is no chemical change in the nerve, for, in the first place, it must not be forgotten that medullated nerves have in the medullary sheath a very large supply of raw material, or food, which is more than sufficient for their nutrition during the longest experiments which have been tried. The only surprising feature of the physiology of the nerve is that in the isolated nerve, where there is no opportunity for getting rid of the products of decomposition, accompanying functional activity, by way of the blood, nevertheless these products do not seem to act deleteriously on the nerve function. But, after all, we have only to assume, in order to understand this, that 
these products are of such a nature that they have very little physiological action. It is quite possible that they are taken care of in the nerve, because it is vitally necessary to animals that those of their nerves which go to skeletal muscle, at any rate, shall not be easily fatigued. There are also other tissues in which it is perfectly certain that there is a rapid metabolism and which also show a no less remarkable freedom from fatigue. We may cite, for example, the contracting wings of insects which vibrate at a rate as high as three hundred vibrations per second, and yet these insects can fly for hours continuously without muscular fatigue. There is not the least doubt that these muscles which are undergoing this tremendous activity without fatigue are at the same time undergoing a very rapid metabolism. All that is necessary to avoid fatigue is that the tissue shall return each time after activity to its normal state. The ordinary induction coil which we use in these experiments only stimulates a nerve about one hundred times a second, or about one-third as often as the insect's wing muscles contract, so that more time is given for recovery in the nerve than in these muscles. The lack of apparent fatigue in nerves is not, then, any proof of the absence of metabolism.

When we examine nerves more closely and by more delicate methods, we find unmistakable evidences of fatigue in them. The only remarkable thing about them is that they recover from that fatigue very rapidly. Thus Gotch and Burch discovered in 1889 that if two stimuli are successively applied to a nerve within I/ 5,000 of a second, only a single nerve impulse is produced. One cannot generate a second impulse until 
the nerve has recovered from the first. This refractory period of I/5,000 of a second may be considerably prolonged under certain conditions, such as low temperature, high temperature, asphyxiation, various drugs, and certain anesthetics. Frölich prolonged this refractory period by partial anesthesia and succeeded in producing fatigue phenomena by repeated electrical stimulations at shorter intervals than the prolonged refractory period of the nerve.

The idea that all the physiological activities are composed of at least two opposing metabolic phenomena was expressed by Claude Barnard and later extended by Hering. Thus metabolic activities are considered as consisting of two phases, namely, a breaking down, or katabolic, and a building up, or anabolic, phase. That two such phenomena are involved in nervous metabolism and are closely connected with the phenomena of fatigue may be shown by the use of certain drugs in connection with electrical changes and refractory periods. Waller observed that protoveratrin slows up one of the electrical changes (positive variation) of the nerve, while the other (negative variation) is little influenced. $\mathrm{He}$ contended accordingly that this drug does not alter katabolic changes of the nervous metabolism but retards the anabolic activity to a considerable degree. It is by its anabolism that the nerve is restored to its normal state after the passage of the impulse. Since the pharmacological action of protoveratrin and yohimbin on muscle are known to be very similar, Tait concludes from the study of the effect of yohimbin on the refractory period of the nerve that these drugs must attack nerves in a similar manner. Yohimbin, in other words, retards 
anabolic processes considerably, thus prolonging the one phase of the refractory period or increasing thus the inefficiency of the nerve. From these considerations we may conclude that the nerve may be fatigued by repeated stimulations if we can prolong the time interval of either the excitatory or the repair state.

The general conclusion to which this leads us is that what we call fatigue in a tissue of any kind is due to a failure of the tissue to recover completely its normal state after it is excited. In some tissues this state of fatigue is very easily demonstrated, but in medullated nerves the mechanism of recovery is so perfect that ordinarily the restoration of the nervous substance to its original state after the passage of the impulse takes a very short time - a fraction of a thousandth of a second. Nevertheless, by the conditions stated, namely, by lack of oxygen, by partial anesthetization, by the action of drugs like yohimbin and protoveratrin, the recovery is delayed, and in these cases the nerve exhibits phenomena which may properly be called fatigue. The failure of a nerve to show fatigue under ordinary circumstances should not, therefore, cause us to conclude on this account that there had been no destruction of nerve substance by its excitation, but rather that the nerve had in its medullary sheath an especial supply of a food particularly formed to serve as a speedy pabulum for the fibers, and that the means of reconstituting the nerve tissue after excitation had been so perfected that the result was accomplished in a very brief time.

Heat formation.-Another evidence which has been often cited as showing that there was no chemical change accompanying the nerve excitation is the fact that there 
is no heat produced in excited nerves. How shall we explain the fact that this relatively tremendous chemical transformation can occur without heat formation? There are several explanations which might be given of this fact, but before considering them we may see first what the evidence is that there is no heat produced.

Although there have been in the literature many contradictory statements as to heat formation in the active nerve, the original negative results of Helmholz, Stewart, and Rolleston have been confirmed recently by A. V. Hill's work, which shows that there is no measurable liberation of heat when the nerve is stimulated. Since his apparatus is exceedingly sensitive, being susceptible to the change of I/I,000,000 of a degree Centigrade, the lack of observed heat production is not apparently to be explained by any lack of a proper method of measuring temperatures. His work is remarkably significant in that according to his calculation not more than one single oxygen molecule in every cube of a nerve containing 3.7 cubic $\mu$ can be used up by a single propagated nerve impulse, since more than this amount would produce a measurable amount of heat. Thus he is convinced that a nerve impulse is not of an irreversible chemical nature, but must be of a purely physical nature.

Negative evidence of this kind cannot be taken at. its face value without considering the limitations of the method. Stewart calls attention to the fact that we should not forget that if the axis cylinder is the only portion which is conducting a nerve impulse, as we believe, the measurement in medullated nerves with which most experiments were made does not express the true state in the axis cylinder. We should consider, 
not only the volume ratio between the axis cylinder and sheath, but also the exact coefficient of the temperature radiation in the sheath. In this connection it is interesting to note the very recent work of Snyder, who showed that a smooth muscle also, when measured in the same way, failed to produce heat during its contraction. But no one doubts that during muscle work the metabolic activity is greatly accelerated. He used, by the way, exactly the same technique as Hill. Either, then, heat is produced, but owing to some circumstance it is not detected, or else it is not produced. Now, most muscles certainly produce heat when they work, and it is probable that smooth muscle does so also. It is not to be supposed that the muscles are a perfectly reversible engine. On the contrary, we all know that we become warm when we exercise. When, then, it is reported that smooth muscle produces no heat when it contracts, we are at once skeptical of the method which gives such a result. Consequently, therefore, while the method for the detection of the nerve heat on stimulation appears to be a competent method, we do not feel certain that this is the case.

But suppose we grant that the results are correctthat nerves produce no heat when they are exciteddoes that mean that there is no chemical change occurring in the nerve? Is this fact conclusive evidence that these results of a positive kind which we have adduced, showing that chemical changes do occur in the nerves, are, after all, due to some secondary cause or to some undiscovered errors of technique on our part? Certainly this is not the case, for it is quite possible for chemical changes to occur without liberating more than 
a very small amount of heat, or, indeed, they may actually be heat-consuming rather than heat-producing. And, indeed, if we had side by side reactions which produce and reactions which consume heat we might have a considerable chemical change without the liberation of much heat. Thus in a Daniels' cell there is a very large transformation of energy with the liberation of very little heat. The Weston cell has a still smaller heat coefficient. The energy set free in the cell takes the form of electrical energy rather than heat. To be sure, it is ultimately converted into heat, but for the time being it does not appear as such. There are many chemical changes also which yield carbon dioxide and yet liberate very little heat. It is possible that the carbon dioxide is not produced by an oxidation, but by a fermentative process which is hardly exothermic. Many such hydrolyses liberate almost no heat at all. We might have, for example, the oxidation going on at a steady rate all the time, independently of the stimulus. By this means a constant production of heat occurs, but carbon dioxide is not liberated. That is, the change has occurred at a steady rate in the oxygen atoms, which is the essence of the oxidation. A very unstable compound might result, awaiting only the hydrolysis of the carbon dioxide. This last process might be that which is accelerated by the stimulation and the passage of the impulse. This liberates gas, but very little heat. The reconstitution of the irritable substance might then be brought about by a second molecule slipping in to take the place of the first, while the exhausted molecule was withdrawn to be reoxidized and thus made ready for use again. This reoxidation perhaps goes on all the time, 
irrespective of the stimulus, and accordingly excitation appears to generate no heat and there appears to be no fatigue, unless we deprive the nerve of oxygen for some time, and yet we have a copious production of carbon dioxide which is increased on stimulation. The fact, therefore, that there is no increased heat production in a stimulated nerve is by no means contrary to our results, although it is certainly surprising. It indicates, perhaps, that the act of excitation is not primarily an oxidation, but that the oxidation is concerned in the processes of repair. There are several facts which might be cited, were the space at our command, which would lead to the same conclusion. There are also other suggestions which might be made to account for this seeming incompatibility, but it would be useless to do so without experiments.

We may therefore close this brief discussion with the statement that the failure to detect heat production in nerves during excitation is no evidence of value against the occurrence there of chemical changes resulting in carbon dioxide production and correlated with the irritability. The conclusion drawn from it by some authors that the nerve impulse does not, on this account, involve any chemical processes is entirely unwarranted.

We may in this connection stop for a moment to consider what is known of the oxygen consumption of nerves, for while we have ourselves as yet carried out no experiments in this line, yet there have been some observations made which can be correlated with the carbon dioxide production. In the first place, it may be noted that there is no immediate dependence of some nerves, at least, on atmospheric oxygen for their activity. In this respect the carbon dioxide production and the 
oxygen consumption of the nerve appear to be on a somewhat different footing. I say "appear to be," because the methods of determining the oxygen consumption are still rather crude, and the studies have been few. A nerve always gives off more carbon dioxide when it is stimulated or active, whereas we know very little about whether its intake of oxygen is increased in anything like the same degree. The sciatic nerve of a frog - a medullated nerve can remain excitable for a long time in the absence of atmospheric oxygen, although its irritability diminishes under these circumstances, and, as already explained, its fatigability increases.

There is a considerable amount of evidence to show that oxygen is very closely associated with the state of excitability. To harmonize these two facts, namely, the independence of atmospheric oxygen and the fact just stated, the oxygen-storage hypothesis has been suggested, by which the exhaustion is attributed to complete consumption of stored oxygen. Excitability is restored when atmospheric oxygen is readmitted. Without committing ourselves to this hypothesis, we may add that according to Haberlandt's figure the resting nerve of ro $\mathrm{mg}$. weight will consume only 0.0042 c.c. oxygen in ten hours. If we take our figure of carbon dioxide output and assume that one volume of oxygen was necessary to produce one volume of carbon dioxide (this assumption is made without any significance except to give a liberal estimate), the carbon dioxide production would require a consumption of about 0.015 c.c. of oxygen for ten hours. And if we assume again that activity will increase oxygen consumption 
in proportion to carbon dioxide production, then it means that the nerve when stimulated would take up only 0.03 c.c. of oxygen during ten hours' stimulation. It is extremely difficult, as everyone who has tried it knows, to free any gas from such small amounts of oxygen as those which are required to keep up irritability. Our experience in freeing gases from traces of carbon dioxide makes us realize the difficulty of getting the nerve in the first place in a gas quite free from oxygen, and we believe that many experiments have been tried in which there is still some probability that enough oxygen remained to supply these small amounts needed. More delicate determinations will have to be made before we feel certain that nerves have been found to be irritable for some time in atmospheres which are free beyond question from all traces of oxygen. How shall we know when the gas we use is free from oxygen in these minute amounts? Yet until we know this it is impossible to study accurately the relation of irritability to oxygen. Meanwhile, however, we may recall the fact that carbon dioxide production in the spider crab's nerve is not only reduced in the absence of oxygen, but also that we cannot increase its production in such an atmosphere by a stimulation which in the presence of oxygen increased the production of carbon dioxide over 200 per cent. These facts show conclusively, negative evidence to the contrary notwithstanding, that oxygen is in some way involved in the anabolism or katabolism of nerve fibers.

Summary. - The facts presented in this chapter prove that all kinds of nerves, medullated and nonmedullated, when stimulated increase their output of 
carbon dioxide two or three times above that of their resting state. This increase comes whatever the method of stimulation, provided only that the nerve is alive and irritable. Dead or anesthetized nerves show no such an increase. The state of excitation in a nerve, which we call a nerve impulse when it spreads from one place to another, is not a purely physical change of state, as it has been represented hitherto as being, but it undoubtedly involves a corresponding chemical change. Perhaps the excitation is this chemical change itself. Furthermore, the facts that nerves do not increase their heat output on stimulation and that they are nearly free from fatigue effects are evidently not incompatible with the vigorous metabolism discovered to exist in them. 


\section{CHAPTER IV}

\section{EXCITATION AND CONDUCTION}

We have shown by this study of nerves that living matter must necessarily undergo metabolic activity and that without an increase of this activity protoplasm will not function. In short, to be excitable, the protoplasm must respire, and to be excited, its metabolic activity must be accelerated. It has also been demonstrated that the excited state travels along the fiber with simultaneous increase of the metabolism. Although our theme in this little volume is not a consideration of how this state of excitation is transmitted, but is rather an analysis of the conditions which characterize the irritable tissue, the relation between these two phenomena is so close that we shall consider certain facts which are directly concerned with them.

The two phases of protoplasmic irritability are excitability and conductivity, or transmission, of this excitation. Since it is very difficult experimentally to produce excitation without conduction, we are accustomed to consider the fundamental processes underlying these two processes as probably identical. There are certain facts which are sometimes cited as evidence that these phenomena are not necessarily interdependent. In the case of localized and partial narcosis, for instance, local excitability in the narcotized portion does not disappear simultaneously with conductivity through 
this region, assuming, of course, that the same strength of current when stimulating in or above the narcotized part is made use of. Since we have no evidence that the resistance of the surrounding sheath of the fiber and that of the conducting medium are the same, we cannot assume that in both experiments the same strength of stimulus was really applied to the conducting portion. The non-transmissibility of the inhibitory state is regarded as another distinction between excitation and conduction. We can abolish excitability at one point without making its neighboring region inexcitable. It is rather difficult to consider an analogy between depression and excitation, but the fact is that even if we may not be able to make other than one point inexcitable by one depressing agent, it is doubtful whether we can produce local inexcitability without affecting the contiguous parts of the nerve. Waller has demonstrated, in the case of inhibition by heat, that the point of application of gentle heat became electropositive to the rest of the nerve instead of negative, as is the case in ordinary stimulation. According to him, heat does not stimulate the tissue, but depresses it. If this is the case, as he seems to have demonstrated in a variety of tissues, it indicates that although we cannot produce depression at points other than the point of application, yet certain conditions along the nerve must surely be altered through such an inhibition. In any event, we cannot consider non-conductivity of the inhibitory state as evidence that excitability and conductivity are entirely different processes.

Let us now consider in detail the relation between excitation and conduction. 
Excitability.-The excitability of the nerve fiber has three criteria: (I) the degree of irritability, i.e., the ease with which it can be stimulated; (2) velocity of the nerve impulse, i.e., the speed with which the state of excitation travels from one point to another; (3) the direction of the nerve impulse. All nerves are classified into two general functional types: efferent and afferent, the former conducting away from the nerve center (brain, etc.), the latter toward the center. We shall consider somewhat in detail in this chapter what relation the metabolic condition bears to these three phenomena in the nerve.

Degree of excitability. - Not all nerves can be stimulated equally well by the same strength of stimulus. The threshold value - the minimum strength of stimulus which can call forth functional activity-is different in different nerves. Not only have the different nerves different degrees of excitability, but the same nerve can be made excitable in different degrees under a variety of conditions. If we study metabolic activity in nerves under different conditions which we know affect the state of excitability, we find that there is a very close relation between metabolism and excitability.

a) If the sciatic nerve is removed from a frog, it exhibits electrical phenomena for many hours. Since electrical changes are characteristic of living nerves only, we consider that the isolated nerve does not die for many hours. Such a nerve, although it shows large electrical responses, is nevertheless less excitable than a fresh one. If measurements are made on an isolated nerve at successive time intervals for many hours, we find that the carbon dioxide production steadily dimin- 
ishes as the nerve approaches death. The point of minimum production of the gas corresponds approximately to the point where an electrical response ceases (see p. 28).

b) Although the nerve remains active for some time without oxygen, it is known that the absence of oxygen diminishes the excitability of the nerve. This diminution of the excitability when in hydrogen is accompanied with a lowering of carbon dioxide production in the nerve.

c) Further facts showing the relation between excitability and metabolic activity are brought out by the study of the effects of narcotics on the nervous metabolism. There are several compounds which alter the state of excitability of nerves to a considerable degree. The discovery of just what happens to respiration during anesthesia will throw much light on the nature of irritability. It is this which we shall now study in detail.

In recent years many experiments have been performed which are supposed to prove that oxygen consumption can go on uninterruptedly during narcosis, and the consequent conclusion has been that narcosis is not produced by asphyxiation. This is not the place for us to weigh the merit of these arguments, nor are we concerned here with the question of how narcotics act on protoplasm, but it is very important to know whether or not metabolic activity in nervous tissue can go on undisturbed while the tissue is unable to perform its own function. Are respiration and irritability independent processes? To show that they are dependent we shall cite in detail experiments on the effects of anesthetics on respiration. 
- We have already mentioned the effect of ether on nerves and demonstrated that lowering the excitability of a nerve is accompanied by a lowering of carbon dioxide production. For the quantitative experiments, carried out in conjunction with Dr. Adams, we used chloral hydrate and ethyl urethane in preference to the ordinary volatile narcotics. If we anesthetize a nerve with the lowest concentration of ether or chloroform that produces a reversible loss of irritability, then the anesthetized nerve regains its excitability during the course of the experiments, for in order to make the apparatus free from carbon dioxide after introducing the nerve we have to wash it with carbon-dioxide-free air several times. By so doing the most volatile narcotics are removed from the nerve. On the other hand, if we use higher concentrations, which, as we know, lower carbon dioxide production, we may be subject to the criticism that the lowering of metabolism may be due partly to death or injury. It is therefore essential that we should investigate the effect of various concentrations, from such as have apparently no narcotic effect to those from which recovery is doubtful or absent. Thus the use of suitable narcotics as well as concentrations seems to be of prime importance. For even those who consider that narcosis is not due to an asphyxiation admit that the oxygen consumption is greatly depressed if the narcosis is pushed too far, although such depression in the rate of oxidation may have nothing to do with the cause of the narcosis.

With a view to studying the effect of various concentrations of anesthetics, the claw nerve of a crab was isolated, its excitability tested by electrical stimulation, and, without being cut off from the claw, it was immersed 
in the narcotic solution, care being taken that the claw muscle did not come in contact with the solution. After ten minutes it was removed, freed from excess liquid by means of filter paper, its state of excitability determined by stimulation, and, with claw attached, it was placed in a moist chamber for ten minutes, which is the time

TABLE VII*

Effects of Ethyl Urethane on Claw Nerve of Spider Crab, Libinia canaliculata

\begin{tabular}{|c|c|c|c|c|c|}
\hline \multicolumn{2}{|c|}{ Treated BY } & \multirow{2}{*}{$\begin{array}{l}\text { EFFECTS ON } \\
\text { EXCITA- } \\
\text { BILITY }\end{array}$} & \multirow{2}{*}{$\begin{array}{c}\text { AFTER } \\
\text { RETURN To } \\
\text { SEA-WATER }\end{array}$} & \multirow{2}{*}{$\begin{array}{c}\text { Change } \\
\text { IN WEIGHT } \\
\text { IN IO } \\
\text { MiNUTES }\end{array}$} & \multirow{2}{*}{$\begin{array}{l}\text { AMOUNT OF } \mathrm{CO}_{2} \text { Pro- } \\
\text { DUCED BY IO MG. OF } \\
\text { NERVE IN IO MINUTES }\end{array}$} \\
\hline $\begin{array}{l}\text { Concen- } \\
\text { tration in } \\
\text { Sea-Water }\end{array}$ & $\begin{array}{l}\text { For } \\
\text { How } \\
\text { Long }\end{array}$ & & & & \\
\hline \multirow{2}{*}{ o per cent. } & \multirow{2}{*}{ ro min. } & \multirow{2}{*}{$\begin{array}{c}\text { I, Excitable } \\
\text { nerve } \\
\text { 2, Inexcit- } \\
\text { able nerve }\end{array}$} & \multirow[b]{2}{*}{ Excitable } & No change & $7.9 \times 10^{-7}$ g. at $20^{\circ} .2$ \\
\hline & & & & No change & $5.7 \times 10^{-7}$ g. at $22^{\circ}$ \\
\hline I per cent. & ro $\mathrm{min}$. & Excitable & Excitable & No change & $21.7 \times 10^{-7}$ g. at $23^{\circ} .8$ \\
\hline 2 per cent. & Io $\mathrm{min}$. & Narcosis & Excitable & No change & Not determined \\
\hline 3 per cent. & $10 \mathrm{~min}$. & Slow, partial & Excitable & No change & Not determined \\
\hline 4 per cent. & ro min. & Practically & Good return & No change & $3.3 \times 10^{-7}$ g.at $2 \mathrm{I}^{\circ}-2 \mathrm{I}^{\circ} .5$ \\
\hline 5 per cent. & ro min. & $\begin{array}{c}\text { Completely } \\
\text { narcotized }\end{array}$ & $\begin{array}{l}\text { Recovery is } \\
\text { not always } \\
\text { good }\end{array}$ & No change & Not determined \\
\hline
\end{tabular}

* Since our previous determinations of the carbon dioxide production of the spider crab's nerve were made at a much lower temperature ( $15^{\circ}$ to $\left.16^{\circ} \mathrm{C}.\right)$, the work was repeated at the higher temperature at which most of the present experiments were made. In order to make the comparison a rigid one, the normal nerve was subjected to a treatment similar to that employed with the narcotized nerve, except that it was not narcotized. It was isolated, quickly weighed, and immersed in sea-water for ten minutes, after which the rate of carbon dioxide production was determined in the usual way. As was expected, the nerve exhibited a somewhat higher rate of metabolism at the higher temperature. The results are incorporated in the table.

usually required in making a determination of the carbon dioxide production. After this the nerve was brought back to fresh sea-water and the return of irritability was determined, as evidenced by contraction of the claw or joint in response to the electrical stimulation of the nerve. Thus the essential conditions obtaining 
in the actual determination of carbon dioxide were reproduced.

From the results so obtained the minimum concentration which produced a reversible loss of irritability was chosen for our experiments on the carbon dioxide production, and we are thus assured that the nerve has been narcotized, but that, since its excitability returns, no permanent injury has been caused. The carbon dioxide production of the nerve thus treated has been determined and compared with that of a normal nerve. These results are tabulated with the physiological data and given in Table VII.

\section{ETHYL URETHANE}

As shown by physiological tests, a freshly isolated claw nerve on immersion in a 4 per cent solution of ethyl urethane loses its excitability within ten minutes. Such a nerve, however, if left in a moist chamber for ten or fifteen minutes and then returned to sea-water, comes back to a normal condition of excitability with apparently no injurious effects. That the nerve so narcotized gives off less carbon dioxide than a normal one can be demonstrated qualitatively as follows:

Two nerves of approximately the same weight are isolated, and one is immersed in sea-water while the other is treated with a 4 per cent urethane solution for ten minutes. At the end of this time their rates of carbon dioxide production are compared simultaneously in the biometer by placing the normal nerve, for example, in the right chamber and the other in the left. Within ten minutes the difference in carbon dioxide output will become evident, for not only does the precipitate 
appear first on the barium hydroxide in the right chamber, containing the normal nerve, but the amount of precipitate later is seen to be much greater in this chamber than in the other. The narcotized nerve is giving off less carbon dioxide than the normal one.

That the narcotized nerve produces less carbon dioxide than the normal is shown more strikingly by quantitative determinations. The average carbon dioxide output for the nerve when treated for ten minutes with a 4 per cent ethyl urethane solution is less than 50 per cent of that of the normal nerve. At $20^{\circ}$ to $22^{\circ} \mathrm{C}$. the narcotized nerve gives $3 \cdot 3 \times 10^{-7} \mathrm{~g}$. per centigram of tissue for ten minutes' respiration, while the normal nerve, calculated for the same units, produces $7.9 \times \mathrm{IO}^{-7} \mathrm{~g}$. One exception may be noted here -an experiment in which the respiration of the narcotized nerve was $4.9 \times 10^{-7} \mathrm{~g}$. -but this is partly explained by the fact that the particular determination was effected at $25^{\circ} \mathrm{C}$. Even in this case the decrease of carbon dioxide was marked. Qualitative experiments with a 2 per cent ethyl urethane solution show that even this concentration produces a diminution of carbon dioxide output.

\section{CHLORAL HYDRATE}

As indicated in Table VIII, a 2 per cent solution of chloral hydrate in sea-water partially or wholly paralyzes the nerve in ten minutes and recovery is apparently perfect. A 3 per cent concentration produces complete paralysis and the return of excitability is good. Treatment with a 4 per cent chloral hydrate solution for the same period of time also produces paralysis, but recovery is not always good. In each 
case the decrease of carbon dioxide production is decided. Table VIII illustrates quantitatively the difference in carbon dioxide production under these different conditions. The interesting results with 3 per cent and 4 per cent solutions will be considered later.

\section{TABLE VIII}

Effects of Chlorad Hydrate on Claw Nerve of Spider Crab, libinia canaliculata

\begin{tabular}{|c|c|c|c|c|c|}
\hline \multicolumn{2}{|c|}{ Treated By } & \multirow{2}{*}{$\begin{array}{l}\text { EFECTS ON } \\
\text { EXCITABILITY }\end{array}$} & \multirow{2}{*}{$\begin{array}{c}\text { AFTER } \\
\text { RETURN TO } \\
\text { SEA-WATER }\end{array}$} & \multirow{2}{*}{$\begin{array}{l}\text { CHANGe } \\
\text { IN WEIght } \\
\text { IN Io } \\
\text { MiNUTES }\end{array}$} & \multirow{2}{*}{$\begin{array}{l}\text { AMOUNT OF } \mathrm{CO}_{2} \\
\text { PRODUCED BY } \\
\text { IO MG. OF THE } \\
\text { NERVE IN IO } \\
\text { MINUTES }\end{array}$} \\
\hline $\begin{array}{l}\text { Concentra- } \\
\text { tion in } \\
\text { Sea-Water }\end{array}$ & $\begin{array}{l}\text { For } \\
\text { How } \\
\text { Long }\end{array}$ & & & & \\
\hline o per cent... & ro $\mathrm{min}$. & Excitable & & No change & $7.9 \times 10^{-7}$ g.at $20^{\circ} .2$ \\
\hline o per cent... & Io $\mathrm{min}$. & Inexcitable & & No change & $5.7 \times 10^{-7}$ g. at $22^{\circ}$ \\
\hline 0.4 per cent. & Io $\mathrm{min}$. & Becomes more & Excitable & No change & II. $5 \times 10^{-7}$ g.at $20^{\circ} .4$ \\
\hline I per cent... & $10 \mathrm{~min}$. & Slow narcosis & Excitable & No change & Not determined \\
\hline 2 per cent... & Io $\mathrm{min}$. & $\begin{array}{l}\text { Partial or com- } \\
\text { plete narcosis }\end{array}$ & Good return & $\begin{array}{l}\text { Very slight } \\
\text { gain }\end{array}$ & $4.2 \times 10^{-7}$ g.at $22^{\circ} .5$ \\
\hline 3 per cent.. & ro $\mathrm{min}$. & $\begin{array}{l}\text { Completely } \\
\text { narcotized }\end{array}$ & Fair return & 25 per cent & $2.8 \times 10^{-7}$ g.at $23^{\circ} .5$ \\
\hline 4 per cent... & Io $\mathrm{min}$. & $\begin{array}{c}\text { Completely } \\
\text { narcotized }\end{array}$ & $\begin{array}{c}\text { Partial or } \\
\text { doubtful } \\
\text { return }\end{array}$ & $\begin{array}{l}50 \text { per cent } \\
\text { gain }\end{array}$ & $3.6 \times 10^{-7}$ g.at $23^{\circ} .5$ \\
\hline
\end{tabular}

Is the decrease of carbon dioxide due to narcosis? The results given above establish beyond a doubt that during treatment with narcotics, in concentrations which produce a reversible loss of irritability, the carbon dioxide output of a nerve is greatly reduced. The differences thus produced are far beyond the limits of experimental error and there can be no suspicion that the phenomenon is the result of faulty observation. The question might be raised, however, whether this diminution is directly related to the narcosis, or whether it might not be due to some factor casually introduced 
during the experiment. With this contingency in view, certain possible objections are here considered.

The method employed for carbon dioxide determination is so delicate that a change in the reaction of the sea-water, brought about possibly by the addition of the narcotic, might be sufficient materially to alter the values obtained. This, indeed, is the reason why we have never been able to investigate the effects of potassium cyanide, since the slight trace of alkalinity thus introduced seriously modifies the results. This objection, however, we have been able to refute by direct experimental means.

If the solution of the narcotic differs in reaction from sea-water sufficiently to influence the determination, a similar effect should be observed in the case of a nerve which has been killed. Two freshly isolated nerves of approximately the same weight were killed simultaneously by means of steam and left for twenty minutes, one in a 2 per cent solution of chloral hydrate and the other in sea-water. A measurement of the adventitious carbon dioxide production from the two nerves so treated gave no evidence of any difference. The diminution of carbon dioxide from nerves subjected to the action of narcotics cannot, therefore, be referred to any change in the reaction of the sea-water produced by the narcotic.

Another possibility is involved in the fact that certain narcotics produce phenomena other than those of narcosis. This is probably the reason why the metabolism change is never exactly the same in the case of two nerves in which typical narcosis has been induced by different means. One of these effects must be a change 
in 'osmotic pressure, but that the lowering of carbon dioxide output cannot result essentially from the osmotic effect is evidenced in many indirect ways. We found that the sciatic nerve of the frog when treated with 2 per cent ethyl urethane solution gains about 30 per cent in weight during ten minutes' immersion. No change in weight, however, takes place in the spider crab's nerve on a similar treatment with the same concentration of this narcotic. Loss of irritability ensues in each case, and in each case the carbon dioxide production is greatly diminished. A 4 per cent solution of chloral hydrate causes the spider crab's nerve to increase 50 per cent in weight in ten minutes, while 4 per cent ethyl urethane solution produces no change of weight in the same nerve. Yet both narcotics depress carbon dioxide output greatly. That this decrease is independent of osmotic effect is further shown by our work on the effect of ether vapor on carbon dioxide production in a frog's nerve.

In this work with a frog's nerve it was found that ethyl urethane will reduce carbon dioxide production, but that soon after the nerve begins to gain in weight the tendency is for this production to increase slightly, though not sufficiently to raise it to its normal value. Although this point is still under quantitative investigation, it seems certain that this increase of carbon dioxide is casual, and probably due to a sort of water rigor. Somewhat similar results are obtained with the spider crab's nerve (Table VIII). Thus we find that with a 3 per cent chloral hydrate solution the carbon dioxide production is least-about one-third that of the normal nerve - while with a 4 per cent solution it is a little less than one-half. Investigation of the effect of 
this narcotic on the weight of the tissue shows that a 2 per cent concentration has but little effect for the first ten minutes, though during the course of half an hour a gain of 50 to roo per cent takes place. A 3 per cent concentration produces a gain of 25 per cent in ten minutes, while in a 4 per cent solution the nerve gains 50 per cent in the same space of time. These results, together with those on the frog's nerve, indicate that, whatever interpretation we put upon this change in weight, the result of such a process is temporarily, at least, to increase slightly the amount of carbon dioxide evolved, and that, so far as the effects of narcotics are concerned in our work, its slightly increased production from the narcotized nerve which gains in weight may be looked upon as adventitious. The correctness of our interpretation of the diminution of carbon dioxide output as an effect primarily connected with narcosis is further supported by a study of the effects of weak concentrations of narcotics for different periods of time.

Effects of weak concentrations of narcotics on carbon dioxide production in the nerve fiber. - It is well known that the primary effect of narcotics is to increase irritability, after which the typical depression follows. This primary effect is well brought out by the use of rather weak concentrations of narcotics. Although we have made no quantitative determination of the degree of irritability, it is evident that a nerve after ten minutes' immersion in a 0.4 per cent chloral hydrate solution has become abnormally irritable. After about one hour's treatment, however, the nerve finally becomes paralyzed. If the carbon dioxide output of a nerve treated for ten minutes with a 0.4 per cent chloral 
hydrate solution is compared in the usual manner with that of a normal nerve, it is easily demonstrated that the carbon dioxide production of the nerve so treated is greatly increased. The quantitative determinations tabulated above illustrate this perhaps more convincingly (see Table IX, horizontal column 3 ).

That this change in the carbon dioxide production of the nerve when treated with the lower concentration is closely connected with the physiological state is further demonstrated in the following experiments. Many claw nerves were isolated from several spider crabs, each pair chosen being approximately of the same weight, and of each pair one was placed in a 0.4 per cent solution of chloral hydrate and the other in sea-water. A comparison was made of the rate of carbon dioxide production of the first pair in the biometer in the usual manner at the end of ten minutes; at the end of half an hour a second pair was compared similarly, and so on. The result is given in Table IX. This table is of more than passing interest, for it illustrates an easy source of error in the study of narcosis. Evidently it is of prime importance to determine the carbon dioxide output during a comparatively small time interval, rather than during one of long duration. If we were to determine the output of the gas for sixty minutes' respiration of the nerve treated with a 0.4 per cent chloral hydrate solution, we might be led to the conclusion that the narcotic has no effect whatever on the metabolic rate. For although we have shown, by taking corresponding nerves at the beginning and at the end of the narcosis, that the primary effect is to increase carbon dioxide production and that later it is greatly diminished, the 


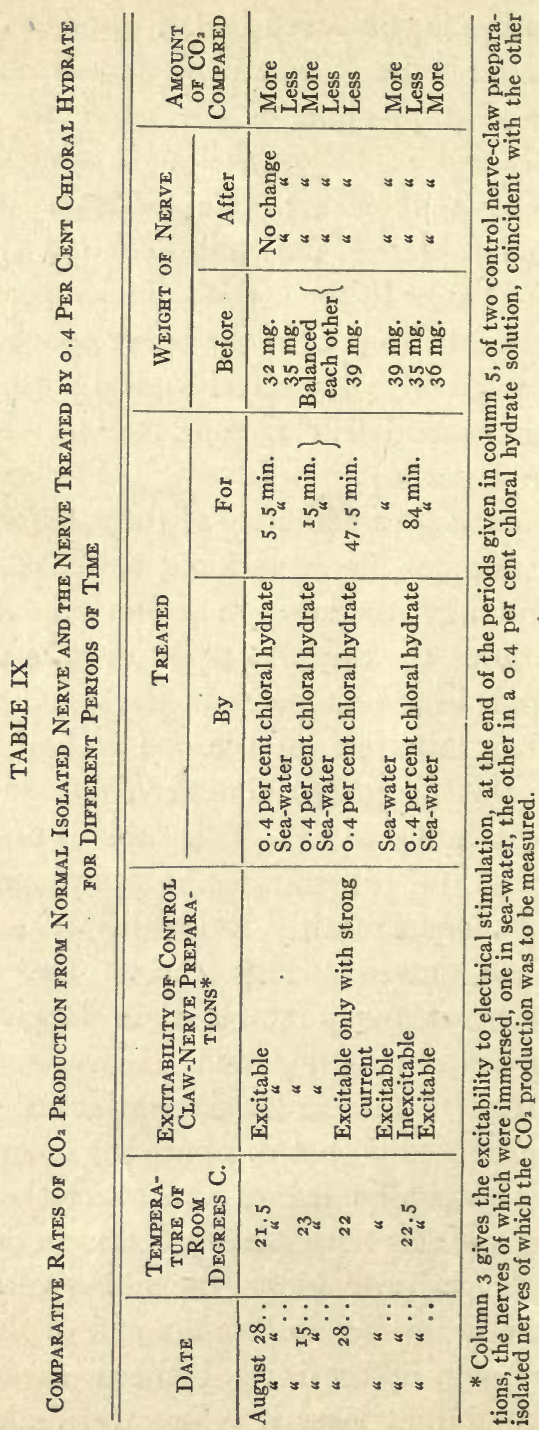


algebraic sum of these results might readily approximate the value found for normal respiration.

The general phenomena are the same for ethyl urethane, except that the primary increase of the gas in light narcosis is much more marked, being more than twice as great if compared with the value for the normal nerve at $20^{\circ} .2 \mathrm{C}$. It was noted that the nerves after treatment with a I per cent urethane solution were hyper-irritable, but a part of this large increase must doubtless be due to the higher temperature at which the experiment was performed.

Carbon dioxide production from "inexcitable" normal nerve.-During the warm weather we occasionally came across a claw-nerve preparation in which no sort of stimulation of the nerve could evoke any response whatever, although the peripheral organs were perfectly excitable. Response by the attached muscle to stimulation of the claw nerve of the spider crab is of three sorts: contraction, or relaxation of the claw, and movements of the lower joint. In general, different strengths of the stimulating current result in different responses. It was at first thought possible that in these cases the stimulation might be calling forth opposed responses, so that one neutralized the other, and thus that no response resulted. But further investigation showed apparently that the nerve was inexcitable, since after immersion in the sea-water irritability was often restored. To whatever cause this may have been due, the interesting fact is that such "inexcitable" nerves invariably showed an abnormally low rate of carbon dioxide production. The results of the quantitative estimates on these nerves are given in Tables VII and VIII, horizontal column 2. 
Summary.-The main points brought out by the study of narcosis are: ( $\mathrm{r}$ ) carbon dioxide production is greatly diminished when the nerve is narcotized either by chloral hydrate or by ethyl urethane in concentrations which produce a reversible loss of excitability; (2) with a weak concentration of these narcotics, at the beginning, the carbon dioxide production is increased, but later is diminished. This is in accord with the facts that these concentrations primarily stimulate, or increase, the irritability of the nerve for a time. The conclusion drawn from these facts is that metabolism in the nerve is interfered with by any agency which interferes with the excitability of the nerve. Excitability and resting respiration go hand in hand.

The direction of the nerve impulse and the metabolic gradient.-Although, it has been established that an excitation wave travels in both directions from the point of the stimulus and that this wave is in all probability identical with the nerve impulse, yet in the normal condition in the body one fiber is supposed to conduct the impulse in one direction only. Based on this difference in the direction of the conduction, one set of the nerve trunks is called efferent and the other afferent, according as they conduct from or toward the central nervous system. That there is a very interesting rela-

- tion between the direction in which the impulse normally goes and the rate of metabolism at different parts of the nerve will be set forth in the following paragraphs.

Efferent fibers. - If we take the bundle of nerves between the second and third joints of the claw of the spider crab and cut it at the middle, the two halves being of about equal weight, and place each in a chamber of the 
biometer and measure its rate of carbon dioxide production, we find that the part of the nerve nearer the body, the proximal portion, gives off more gas than the distal end of the nerve. This nerve is mainly efferent and normally conducts the impulse down the claw from proximal to distal direction. A quantitative estimation shows that the proximal end gives more than twice as much carbon dioxide as the distal, the former giving at least $7.9 \times 10^{-7} \mathrm{~g}$. and the latter $3.7 \mathrm{IO}^{-7} \mathrm{~g}$. per centigram per ten minutes.

TABLE $\mathrm{X}$

Carbon Dioxude Production from Two Different Portions of Craw Nerve of Spider Crab,

Libinia canaliculata

\begin{tabular}{|c|c|c|}
\hline Portion of Nerve & $\begin{array}{l}\text { Temperature } \\
\text { Degrees C. }\end{array}$ & $\begin{array}{l}\text { Amount of } \mathrm{CO}_{2} \\
\text { Given Off by Io mg. } \\
\text { of the Nerve in } \\
\text { Io Minutes }\end{array}$ \\
\hline Whole... & $\begin{array}{l}15-16 \\
20.2\end{array}$ & $\begin{array}{l}6.7 \times 10^{-7} \mathrm{~g} . \\
7.9 \times 10^{-7} \mathrm{~g} .\end{array}$ \\
\hline $\begin{array}{l}\text { Proximal.......... } \\
\text { Distal......... }\end{array}$ & $\begin{array}{l}21 \\
23.2\end{array}$ & $\begin{array}{l}8.0 \times 10^{-7} \mathrm{~g} . \\
3.7 \times 10^{-7} \mathrm{~g} .\end{array}$ \\
\hline
\end{tabular}

From a study of the various conditions which modify this difference in carbon dioxide production in the various portions of the nerve we are probably safe in stating that we are here dealing with a physiological gradient, experimental error playing no part. There are three physiological causes which might account for a different rate of carbon dioxide production: ( $I$ ) different degrees of injury; (2) different rapidity of death; or (3) unequal rates of metabolism. The first alternative is possible only on the assumption that the proximal region must be more excitable (greater susceptibility to an injury), which always causes the production of 
more carbon dioxide. If we are to assume the second possibility, we must inquire why one portion should die earlier than the other. The fact that an isolated nerve stays excitable for a considerable period of time makes this interpretation quite untenable, although we support the idea set forth by Child that the death gradient is directly associated with the metabolic gradient. It may be added here that death modifies the carbon dioxide production gradient.

Whatever interpretation we choose, inasmuch as we contend that the rate of metabolic activity as measured by the carbon dioxide output is a function of the irritability, we are assuming that there must be different rates of metabolism along the normal nerve fiber. Not only that such an assumption is correct, but also that the effect of injury and death are only secondary (6) and minor factors, can be shown in the light of Child's experiments when the same nerve was examined, resulting in the confirmation of our results by an entirely different method.

He has shown that in various concentrations of potassium cyanide, from 0.001 to o. or molecular in strength, the fibrillae of the claw nerve of the spider crab after a time become irregular in outline and more or less varicose, so that a strand appears more or less granular instead of fibrillar, like a fresh nerve. With this criterion he has discovered a gradient similar to our metabolic gradient, which appears in the structural death changes. Using a I per cent ethyl ether solution in sea-water, or even a somewhat lower concentration, he found that the change from fibrillar to granular appearance begins at the ends of the nerve very soon after it is biought into 
the' solution, but that it does not progress equally from the two ends. A distinct gradient in this change can be seen extending peripherally for a few millimeters from the central end and a shorter distance centrally from the peripheral end. This first change remains limited to the terminal regions of the nerve and is undoubtedly, as he interprets it, a temporary metabolic gradient from the ends inward, due to stimulation and injury resulting from severing the nerve at these points. Later, however, the fundamental metabolic gradient in the nerve appears, in that the change begins to progress along the nerve from the central toward the peripheral end; but the change at the peripheral end progresses but slowly, or not at all, in the central direction. From this time on a distinct gradient in the change is visible until it has progressed along the whole length of the nerve. Except in the terminal region adjoining the peripheral cut end the death change always progresses in the peripheral direction. The peripheral third of the length may be entirely unchanged at a time when the central third or more has completely lost the fibrillar appearance. Thus the fundamental difference of the two ends is made apparent. Child has further shown that if the nerve is crushed or injured at any point similar gradients appear on both sides of the injury, but do not extend to a great distance before the general change reaches this region in its progress peripherally.

Since it has been demonstrated repeatedly that susceptibility of other tissues and organisms to reagents like ether and cyanide is an expression of the rate of metabolism in the tissue, these results of Child not only confirm our demonstration that there is a clear 
centro-peripheral respiratory gradient in the claw nerve of the spider crab, but also indicate very clearly that this gradient exists in a normal nerve independent of injury.

Afferent fibers. -The optic nerve of Limulus was tried next. It is a non-medullated, long, apparently uniform, nerve. It can be isolated in a length of four or five inches without cutting it at either end, though the task is rather laborious. It is important that the peripheral end should be left intact with the eyes. This is accomplished by cutting the shell about two inches square around the eye. By gently lifting the eye with the nerve, we can easily trace the nerve centrally up to the brain without any injury.

TABLE XI

Carbon Dioxide Production from Different Portions of Optic Nerve of King Crab, Limulus polyphemus, FEMALE

\begin{tabular}{|c|c|c|}
\hline Portion of Nerve & $\begin{array}{l}\text { Temperature } \\
\text { Degrees C. }\end{array}$ & $\begin{array}{l}\text { Amount of } \mathrm{CO}_{2} \\
\text { Given Off by ro mg. } \\
\text { of the Nerve in } \\
\text { to Minutes }\end{array}$ \\
\hline $\begin{array}{l}\text { Whole............... } \\
\text { Proximal ............ } \\
\text { Distal............. }\end{array}$ & $\begin{array}{l}17.8 \\
22.5 \\
22\end{array}$ & $\begin{array}{l}2.6 \times 10^{-7} \mathrm{~g} . \\
3.0 \times 10^{-7} \mathrm{~g} . \\
5.0 \times 10^{-7} \mathrm{~g} .\end{array}$ \\
\hline
\end{tabular}

When such a long stretch of the nerve is cut at both ends simultaneously and is then divided at the middle so as to furnish two parts of approximately the same weight, and the rate of carbon dioxide production of these two parts is compared, we find that the centroperipheral gradient discovered in the case of the claw nerve is exactly reversed. In the optic nerve of Limulus the proximal portion (nearer to the brain ring) rives 
much less carbon dioxide than the distal portion (nearer to the retina), where the impulses normally originate.

Table XI shows the quantitative results.

Sensory dendrites.-These results were at first surprising; but they became exceedingly interesting when we took into consideration the functional or developmental difference between the two nerves. The claw nerve of the spider crab is believed to be composed mainly of efferent fibers, while the optic nerve of Limulus is an almost purely afferent nerve. The direction of the normal nerve impulse in one of these nerves is, therefore, exactly opposite to its direction in the other. Developmentally speaking, however, the distal portion of the optic nerve corresponds to the proximal portion of the claw nerve in that these portions are in each case nearer the nerve cells from which the fibers come. Thus our results with the two opposing gradients may be subject to two alternative interpretations. Either the metabolic gradient may correspond to the developmental gradient, i.e., all the portion nearer to the mother-cells may have a higher rate of metabolism, or it may correspond to the functional gradient, i.e., the nearer the portion is to the stimulus the higher is the carbon dioxide production.

This question will be automatically solved if we study the metabolic gradient of a fiber whose functional direction is opposite to its developmental direction; e.g., an afferent nerve fiber lying peripherally to its nerve cells - i.e., a sensory dendrite-should be studied. Professor C. Judson Herrick kindly suggested that we use a lateral line nerve, or an accessory lateral line nerve, of a fish. In the carp and the catfish both of 
these nerves are present in the body region, and they are wholly sensory without admixture of motor fibers. The fibers of both nerves are dendrites of ganglion cells which lie in the head.

When these fibers were subjected to our tests it was found that in every case the proximal portion of the fresh nerve gave much less carbon dioxide than the distal portion, indicating that the gradient is correlated with function and not with development. And in this case it should be noted that, although the fibers of both nerves are dendrites of their respective neurons and-conduct afferent impulses, the function of the two nerves is widely different, the lateral line nerve (ramus lateralis vagi) being excited by water vibration and the accessory lateral line nerve (ramus lateralis accessorius) being exclusively gustatory in function. The quantitative estimates on these nerves given in Table XII will illustrate the presence of this marked gradient of carbon dioxide of the sensory dendrites.

TABLE XII

Carbon Dioxide Production from Different Portions of Lateral Line Nerve (Ramus Lateralis

VAGI) OF CARP

\begin{tabular}{c|c|c}
\hline $\begin{array}{c}\text { Portions of } \\
\text { Nerve }\end{array}$ & $\begin{array}{c}\text { Temperature } \\
\text { Degrees C. }\end{array}$ & $\begin{array}{c}\text { Amount of } \mathrm{CO}_{2} \\
\text { Given Off by } \mathrm{IO}_{\mathrm{mg} .} \\
\text { of the Nerve in } \\
\text { Io Minutes }\end{array}$ \\
\hline $\begin{array}{c}\text { Proximal...... } \\
\text { Distal......... }\end{array}$ & 24 \\
\hline
\end{tabular}

That the metabolic gradient is directly associated with the functional direction is strikingly shown also by further studies with different fibers in which quantitative determinations were not made, but in which the output 
of carbon dioxide of two equal weights of proximal and distal portions of the same nerve were compared in the biometer under identical conditions. The portion of the nerve which gave off sufficient carbon dioxide to produce the precipitate of barium carbonate in the shortest time and the greatest abundance evidently produced the most carbon dioxide.

\section{TABLE XIII}

Comparative Studies on Rate of Carbon Dioxide Production from Two Portions of Various Nerves

\begin{tabular}{|c|c|c|c|c|c|c|}
\hline \multirow{2}{*}{ Date } & \multirow{2}{*}{$\begin{array}{l}\text { TEMPERA- } \\
\text { TURE OF } \\
\text { ROOM } \\
\text { DEGREES } \\
\text { C. }\end{array}$} & \multicolumn{4}{|c|}{ Nerve } & \multirow{2}{*}{$\begin{array}{c}\text { AMOUNTS } \\
\text { OF } \mathrm{CO}_{2} \\
\text { COMPARED }\end{array}$} \\
\hline & & Name of & Kind of & Portion of & Weight of & \\
\hline $\begin{array}{l}\text { Aug. } 31 \ldots \\
\text { Sept. } 15 \ldots \\
\text { Feb. } 15 \ldots \\
\text { Dec. } 20 \ldots \\
\text { Dec. } 13 \ldots \\
\text { Nov. } 23 \ldots\end{array}$ & $\begin{array}{l}23.2 \\
18 \\
22 \\
20 \\
17 \\
25.5\end{array}$ & $\begin{array}{l}\text { Optic nerve of } \\
\text { Limulus } \\
\text { Optic nerve of } \\
\text { skate } \\
\text { R. lat. vagi of } \\
\text { carp } \\
\text { R. lat. vagi of } \\
\text { catfish } \\
\text { R. lat. acc. of } \\
\text { catfish } \\
\text { Posterior root } \\
\text { of dog }\end{array}$ & $\begin{array}{c}\text { Afferent } \\
\text { mainly } \\
\alpha \\
\alpha \\
\alpha \\
\alpha \\
\alpha\end{array}$ & $\left\{\begin{array}{l}\text { Proximal } \\
\text { Distal } \\
\text { Proximal } \\
\text { Distal } \\
\text { Proximal } \\
\text { Distal } \\
\text { Proximal } \\
\text { Distal } \\
\text { Proximal } \\
\text { Distal } \\
\text { Proximal } \\
\text { Distal }\end{array}\right.$ & $\begin{array}{l}\text { I7 mg. } \\
\text { I7 } \\
23 \\
23 \\
4.4 \\
4 \\
2 \\
1.8 \\
1.4 \\
1.4 \\
6.5 \\
6\end{array}$ & $\begin{array}{l}\text { Less } \\
\text { More } \\
\text { Less } \\
\text { More } \\
\text { Less } \\
\text { More } \\
\text { Less } \\
\text { More } \\
\text { Less } \\
\text { More } \\
\text { Less } \\
\text { More }\end{array}$ \\
\hline $\begin{array}{l}\text { Aug. } 30 . . \\
\text { Feb. } 26 \ldots \\
\text { Feb. } 21 \ldots \\
\text { Sept. } 15 \ldots \\
\text { Nov. } 26 \ldots\end{array}$ & $\begin{array}{l}21.8 \\
\text { I9 } \\
23 \\
17.8 \\
26\end{array}$ & $\begin{array}{l}\text { Claw nerve of } \\
\text { spider crab } \\
\text { Hypoglossal } \\
\text { nerve of dog } \\
\text { Same nerve of } \\
\text { carp } \\
\text { Oculomotor } \\
\text { nerve of skate } \\
\text { Anterior root } \\
\text { of dog }\end{array}$ & $\begin{array}{c}\text { Efferent } \\
\text { mainly } \\
\propto \\
\propto \\
\propto \\
\propto\end{array}$ & $\left\{\begin{array}{l}\text { Proximal } \\
\text { Distal } \\
\text { Proximal } \\
\text { Distal } \\
\text { Proximal } \\
\text { Distal } \\
\text { Proximal } \\
\text { Distal } \\
\text { Proximal } \\
\text { Distal }\end{array}\right.$ & $\left\{\begin{array}{l}32 \\
44 \\
\text { Equal } \\
\text { weights } \\
\text { Equal } \\
\text { weights } \\
\text { II } \\
\text { II } \\
\text { I. } 6 \\
\text { I. } 8\end{array}\right.$ & $\begin{array}{l}\text { More } \\
\text { Less } \\
\text { More } \\
\text { Less } \\
\text { More } \\
\text { Less } \\
\text { More } \\
\text { Less } \\
\text { More } \\
\text { Less }\end{array}$ \\
\hline
\end{tabular}

While we have not by any means exhausted the various kinds of nerve fibers available for the study of this gradient, the results obtained in those nerves already examined have been very uniform and the nerves themselves have had varied functions and have come from several different classes of animals, namely, 
fishes, mammals, crabs, and arachnids. We feel certain, therefore, that the existence of a metabolic gradient in nerve fibers correlated with the functional activity, and related to the direction the nerve impulse takes, must be a very general phenomenon. From these facts we come to the very simple conclusion that is summarized in the following statement: The normal nerve impulse passes from a point of higher toward a point of lower carbon dioxide production - from the more irritable to the less irritable parts. There is also a decrement in the nerve impulse. It cannot proceed indefinitely along a nerve; it will ultimately die out.

Velocity of the nerve impulse and its relation to respiration.-If the nerve impulse cannot pass through the fiber without consuming substance, it is reasonable to expect that there may be some relation between the rate of production of carbon dioxide in the resting nerve and the velocity of the nerve impulse. The reason for such a supposition is clear. It has already been indicated that the more irritable a nerve is the more carbon dioxide does it produce in the resting state. Hence, the more it respires, the more irritable it is, the faster should it conduct the impulse. This is actually found, within limits, to be the case. If one compares corresponding nerves of different animals, or different nerves of the same animal, it is found, other things being equal, that there is a relation between the speed of contraction of the muscles supplied by the nerve and the velocity with which the nerve supplying the muscle conducts the impulse. Obviously it would be foolish to have a very rapidly contracting muscle, or limb, supplied with a nerve which conducted the impulse to the muscle at a 
very slow rate. And, being foolish, this does not happen. We can use the speed of contraction, therefore, as a rough index of the relative velocities of the nerve impulses in nerves supplying the muscles. In this way the rates of the nerve impulse of the ambulacral nerves of the king crab, the spider crab, and the lobster are in the ratio of $1: 2: 4$. This ratio, as far as the king crab and the spider crab are concerned, is very nearly the same as that found for the carbon dioxide output of these nerves, as may be seen in Table IV (p. 32). Low respiration, low irritability, and low speed of conduction appear to go together.

We can also test the rate of metabolism in these nerves indirectly by Child's method, and this gives us just the same result. This method consists in determining the speed with which the excitability of the nerves is abolished when they are treated with the same concentration of a narcotic. The greater the rate of metabolism the more susceptible is the tissue to narcotics. We found in the case of these three nerves that the excitability of the lobster nerve is most quickly abolished, then that of the spider crab, and finally that of the king crab. This is the same order in which the nerves conduct the impulse, the lobster conducting fastest. This is therefore additional proof of the fact that the speed of the impulse and the degree of metabolism in the resting nerve are correlated, at least in these nerves. It is remarkable to note that the carbon dioxide output of the nerves of Limulus, the king crab, is very low in comparison with that of other animals. This may be correlated with the very sluggish behavior of this animal and its power of living for a long time without food and with very little air. 
While there seems, then, to exist a very close correlation between the rate of respiration of resting nerves and the velocity with which they conduct a nerve impulse, the data for the establishment of this generalization must necessarily be cumulative, and we are not yet able to state positively that all nerves which give off much carbon dioxide in the resting state will be found to conduct the impulse more rapidly than those which give off less. There are, however, several conditions which influence the rate of the nerve impulse, and we have investigated the effect of these conditions on the production of carbon dioxide. Two of these conditions are: changes in the salts in the nerves, and temperature.

a) Changes in salts: Mayer found that the rate of nervous conduction in the sub-umbrella regions of the subtropical jelly fish, Medusa cassiopea, increases about 5 per cent in sea-water diluted with distilled water in the proportion of 9: $\mathrm{I}$, while it decreases 50 per cent in seawater diluted to 50 per cent with fresh water. By substituting $0.9 \mathrm{M}$ dextrose for the distilled water he demonstrated that the change in rate of the impulse in diluted sea-water was not due to the decrease of osmotic pressure, but was due to the change in concentration of the salt. If under those conditions which decrease the rate of the conduction a measurement is made of the amount of carbon dioxide produced from the thin layer of the regenerating ectoderm tissue, it is found that a change in the, rate of carbon dioxide production goes parallel with the decrease in the rate of conduction. As a result of using the regenerating tissue just mentioned, the nervous tissue regenerates before the muscular, so 
that we can in this way eliminate the effect of the salt on the muscles.

b) Temperature: It is well known that a change in temperature affects the speed of the nerve impulse; an increase of $10^{\circ} \mathrm{C}$. increases the velocity of the impulse by four-fifths, or even more. This is very significant in view of the fact that for most physical processes the same increase in temperature increases the velocity of the process by at most one-fifth. Chemical processes are accelerated about roo per cent. While the magnitude and variation of the temperature coefficient of velocity of a physiological process do not necessarily tell us what kind of reaction is involved in the process, they nevertheless indicate in this instance very clearly that conduction by a nerve is not a purely physical process, as some have imagined it. It is very important, evidently, that we should compare the effect of temperature on the carbon dioxide output with its effect on speed of conduction.

We have made studies of the metabolic rate of the nerve of the king crab at different temperatures, such as naturally occur at Woods Hole and at Dry Tortugas, and we have discovered that the temperature coefficient of the production of carbon dioxide by the resting nerve is just about the same as the temperature coefficient of the speed of conduction. A similar result was obtained with a sciatic nerve of a frog under experimental changes of temperature. We thus have this additional point of parallelism between the rate of conduction and the production of carbon dioxide in the resting nerve.

It is extremely interesting and significant that the fundamental condition for the conduction of a nerve 
impulse is determined by the chemical change going on in the nerve at the time of stimulation, and that it is the resting respiration, or metabolism, which seems to determine how fast the nerve impulse should travel along the fiber. It is exactly as if, during rest, the nerve substance was sustained in a very unstable state by the expenditure of energy by processes which set free the carbon dioxide. It is as if the irritable or unstable condition was like a stone rolled partly up a hill and kept there at the cost of considerable panting by the toiling demon of life. When the nerve impulse comes along, the stone escapes from his grasp and rolls downhill. During the period of rest or recovery which follows, this tiny, toiling Sisyphus, with infinite labor and panting, pushes the stone uphill. The higher he gets it the more he gasps, the more unstable it becomes the more easily it escapes his grasp, the more rapidly does it crash down, and the more irritable is the nerve the more rapidly does the impulse travel.

Conclusion.-Basing our conclusions on the foregoing experimental facts, we may express the relation between excitation, conduction, and respiration in nerves as follows:

The maintenance of chemical activity, or metabolism, is responsible for that unstable condition in the nerve, whatever its nature, which we call the state of irritability or excitability. All irritable tissue must respire. The tissue cannot be made irritable and then kept so without effort. Chemical energy must constantly be expended to keep the tissue irritable. The amount of this expenditure of energy is not the same at all points along the fiber, but it diminishes in one direction or the 
other, generally toward the central nervous system in sensory nerves and toward the periphery in motor nerves. The nerve impulse/generally travels in the direction of this gradient. When we stimulate a nerve at any point, the stimulation consists in the local increase of metabolic activity at the point of irritation. The irritability is raised and the carbon dioxide output is increased at that point above the production on either side of it. This causes a local metabolic. gradient in the nerve in both directions from the point of excitation, but the difference between this point and its surroundings will be greater on one side than on the other, owing to the gradient in the nerve just mentioned. If this state of excitation is sufficiently great, it upsets the equilibrium and the impulse will be propagated in each direction from the point of excitation. The possibility exists that it ought to travel more easily in the direction which the nerve impulse normally takes, and it ought to be possible, with a proper amount of stimulus, to start a propagation in only one direction from the point of stimulus, but we have not yet tested this possibility experimentally. The excitation always travels from the point where the excitation is greatest to that where it is less. The repair process, or the anabolic process, is also propagated.

The conditions which affect the rate of nervous metabolism not only alter the state of excitability of the nerve, but also change the speed of the conduction of the state of that excitation. Although we have no evidence to show that the chemical change itself constitutes the nerve impulse, the conclusion is almost inevitable that the nerve impulse is brought about by, or is itself 
nothing else than, a propagation of chemical changes, the propagation in wave form being due to the restoration of an unstable equilibrium disturbed by the increase of metabolism at the point of stimulus. This propagation is always toward the point where there is less chemical activity, as measured by the carbon dioxide output. 


\section{CHAPTER V}

\section{CHEMICAL SIGNS OF LIFE}

We have endeavored to show that the living nerve, as long as it is irritable, is chemically active and that when it functions this metabolism is accelerated. As the irritability of the nerve varies, there are simultaneous changes in chemical activity. What characterizes the living state is respiration and its increase on stimulation.

We have come now to our main inquiry, namely, whether or not all living matter undergoes respiration as long as it is alive, and whether stimulation always increases its respiration. In addition, we have to ask whether, if this is true, it can be used as a sign of life in all living matter.

Seeds. - It has hitherto been maintained that since dry seeds do not respire but are irritable, irritability is independent of respiration. The work of Horace Brown, Thistleton Dyer, and others indicates that dry seed can be kept alive at very low temperatures in conditions where no ordinary gaseous exchange is possible. It is argued, therefore, that life is possible without any metabolic activity. Dry seeds, kept for long periods in a closed vessel, have not been found to give any evidence of this fundamental chemical change occurring in living matter, namely, the production of carbon dioxide. Such seeds, it is well known, are not really dead, for under proper conditions they germinate. They appear to live without respiration, but this is but 
an appearance. The seeds really respire. Waller considered that our present chemical technique is not refined enough to reveal to us the smallest and most infinitesimal chemical changes which may be going on in the apparently dry and perfectly dormant seed. He based his hypothesis on two considerations: First, was the fact that the seeds wear out, as shown by their losing their power of germination and growth in proportion to the length of time they have been kept. The deterioration is more or less rapid, according to the nature of the seed and the character of the protective coats, but in every instance there is deterioration sooner or later. $\mathrm{He}$ attributes this gradual deterioration to chemical activity in the seed.

In the second place, there was the fact, which he showed by his electrical method, that a living seed not only differs from the dead one in respect to its electrical response, but that the amount of its response varies according to its age. Thus, if he took a living seed, a dead seed killed by heat, and a very old Egyptian seed from about the Twelfth Dynasty (about 4,400 years old) and determined their electrical response, he found a very interesting result. The first, or living, seed gave a large electromotive force, while the others, the old as well as the dead, gave none. If he took a group of seeds from crops of different years, he found that there was also a gradual decline in the electrical response as the seed became old. He considered this electrical sign as the expression of the chemical changes which cannot otherwise be determined, and such a sign of death, according to him, is manifested long before microscopic or chemical changes can be detected. 
He found that this electrical change - the blaze current, as he called it - which appeared when the living seed was stimulated by a strong induction current was not confined to seeds, but occurred also in other varieties of living matter, such as the eyeball, skin, leaves, petals, and many other tissues of plants and of animals. This momentary electrical change produced thus only by living matter is accordingly a reliable sign of life, since it does not occur in dead matter.

When we discovered that even a resting nerve gave off carbon dioxide if we used a sensitive method, we at once proceeded with some curiosity to determine whether or not ordinary seed is chemically inactive. We had in mind thus to test Waller's conclusion that the electrical sign in the seed is really the sign of chemical changes which, however, were not large enough to be detected by ordinary chemical methods.

Resting metabolism in seeds. - If a few kernels of wheat are placed in one chamber of the biometer, there is no difficulty in showing that seeds give off carbon dioxide, since a drop of barium hydroxide in the chamber containing the seeds becomes covered after a time with a precipitate of barium carbonate. It is true that the amount of carbon dioxide given off is exceedingly small, being many times less than that of the resting nerve, but that this carbon dioxide is produced by a vital metabolism is shown by the fact that living seeds give far larger amounts of the gas than dead ones. A seed respires, therefore, as long as it is alive; and we can measure the amount of respiration. Of course the mere production of this gas from a seed does not mean necessarily that the seed is alive, for the reason 
(already discussed on p. 34) that carbon dioxide is produced by many purely chemical processes. So we proceed to inquire whether the output is increased on stimulation.

Increased metabolism in seeds.-The most interesting thing ascertained was that the living seed, like any other living tissue, can be made to give off more carbon dioxide on stimulation. It responds to an injury and is, therefore, irritable. It has already been stated that a nerve injured by crushing gives off more carbon dioxide than a resting nerve, just as if it had been stimulated by an electrical shock. Since there was no way of telling what strength of electrical stimulation was required in order to arouse the seed, we stimulated it by an injury, namely, by crushing it. The seed thus stimulated showed a marked acceleration of its respiration. If two apparently living kernels of wheat are taken and one of them is crushed and their carbon dioxide production is compared in the biometer, the crushed one always produces more carbon dioxide than the normal one. That this is a vital response is shown by the fact that only living seeds behave in this way. If one takes two kernels of any similar seed, which have been killed in an electrical oven heated to $60^{\circ} \mathrm{C}$., and one of them is crushed, there is no difference in the carbon dioxide output of the two seeds. The difference in amount of carbon dioxide produced by crushing cannot be observed in dead seeds or in anesthetized seeds. In this respect a seed and a nerve are alike; the chemical signs of irritability are identical. Both, as long as they are alive, respond to a mechanical stimulation by producing more carbon dioxide. 
Is an injury a stimulation?-Are we justified in regarding the increase of carbon dioxide following injury by crushing as in the same category as the increase of carbon dioxide production by ordinary stimulation? That this conclusion is justified is shown by the fact that such an acceleration of carbon dioxide production will not take place in inexcitable tissue. Neither killed nor narcotized tissue can be made to give off more carbon dioxide when crushed. Response to an injury is given by living irritable tissue only. It is impossible to injure the dead tissue.

Other tissues.-When we discovered that the irritability of a kernel of wheat and that of the nerve fiber are identical, so far as their metabolic expressions are concerned-i.e., no irritability without resting metabolism, increased metabolism on stimulation, and changes in metabolic condition, according to the state of excitability - we thought it might be possible that this similarity between the nerve and wheat is special, and that other plant tissues may not behave at all in the same way as do seeds. Similar experiments were consequently tried on several other seeds, including wild oats, Lincoln oats, Swedish select oats, rice, corn, mustard, and various others, with the result that, although the amounts of carbon dioxide given off varied considerably, all living seeds were found to be metabolically active. All of them responded to an injury, giving off more carbon dioxide on crushing. And in no case did we succeed in producing more carbon dioxide on crushing killed seeds, or seeds which had lost germinating power. Thus we made certain that under the experimental conditions in the biometer it is possible to detect the fundamental 
difference between dead and living seeds, namely, the matter of metabolic acceleration on injury. The increased carbon dioxide production on stimulation is the chemical sign of life of seeds and tissues generally, as well as of nerves.

Once this interesting similarity between seeds and nerves was well established we made further investigations on other plant tissues, in which conditions were somewhat different. It was possible that the removal of the heavy coat from seeds in crushing them might have something to do with the increased metabolic activity, and that this activity, therefore, might not be manifested by all tissues. In fact, Crocker has shown that the removal of the coat is one of the factors which initiates germination in dormant seeds. When we tried different leaves, however, they all behaved in the same manner as did seeds and nerves. The leaves selected for test were necessarily small, with the object in view of being able to place the whole leaves in the chamber with the least injury. They included such as Japanese ivy, common grass, Australian pine, and various others. We may add here that the increase of carbon dioxide output as a result of some other forms of injury in leaves has been recorded by several investigators.

Some objection might be made against our experiments, however, on the ground that the injury to the stomata may be responsible for the output of more gas in the case of leaves. That this is not the sole cause of the escape of the gas is shown by our experiments on a plant tissue without stomata. Red algae were tested at the suggestion of Professor Osterhout and gave similar responses. 
- Thus we extended our experiments to the best-known tissues in the plant and animal kingdoms, and found no exception to the general rule cited. These results surely justify the generalization that all living tissues differ from all dead tissues in that they respond to injury, producing more carbon dioxide than the normal tissues; and that by measuring this output of the gas in comparison with the uninjured we can detect the vitality of the tissue.

Chemical sign of life.-We have now come to a conclusion on all the facts that we have presented so far. Of all the signs of living processes irritability is one of the most universal. This phenomenon of irritability is expressed in the power of feeling the external world. It is the inherent power of the living to react against a stimulation. The necessary condition for this irritability of tissues is metabolic activity. Although this chemical condition is necessary for all tissue in order that it shall be irritable, yet it is not a sufficient criterion for the detection of vitality in it. We must inaugurate a further test of whether or not it reacts chemically to a stimulation. In order to test this power, we injure the tissue and watch the response. If the tissue is alive, mechanical crushing will produce a metabolic response; if it is not alive, there is no response.

The detail of testing the vitality of a tissue is as follows:

In order to test that of a seed, take two or more kernels of the seed in question having about equal weights. One is placed in the right chamber of the biometer, and the other is crushed, or is cut to pieces, and placed in the left. The apparatus is filled with 
air free from carbon dioxide, and a drop of barium hydroxide is introduced at the top of the tube in each chamber. If the crushed seed gives off more carbon dioxide than the uncrushed, as evidenced by a larger deposit of the carbonate on the top of the drop in the chamber containing the crushed seed, the seed is alive. If the seeds are alive, such a distinction in the carbon dioxide output will be noticeable in a few minutes in some cases, or in an hour or more in other cases, all depending on the size, the number, and the kind of seed we are testing. With several seeds, as with the fresh nerve of a frog, we can detect vitality in this way in a few minutes. 


\section{CHAPTER VI}

\section{CONCLUSIONS}

Summary.-While we cannot define life in a physical sense, for the reason that we have no measure of the psychic phenomena shown by living things, and these psychic phenomena are, after all, the most important of the characteristics of life, there are nevertheless certain phenomena associated always with the living processes which are so characteristic that for the majority of organisms with which we are familiar we have no difficulty in determining whether they are living or dead. Irritability is the universal sign of life, and by it living matter adjusts itself to its environment. The sign of this irritability is the functional power of the tissues. Thus by measuring the functional power we can speak of measuring the amount of irritability. The changes of a physical or chemical kind which accompany this functioning are very important for an understanding of the living process, for when we know them completely we shall probably understand the nature of irritability itself.

In chapter ii we showed how it happened that, because of the apparent exception in the case of nerves, it has been generally concluded that chemical changes could not be considered to be essential to all living processes. Some of these changes, it appeared, must be due solely to physical processes, and for this reason irritability had come to be regarded as a purely physical phenomenon. Various hypotheses had been made to explain how 
this could be; the change in state, which was the essence of irritability, was pictured as a change in the state of the colloids or the structure of the protoplasm, or, more recently, in the state of its permeability. But how on this basis irritability was to be understood was by no means clear. On examining the irritability of nervesthe apparent exception which had led to the conclusion that irritability had a physical and not a chemical basis-we found that this apparent exception was really due to the fact that our methods had not hitherto been sufficiently delicate to detect the chemical changes which accompanied the process. By devising a new method for the study of carbon dioxide - one of the terminal products of metabolism everywhere - we found that living nerve fibers in reality were undergoing chemical change at quite a remarkable rate and were producing carbon dioxide faster than any other tissue of the body, if equal weights were compared. And we found, further, that reagents or physical methods which change the state of excitability of the nerve changed also the rate at which it was producing carbon dioxide, so that the gas production was evidently correlated with its vitality and not with adventitious processes.

In chapter iii we found that although the chemical activity is a necessary condition for all living nerves, yet by itself it is not a demonstrative sign of life; i.e., it is not a sufficient criterion of living. An additional criterion is needed in order to be sure that any tissue is living. In the case of the nerve, we demonstrated that this additional sign was also present. This sign is the fact that all living matter, including the nerve, responds to a stimulus by the production of more carbon dioxide. 
There is no functional activity without the simultaneous consumption of the nervous material. In the nerve, then, irritability can be measured by the increased metabolism which occurs on stimulation. If the irritability is high, the carbon dioxide increment is also large, and vice versa. The response to stimulation is the sign of irritability. We measure this response by measuring the simultaneous output of carbon dioxide, which must be the sign of that metabolic activity in virtue of which the function is performed.

In chapter iv we demonstrated further the importance of the metabolic changes for the functional activities of the nerve, and we hinted that the real mechanism which makes the nerve able to perform its function must be the chemical changes which go on in the resting condition of the nerve, and which must determine not only the degree of excitability of the nerve the direction of the nerve impulse- but also how fast this transmission travels. (We found, for example, that the part of the nerve from which the nerve impulse normally comes always produces more carbon dioxide than the part toward which it is going. It is well known that nerves are more excitable in the parts which normally originate the impulse and that the excitability decreases down the fiber. Thus there is a parallelism between the degree of excitability and the amount of carbon dioxide produced in different parts of the same fiber, a parallelism the profound importance of which is not easily overlooked. For nerves are thus shown to have in them a metabolic gradient. They are, as it were, polarized metabolically, and thus we have for the first time the explanation of the electrical current which has been 
found to run in nerves between the two cut ends of the nerve, up or down it, as the case may be. Evidently electrical current is generated in a nerve between two parts which are unequally irritable, or unequally undergoing chemical change. The part of the nerve which is respiring most is in a different electrical state from that which is respiring less, and thus we see the very clear and definite relationship between the chemical and the electrical changes which have been particularly dwelt upon by Waller. This is one of the most important and fundamental discoveries which we have noted, for it means that there must be a decrement in the rate of the impulse as it flows down the fiber, and that the distance to which a nerve impulse can be transmitted is not indefinite, but that that impulse diminishes as it proceeds, and will ultimately die out. In the medullated nerves, to be sure, this decrement is not large, for it is very necessary that it should be as small as possible in the more highly developed nerves; but it is to be found everywhere. And in simple undifferentiated protoplasm of plants and animals it is easily shown to exist. The more rapidly nerves respire the faster do they appear to carry the impulse; irritability and the rate of production of carbon dioxide in resting nerves thus appear to be correlated. The more respiration the more life! If we abolish respiration temporarily, or reduce it, we find that irritability has been reduced in somewhat the same proportion. Anesthetized nerves of all kinds show a reduced output of carbon dioxide, and they recover their irritability when they breathe again. Anesthetics do not, therefore, affect the physical state of the protoplasm only, as they have been supposed 
to do by many, but their action is shown by the change in respiration in a manner more perfect than in any other way except by the electrical response. Small amounts of anesthetics at first increase irritability; and at first they increase the rate of respiration and coincidently they increase the electrical response. Irritability, respiration, and electrical response parallel each other so completely that they are evidently different aspects of the same thing.

In chapter $\mathrm{v}$ what we had established as being true in the case of nerves was shown to be true in the case of all forms of living matter. Taking the least promising kind of living matter, that of a dry seed, we demonstrated that it, too, breathed as long as it lived, that it produced carbon dioxide, and increased its output of carbon dioxide when it was mechanically stimulated by being crushed. Seeds, too, it was shown, could be anesthetized, in which condition they give off less carbon dioxide and no longer respond by an outburst of carbon dioxide when injured. Extending our observations, we found that all kinds of plant and animal tissues, without any exception, respond in a manner similar to that of the nerve fiber. In all cases stimulation causes an increase in carbon dioxide. We could never find any response unaccompanied by an outburst in carbon dioxide. Hence the best way to discover whether a tissue is living is to crush it and see whether it reacts to the injury by producing more carbon dioxide. It is not necessary to put seeds in the ground to determine whether they live; by crushing some of them we may discover whether they are alive or not. Thus the chemical test of life in the tissues, a test which parallels 
at every point Waller's electrical test, is shown to be whether or not the tissue respiration can be accelerated by an injury. And we can measure this with our new apparatus, the biometer, which thus justifies its name, although its applicability is far greater than merely testing the degree of vitality of a tissue.

We have now to compare for a moment this criterion of life - the chemical-with other criteria which have been proposed, and to see whether it lacks anything of the precision of these other methods, and whether life can be shown to exist by other methods where we cannot prove its existence by ours. There is one criterion other than the obvious one of growth which has been proposed to determine whether a seed or other living thing, or piece of a living thing, is alive or not. That is the criterion suggested by Waller. It is the electrical sign of life. Waller discovered a very remarkable electrical sign of life, which may be described as follows: Two electrodes are placed on opposite sides of a garden pea which is living, the electrodes being connected on the one hand with an induction coil and on the other with a sensitive galvanometer. A single induction shock is then sent through the pea. If the pea is alive, this shock is followed by a remarkable outburst of electromotive force in the pea. A current suddenly blazes out, as is shown by the deflection of the galvanometer. It is as if the pea jumped when stimulated. This current sometimes travels in the same direction as the induction shock, and sometimes in the opposite direction. It is of momentary duration. Waller calls it the blaze current. As long as the seed lives, you get it; when the seed dies, you do not get it. The dead or anesthetized seed does not 
blaze up. It no longer reacts to a stimulus. Nearly all kinds of tissues show these blaze currents as long as they are alive, and the outburst is not only a sign of life, but an index of the amount of life. Life and electricity are inextricably bound up together. In the sea algae alone Waller failed to find this blaze current, but he does not doubt that it exists there. One does not obtain it for the reason, probably, that the salts of the sea-water close the current through the tissue rather than through the galvanometer. Perhaps a low-resistance galvanometer would detect it here too. This sign of life of Waller is in many ways the most convenient that we have, if only we have the apparatus for the detection of these currents ready at hand and set up for use.

But up to this point we were still in the dark regarding the cause of this electrical response. We could not know whether it was due to a physical or a chemical change in the tissues. It might be due to some change of permeability of the tissues, or it might be due to a chemical change. Waller believed it to be caused by the latter, and his conclusion was undoubtedly correct.

Waller also observed that following this electrical display there was a sudden lowering in the electrical resistance of the pea or other tissue. This might also be called a sign of life, but it is not so clear and striking as the blaze current. Evidently this is by no means so reliable a sign of life as the other. The decreased resistance might be due to a physical change of state of the protoplasm or of the membranes, so that the salt solution became more continuous; or it might be due to the stimulation increasing in some way the ions in the protoplasm. It is impossible to say which. 
The chemical sign of life which we now propose for acceptance is in many ways more fundamental than the electrical. It is probable, as Waller suggested, that the chemical changes underlie and produce the electrical, and they produce the functional changes, such as the movements which follow the excitation. In the chemical changes, then, we seem to be dealing with something more fundamental than when dealing with the electrical, although, if we admit that all processes of oxidation are in reality electrical, this distinction cannot be sustained. Wherever Waller has been able to show the electrical sign of life, we can show the chemical sign, and we can show life at some points where he could not, as in the case of the sea algae. These, under our method, respond in the same manner as do all other forms of living matter. Moreover, we can use this method where it is impossible to use the electrical; for example, in very minute forms of living things, like eggs of small size, bacteria, or infusoria. Our method can make it clear that they are alive and breathing and responding to changes in their environment like every other living thing. It appears, then, that this sign of life has also certain virtues of its own, although it is not so striking and elegant as the method of Waller. It is also not so easy, perhaps, for the ordinary man to set up and work this apparatus as a galvanometer. But what it lacks in ease it makes up in precision, in the quantitative nature of its results, and, above all, in its fundamental character. By it we get as near as we have yet got to life itself.

In still another way the results which are recorded here are of a most fundamental character, for one of the 
most interesting problems of general physiology has been to determine what is the nature of the irritable response which living matter shows. It is this, the problem of problems, which we wish to have solved. Is that process physical or chemical? Is it simply an alteration of permeability of membranes, as some have supposed, or is it in reality in the nature of an explosion? Is the living thing essentially a bag of jelly with a wonderful membrane about it, that membrane being so wonderful that all the phenomena of life are to be ascribed to its changes in state? For this is the view which some maintain. They lead us to the holy of holies of cells and tell us to behold a membrane! Is life nothing more than a membrane? What kind of a subterfuge is this which we encounter? All the riddles of life are but the peculiar properties of a membrane! Upon this membrane, as upon a magic carpet of Arabia, we are invited to mount and travel over that unexplored country whose mountain peaks shine in the distance. Are we, then, beings of but two dimensions, nothing but membranes, of which the magic proportions mock us derisively, since we can never hope to seize that which has but two dimensions? That such a view resembles the membrane it has conjured up, in that it is surface without depth, is self-evident.

In no such simple and naïve a manner can the unknowns in the equation of life be determined. For we have found that everywhere, paralleling the irritability changes in a perfect degree, as far as we have been able to determine, go the chemical changes. Carbon dioxide, that very simple substance, the last term in the katabolism of living matter, rises and falls with irritability. 
Function without chemical change has been found nowhere. Respiration, or at least this phase of respiration, and irritability are in some way bound up together, and we many now very briefly ask ourselves how they may be related.

The connection between irritability and metabolism.What, then, is the connection between the irritable and the respiratory process? Could we answer this question we should have solved one of the most fundamental of all questions of science. However, we do not hope to be able to answer it at present. But let us at least see what facts we can discover. The first of these facts which strikes us is that living matter, even when it is not stimulated, continues to give off carbon dioxide and to respire. What is the significance of this fact? Why should this constant consumption of material go on in the absence of outside work to do? The main function of the resting metabolism is to keep the tissue irritable. As long as a tissue remains living and irritable we find it to be the seat of production of carbon dioxide. To be sure, it continues sometimes to give off carbon dioxide after death, but it never ceases to do so as long as it is alive. After death the rate, with possibly a temporary increase, soon diminishes. For nothing is more certain than that living matter burns up faster than the same matter after death. Death extinguishes the torch of life, although it may continue to smoulder for a time when the spirit of its flame is gone.

Does not this fact mean that life, or rather the living state, is a dynamic rather than a static phenomenon? We might conceive the living matter as a very highly explosive substance, very unstable and ready to go to 
pieces under a very slight stimulus. It has often thus been represented. But this, after all, is a static view. We have discovered this very fundamental fact, that the resting metabolism goes faster when the tissue is more abounding in life and is more irritable. It is the burning substance which is irritable, or, perhaps, the carbon dioxide thus formed conditions in some way the vital or irritable reaction. It requires the expenditure of energy to keep living matter in an irritable state. The reaction is dynamic and not static. Living matter has been conceived by many physiologists (of whom I may mention only one of the leading exponents, Verworn, for the various modifications of this view of individual authors are not fundamental modifications) as being composed of very complex unstable molecules, or aggregates of molecules which are very unstable. These are called biogens. Now this view is essentially static. There is no reason why a biogen should not be isolated if our methods were but fine enough. There is no reason why a collection of biogens should not exist without any metabolism; why, in other words, suspended animation should not be possible. But the facts which we have discovered of the parallelism of the production of carbon dioxide and irritability lend support, it would seem, to the dynamic, rather than to the static, view.

We can picture the process, perhaps, in the following crude and, of course, indefinite manner: The lifeprocess may be considered as a bicycle in motion. The living process is an unstable condition. It is like a chemical system, the system as a whole having a certain stability, but being at the same time the seat of intense chemical change. It is in an unstable equilibrium. The 
bicycle running rapidly will not fall down. The process of standing up may be compared to the vital process in the resting state. The degree of irritability will be measured by the force necessary to change the angle it makes with the ground. Perhaps the amount of life may be compared to the angle the bicycle makes with the ground. The metabolic activity is the force which moves the wheel. The locomotion of the wheel is the functional activity. There is, however, this differencethe faster the bicycle moves the more stable it is, whereas the faster the respiration drives the less stable is the irritability of the tissues. Our simile breaks down here. And indeed it is but a poor picture, of not much value. But whatever view we may take of the matter, we may at least be sure of this much: that chemical change is involved in irritability. The transmission of a nerve impulse involves material decomposition in the fiber. The impulse may be nothing else than the increased metabolism itself. The nerve impulse is a very real thing, and it has a material basis which we may hope to discover. So far we have found two facts about. it: first, it liberates carbon dioxide as it passes over the fiber; and, second, it depends on the nerve fiber having been previously oxidized or exposed to oxygen. Evidently combustion is involved in the process somewhere, but it appears at present more probable that it is involved in the creation of the irritable substance rather than in the very act of excitation itself. In other words, the oxidation is part of the process of repair or the recovery of the tissue - the process by which the state of irritability is maintained - and not the process of transmission of the impulse itself. 
'Concerning the nature of the material basis of the nerve impulse we can only say that it appears to involve that part of the chemical transformations in protoplasm which result in the production of carbon dioxide. Farther than this we cannot go at present. But it is certain that it has a chemical basis. Whether it has also a physical basis, such as a change in state of the colloidal substratum of the nerve, or not, we cannot yet say. Who shall write the chemical reaction of the future, embracing, not only the energy exchange, but the change in psychism as well?

Finally, we come to the quantity of life, the point from which we started. The measure of this is the amount of respiration, or the amount of electrical response shown on stimulation. The question of how much we are alive must be answered by the determination of the extent to which we are undergoing energy transformation. Death and peace, life and strugglethese are the pairs which go together. The most perfect young life is that which shows the highest metabolic rate. We have shown the general correlation between the carbon dioxide production and the nerve impulse in its speed of propagation and ease of origin. There must, then, be a close correspondence between the habit of the organism and the general metabolic rate. The simile of the torch is obvious. The faster it burns the more light and life it has. The most vigorous life is that with the keenest chemical change. And this is also, as has been shown in another volume in this series, the criterion of youth. The most successful life is that in which the nervous system remains active, youthful, and alive for the greatest number of years. It is the youth- 
ful, keenly metabolic nervous system which is most responsive to its environment.

Whatever may be the nature of that activity going on in our minds, we have at least discovered something about its simplest chemical accompaniment. Perhaps the nerve impulse is something in the nature of a propagated explosive wave in a continuous substance. Whether that wave is in the nature of a hydrolysis or an oxidation we cannot say, but at any rate it results in the liberation, in some manner, of carbon dioxide. This substance tells us whether the nerve impulse has passed this way or not. The change which liberates it may be the impulse itself. Three kinds of changes occur, then, in our brains when the nerve impulses are passing-an electrical change, a chemical change, and a psychical change. Which is the fundamental change? 


\section{APPENDIX}

THE BIOMETER: HOW TO USE IT

The study of carbon dioxide has been so connected with various forms of human activity that in spite of natural difficulties methods for its accurate quantitative determination have been highly developed. Nevertheless, none of the various methods of analysis can be used for very minute quantities of carbon dioxide. The greatest difficulty in using any micro-gas analysis is in securing freedom from the external variations of temperature and pressure. Particularly is this so in the case of carbon dioxide, for we need to consider, not only the effect of temperature and pressure variation, but also how to free the apparatus from atmospheric carbon dioxide. After we discovered a new method which detected exceedingly minute quantities of this gas we found that the ordinary method of freeing air or any other gases from carbon dioxide was not sufficiently accurate, although it should be admitted that our experience in washing gases was not very extensive. The biometer is constructed with a view to meeting these difficulties and has shown itself to be remarkably convenient for many biological as well as chemical investigations.

Uses of biometer.-The biometer can detect carbon dioxide in as small quantities as one ten-millionth of a gram. This is the amount contained in one-sixth of a cubic centimeter of the purest air, in which we assume 
3.0 parts of carbon dioxide present in 10,000 . The delicacy of the apparatus can be illustrated by the kind of experiments we can use it for, e.g.:

I. The different rates at which carbon dioxide is produced by a single fertilized and a single unfertilized egg of a fish (Fundulus hectroclitus) can be distinguished.

2. The unequal rate of metabolism of two different species of the little banana flies can be detected within ten minutes by using a single insect in each chamber.

3. The vitality of a single kernel of wheat can be detected in ten minutes.

4. The daily variation of respiratory activity of a single isopod has been determined.

5. The carbon dioxide production of the different parts of a small nerve fiber can be measured, and the unequal rates of different segments of the nerve detected.

6. The effect on the metabolic rate of the muscular contractions of very small animals, like a worm or insect, or the effect of light on small pieces of a leaf, can be demonstrated in the class in a few minutes.

7. By the use of proper reagents small quantities of many other gases can be measured.

Principle of the method.-The principle of the method was first devised in conjunction with Dr. H. N. McCoy, and, with some modifications, the biometer is constructed so as to conform thereto. The principles involved are as follows:

I. Exceedingly minute quantities of carbon dioxide can be precipitated as barium carbonate on the surface of a small drop of barium hydroxide solution.

2. When the drop of barium hydroxide is exposed to any sample of a gas free from carbon dioxide it remains 
clear, but when more than a definite amount of carbon dioxide is introduced, a precipitate of carbonate appears, which is detectible by means of a lens.

3. By the use of accurately known quantities of carbon dioxide of exceedingly high dilution it was found that the minimum amount of carbon dioxide which gives a precipitate is $1.0 \times \mathrm{IO}^{-7} \mathrm{~g}$.

4. By determining, therefore, the minimum volume of any given sample of the gas necessary to give the first visible formation of the precipitate its carbon dioxide content can be estimated accurately, since this volume must contain just the known detectible amount of the gas, which we found to be $1.0 \times \mathrm{IO}^{-7} \mathrm{~g}$.

5. By having two chambers side by side the different rates of metabolism from two different tissues can be estimated by the different speeds of formation of the precipitate and extent of the precipitate.

Description of the apparatus. - The biometer shown in Figs. I and 3 is made of glass. It consists of two respiratory chambers connected by a three-way stopcock $L$, the other arm of which is connected to one arm of another three-way stopcock $K$. (As is shown in Fig. I, for an ordinary experiment we can connect it directly to the nitrometer.) Each of the other two arms of stopcock $K$ is connected to a nitrometer, $W$ or $X$, which is used for removing the final traces of carbon dioxide from the gas with which the chambers are to be filled. The nitrometer on the right is connected to a carboy $F$ (see Fig. 5, apparatus III), filled with air free from carbon dioxide; and the other, on the left, to a similar carboy as a reservoir for any other gases that may be used as a special medium for different experiments, such 


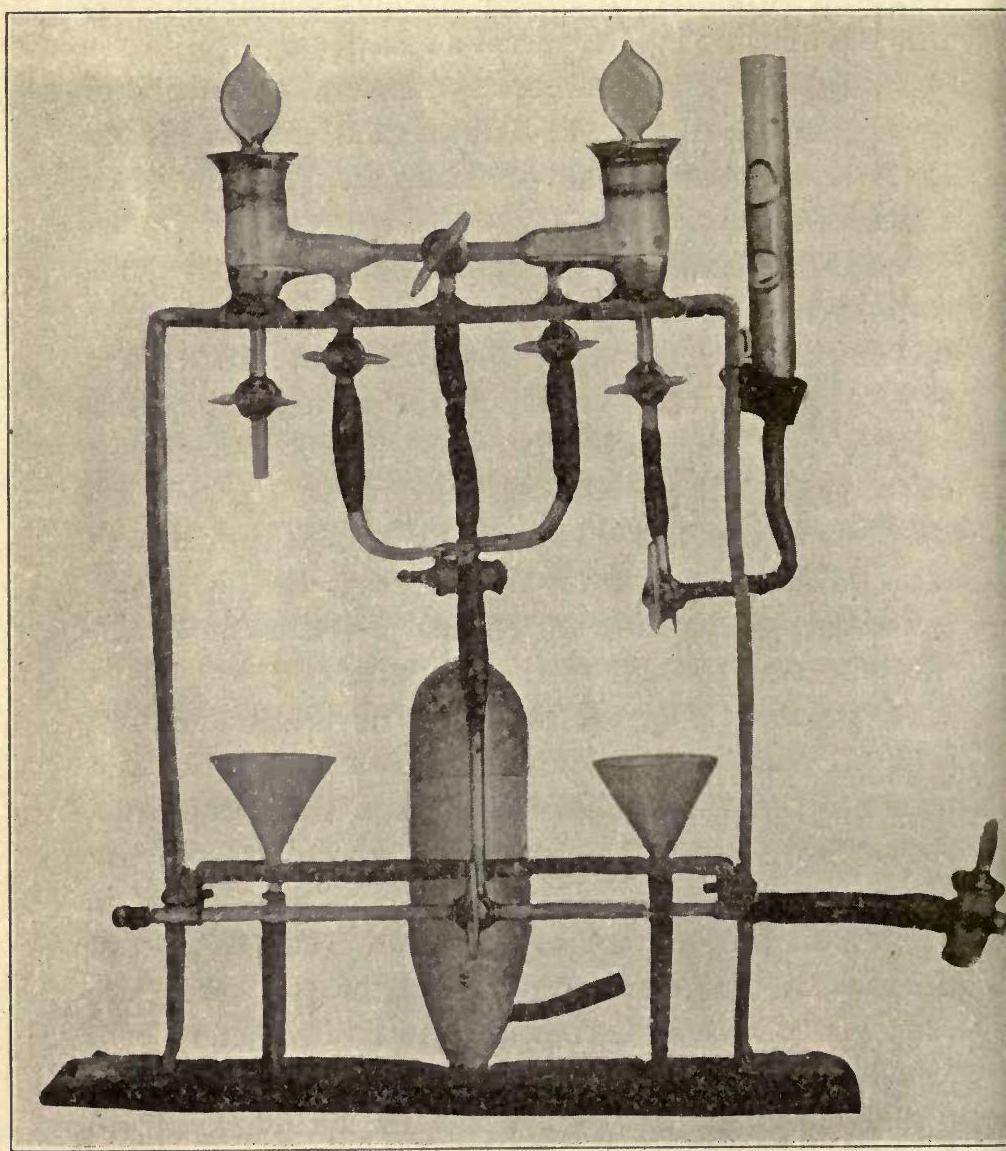

FIG. I.-The Biometer. One-fourth actual size 
as oxygen-free air, hydrogen, or volatile anesthetics, and which are exposed to an alkaline solution in order that every trace of carbon dioxide can be removed from the gas in question. As stated before, for ordinary metabolism experiments we may use but one nitrometer for ordinary air only, as shown in the photograph (Fig. I). Chamber $A$ is drawn to a capillary stopcock $C$; chamber

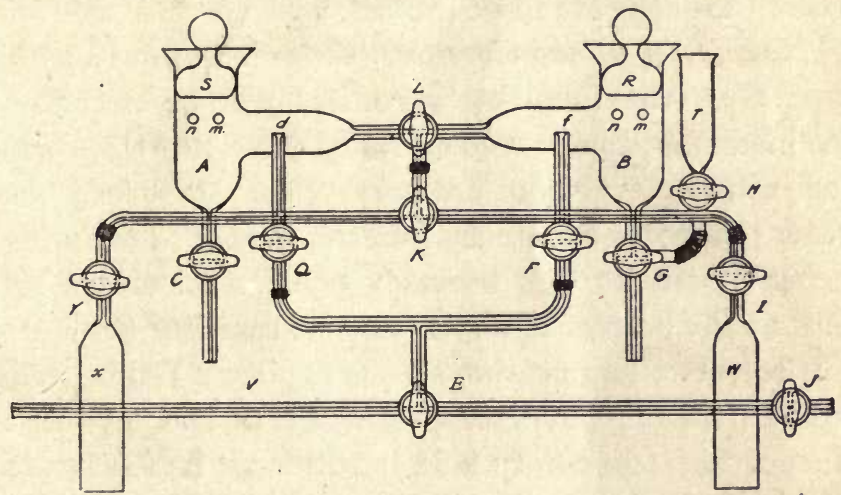

Fig. 3.-Biometer. One-third actual size. The shaded portions of the apparatus indicate the rubber connection, which is first coated by shellac and then sealed with a special sealing wax. Some parts are also sealed with mercury.

$B$ is drawn to a similar capillary stopcock $C^{\prime}$, one arm of which is connected to another three-way stopcock $G$, one arm of which is connected to a mercury burette $T$, which is used for adjusting the pressure in the apparatus. (The slightly different structures should be noted here in Figs. I and 3, the latter having no capillary stopcock $C^{\prime}$, but being directly connected with the three-way stopcock $G$. As the latter apparatus requires considerable experience in order to make it perfectly air-tight, the former type only, as shown in the photograph, is 
furnished by Eimer \& Amend when the biometer is ordered.) Each of the chambers has a capacity of 20 to 25 c.c. and is provided with the platinum electrodes $n$ and $m$ for stimulation purposes, and also with a glass stopper $S$ or $R$, which can be sealed with mercury. The air pump is connected through $J$ and the barium hydroxide solution is introduced through $V$ to $d$ and $f$, where the drops are to be formed.

How to set up the biometer. - In order to get up this apparatus, the following materials will be necessary: one biometer proper; two ordinary three-way stopcocks; one nitrometer; one ordinary glass stopcock; one water pump; one mercury burette, made of four or five inches of any broken burette; one bottle with a side neck at the bottom of about 300 c.c. capacity (aspirator bottles); two large carboys; one capillary T-tube to be bent to fit the biometer proper at $Q$ and $F$; three pinchcocks; one empty acid bottle for a half-saturated solution of barium hydroxide; two $\mathrm{CaCl}_{2}$ tubes or washbottles to protect barium hydroxide, and one carboy; one ro-pound can of Greenbank alkali; 500 g. of C.P. barium hydroxide; one yard of thick-walled pressure tubing; one yard of good antimony tubing to fit the ordinary glass tubing; a little sealing wax; 200 c.c. of redistilled mercury; a few yards of glass tubing of ordinary sizes.

Excepting for the biometer proper, most of the materials mentioned above can be found in an ordinary laboratory or can be substituted with homemade apparatus without losing the accuracy of the method.

With these materials on hand, the apparatus can be set up without any difficulty if one follows the figure very 
closely. The best way to set it up is to mount it permanently, instead of clamping it with several iron clamps and stands. The apparatus set up as in Fig. I in the lead frame or in the wooden frame not only looks better, but is subject to less damage.

How to clean the apparatus. - The apparatus is constructed and is mounted in such a way that washing and cleaning can be done after each experiment without taking it apart. Although the procedure of washing is exceedingly simple, it is better for the beginner to follow exactly the directions given below, for there are many stopcocks which have to be turned in a particular direction in order to avoid unnecessary accidents which sometimes necessitate the expenditure of considerable time in bringing the apparatus back into a working condition. An example will illustrate this: If one forgets to turn the stopcock $L$ during the washing, and the space between $L$ and $K$ becomes wet, it will require about five or six hours to wash the space and clean and dry it. The old saying that an ounce of prevention is worth a pound of cure should be borne in mind here.

Turn the water pump on. Now turn stopcock $E$ $180^{\circ}$ to the right, so that the barium hydroxide solution is entirely out of connection with the other two arms of the stopcock $E$. Remove mercury from stoppers $S$ and $R$ with a pipette, and then remove the stoppers $S$ and $R$, and tissues if there are any. Turn stopcock $L$ in such a way that the bore inside will look like this $\perp$, thus severing the connection between the vertical arm of $L$ and the horizontal arms. Turn on stopcocks $J$ and $Q$ and $F$ in order. Turn stopcock $G 90^{\circ}$ to the left. Withdraw the mercury from chamber $A$ by opening 
stopcock $C$ and from $B$ by opening the corresponding stopcock. Fill both chambers $A$ and $B$ with water acidulated with nitric acid (not more than I per cent), having both stopcocks open, then with distilled water five times, then once with alcohol, and once with alcoholl-ether. Two funnels placed under these two chambers (see Fig. I) are connected with a sink, to form an outlet for this waste water. The alcohol and alcohol-ether drained out of these chambers should be saved for re-use. Replace the stoppers $S$ and $R$. Let the machine remain untouched for drying while the suction pump is going and while the tissue for an experiment is being prepared. Five or ten minutes will be sufficient for complete drying if the water pump is in good order and the alcohol used has not contained too much water.

It is very important that we should leave the apparatus in this condition until we are ready for an experiment, and that no stopcock should be touched, for this is the only condition under which all parts of the apparatus will dry.

How to obtain air free from carbon dioxide. - It is very difficult to make air completely free from carbon dioxide by the ordinary method, i.e., by merely passing it through several alkaline bottles or alkaline towers. A simpler and surer method is shown together with apparatus III in Fig. 5 (p. I $3 \mathrm{I}$ ). It is prepared by shaking air with a 20 per cent solution of sodium hydroxide in a tightly stoppered carboy $F$, supplied with suitable tubes, one of which is led to another carboy $E$, which is filled with about ro to 5 per cent alkali solution. When the air in carboy $F$ is to be used, it is driven into the nitrometer $C$ (apparatus III) or $W$ (in case of the biometer), which is filled 
with a less concentrated alkaline solution (a weaker solution is necessary so that the chamber may be filled with air which is not too dry). Driving the air into the nitrometer is accomplished either by increasing the pressure in carboy $F$, by introducing more alkali from the carboy above $E$, or by introducing more alkali through funnel instead of from another carboy. After each evacuation of the apparatus by a strong suction this air free from carbon dioxide is introduced from the nitrometer $C$ or $W$ into the chambers through the stopcock $I$. For ordinary experiments one can keep the pressure in the carboy $F$ high enough so that air free from carbon dioxide can be driven into the nitrometer simply by opening stopcock 9 after each evacuation.

How to test purity of air.-In order to test whether or not the air in carboy $F$ is free from carbon dioxide the following experiment is necessary. It may be stated that in all ordinary experiments we use exactly the same manipulation as the one now to be described. When the apparatus is perfectly dry, the pump being at work, open stopcock (or pinchcock) 9 so that the nitrometer is filled with the air freed of carbon dioxide from carboy $F$. (If no bubbles come out by opening this pinchcock it means that there is not enough pressure in the carboy. In that case open pinchcock 8 to let more alkali siphon down from the carboy above $E$, until about 200 to 300 c.c. of air can be obtained by opening pinchcock 9.)

Shut stopcocks $C$ and $C^{\prime}$ and $J$. If the pressure pump is strong enough and all the joints are tight, chambers $A$ and $B$ should be under a strong negative pressure by now, so that when you open stopcock $C$ 
the mercury in the little vessel can be sucked up to the mark, thus making the remaining volume of the left chamber exactly I 5 c.c. ${ }^{I}$ With a pipette fill the mercury burette $T$ with mercury to the mark, open stopcock $G$ $90^{\circ}$ to the right, open stopcock $C^{\prime}$ very gently till mercury falls to the second mark in burette $T$, which is so marked that by introducing this amount of mercury the remaining volume in this chamber $B$ is now $I_{5}$ c.c. after the barium hydroxide is introduced to the top of the barium hydroxide tube in left chamber $A$. (Therefore, by introducing mercury to this mark, chamber $B$ has a capacity less than ${ }_{5} 5$ c.c., but by introducing barium hydroxide in the left chamber $A$, some of the mercury will be pushed back, so that the capacity of the right chamber $B$ is now finally exactly I $_{5}$ c.c.) Now shut stopcock $C^{\prime}$ (very important). With a pipette add mercury to the mercury burette till the level of mercury in it becomes a little lower than that of the mercury in chamber $B$. Now pull out the core of stopcock $J$, so as

The exact volume of each chamber should be calibrated once for all. If this is done, one can always work with a constant volume in both chambers, so that when a known amount in cubic centimeters of mercury is introduced so as to bring it up to the marks in the chambers the remaining volume will always be the same. The advantage in having both chambers equal in capacity is obvious. One of our apparatuses has a capacity of 21 . 5 c.c. in chamber $A$ and 22 c.c. in chamber $B$. We therefore introduced 6.5 c.c. into $A$ and marked the level of the mercury, and 7 c.c. into $B$ and did likewise. Thus when mercury is introduced up to the marks, both chambers have the same remaining volume, namely, exactly I $5_{5}$ c.c. A little error in calibrating the chamber $A$ is not very serious, as this chamber is used for the analytic purpose only, while the biometer is to be used as a quantitative apparatus; but the chamber $B$ must be calibrated with extreme care, and each introduction of the known amount of the mercury must be done accurately. This can be accomplished by means of the mercury burette $T$, which is well calibrated and can measure off any known amount of mercury with a high degree of accuracy. 
to admit air into the apparatus, and shut it. (Remove stoppers $S$ and $R$; introduce a tissue to the right chamber $B$ if performing an actual experiment, and replace the stoppers.) Seal the stoppers $S$ and $R$ with mercury. Turn stopcock $L 180^{\circ}$ to the right, so that three arms are now in communication. Shut stopcock $J$ and open $I$ very carefully and shut $I$. (It should never be opened unless the nitrometer contains more than 40 c.c. of air and stopcock $J$ is shut.) Open $J$ and shut $J$; open $I$ and shut $I$. In this way we evacuate the chambers by opening $J$, and fill them up with pure air by opening $I$. This process of washing the apparatus with air freed from carbon dioxide is repeated at least frve times. At the end of the last washing, having stopcock $I$ shut and $J$ opened, shut stopcocks $Q$ and $F$. Without touching stopcock $J$ open stopcock $I$ and raise the safety bottle $D$, so that the pressure inside of the apparatus is now equal to that of the atmosphere, and then shut $I$. Open stopcock $C^{\prime}$; the mercury in the burette $T$ should not move if the previous pressure adjustment with the safety bottle $D$ and nitrometer is properly done. Shut the stopcock $J$ so as to cut off suction; turn stopcock $E$ to right $90^{\circ}$, so that the space between $J$ and $E$ will be filled with barium hydroxide; turn it $90^{\circ}$ more to the right, so as to fill all the capillary T-tube below $Q$ and $F$ with the clear solution of barium hydroxide. Open stopcock $Q$ very gently until a hemispherical drop of half-saturated barium hydroxide is formed at $d$. Then shut $Q$ and make a similar drop at $f$ in the other chamber. Turn stopcock $L 45^{\circ}$, so that the connection between the two chambers is now severed. Shut stopcock $C^{\prime}$. If the air is completely free from a 
- minute trace of carbon dioxide, the drop of barium hydroxide should be clear, not only at the time of introduction of the drop at the beginning, but also after standing for several hours, having not a single granule of the precipitate visible with a lens.

Since the main point of accuracy in our apparatus depends on having the air free from carbon dioxideindeed, it is the most difficult part of the manipulation of the biometer to have good air-particular care must be taken to have every point of junction perfectly airtight. The points most susceptible to leaking will be the stopcocks and the mouth of the carboy where the air is preserved. A strong suction is essential for a complete washing of the apparatus with the air free of carbon dioxide.

Methods for the qualitative detection of carbon dioxide production in the tissue.-After the apparatus is cleaned and dried and the air is ascertained to be pure for use, a prepared tissue is placed on a cover-slide or the glass plate shown in Fig. 2 (p. 38 ) and introduced into the chamber $B$, no tissue being put in the left chamber $A$. The detailed method is exactly the same as the one just described. After both chambers are closed with the stoppers $S$ and $R$ and sealed with mercury, the apparatus is washed with the air free of carbon dioxide in the usual manner. Barium hydroxide solutions are introduced into $d$ and $f$, forming hemispherical drops, and the connection between the two chambers is severed by turning the stopcock between them $(L)$; then watch the drop with a lens. If the air is free from carbon dioxide, the drop in the left chamber ought to be perfectly clear, while the drop in the right chamber, if the tissue gives 
off carbon dioxide, will not be coated with the precipitate, but will have on its surface some crystals of barium carbonate, which becomes more heavily precipitated as the respiration goes on. By repeating the same experiments after interchanging the chambers, using the left for the tissue and the right for a blank, it will be possible to eliminate any possible error which might come from some technical fallacy characteristic of one particular chamber. For a casual observer the initial granule will not be distinct from a granular spot on the glass. The granules, however, will soon increase over the surface of the drop and will gradually collect downward at the edge of junction of the drop with the glass tubing. The thick band of white precipitate around the bottom of the drop will gradually extend toward the top of the drop, so that after the band reaches more than half of the hemispherical drop of barium hydroxide one can see with the naked eye, not only from the side, but also from above, the whole drop, now resembling a contracting iris. When the very top of the drop is filled with the precipitate, the whole drop of barium hydroxide will look very opaque, covered with a thin layer of the carbonate. If one take a small piece of sciatic nerve of a frog, say about $20 \mathrm{mg}$., he can see these different stages of precipitation very distinctly, but when the amount of tissue taken is very large it is very difficult to observe these phenomena on account of the too rapid formation of the precipitate all over the surface of the drop. It is therefore best to take a very small piece of the nerve for the purpose of following these different stages of the precipitation of carbon dioxide as carbonate, for the practice of distinguishing these different stages is very 
useful for a quick comparative estimate of the different rates of carbon dioxide production from two different samples of tissue.

Methods for a quick comparative estimate of carbon dioxide production from two different samples of tissue.By repeating quantitative experiments it was found that the speed with which the first precipitate appears, the sizes of the precipitates, and the shapes of the aggregation of the depesits at different stages represent different quantities of carbon dioxide, if compared simultaneously under the same conditions. Thus, with this remarkably simple means we can determine quickly the comparative output of carbon dioxide from two different tissues at the same time. The method of procedure is best illustrated by the following example:

Two pieces of the sciatic nerve are isolated from the same frog and weighed into approximately the same mass. One piece is laid on one glass plate and the other on the other plate in such a way that one part of the nerve lies across the electrodes of the glass plates as shown in Fig. 2 (p. 38). In this way, when the plates are hung on the electrodes $n$ and $m$ either nerve desired can be stimulated with the induction current. These plates are now hung on the electrodes in each chamber, and the usual procedure is followed for eliminating carbon dioxide from the apparatus. After the connection between the two chambers is closed by means of stopcock $L$, having the drops of barium hydroxide in each chamber as usual, the nerve in chamber $A$ is stimulated by the current. Then if one watches over the surface of the drops carefully from the start, the deposit of carbonate will be seen to appear first on the drop in chamber $A$, in which 
the'stimulated nerve is placed. Later the total amount of the precipitate grows much larger on the drop in this chamber. This clearly shows that the chamber in which the larger amount of the precipitate is found must have the higher concentration of carbon dioxide. Since we had exactly the same kind of air at the beginning, the conclusion is that the nerve when stimulated must give off more carbon dioxide than the resting one. This conclusion can easily be confirmed by exchanging the nerve in the chambers as usual.

The following figures will illustrate the different stages of the granulation of barium carbonate and will show

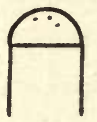

I

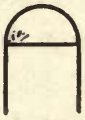

2

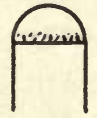

3

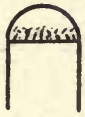

4

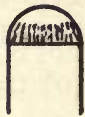

5

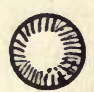

$5 a$

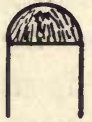

6

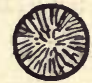

$6 a$

Fig. 4.-Different stages of the granulation of barium carbonate on the surface of the hemispherical drop of barium hydroxide; $5 a$ and $6 a$ show the top views of the drops at the time when "iris effect" is produced.

definitely how easy it is to compare the amount of carbon dioxide production at several points. And such comparison can be confirmed more exactly by the quantitative determination; the details of the method are given in the next paragraph.

The method for quantitative measurement of carbon dioxide. - While the apparatus is drying, prepare the tissue and weigh it. If everything is perfectly dry, fill both chambers with mercury up to the marks, as directed on p. II8. Remove the stopper from the right chamber only, which is to be used as a respiratory chamber, and the tissue is to be left in this; the other chamber 
is for the purpose of quantitative determination, and its stopper need not be removed. The tissue is carefully laid on the glass plate and on the platinum electrodes fused into the chamber, or it can be laid on the coverslide and placed on the mercury. Close the stopper $R$ and seal both chambers with mercury. Wash the apparatus with air free of carbon dioxide, as directed before. At the end of the sixth or seventh washing stopcocks $G$ and $F$ are closed and the time is recorded, since it is plain that from this time on we are retaining any gas given off by the tissue in the chamber. The apparatus is filled once more with air free of carbon dioxide by opening stopcock $I$; the pressure is quickly adjusted by raising the safety bottle $D$, while the stopcock $I$ is still open, and then $I$ is shut. After opening stopcock $C^{\prime}$, barium hydroxide is introduced into the tube $d$ of the left chamber $A$ only, but the solution is never introduced into the respiratory chamber $B$. Turn the stopcock $L$ in such a way as to sever the connection between these two chambers. It is imperative, not only that the hemispherical drop formed at $d$ in the left chamber should be perfectly clear at the time of introduction of this solution, but also that no visible granule of any kind should be produced on standing. No quantitative experiment can be performed unless the air is absolutely free from carbon dioxide. We have thus a control for each quantitative experiment. If at the end of the desired period of respiration, say ten minutes, the drop is perfectly clear, not having any deposit visible with a lens, a portion of the gas from the respiratory chamber $B$ is introduced into the left chamber. This is accomplished by drawing a designated amount of mer- 
cury from the left chamber $A$ by opening the stopcock $C$ and returning the same amount of mercury to the mercury burette $T$, opening the stopcock $L$, and quickly shutting the stopcock, so that the communication of the gases between these chambers is momentary. This process of driving the known amount of the gas from the respiratory chamber to the analytic chamber must be done in a few seconds. The volume of mercury withdrawn from the analytic chamber is easily determined by drawing it into a small graduated cylinder, or, more accurately, by weighing it, and this volume corresponds to the exact amount of the gas we took from the right chamber to the left, since the pressures in $A$ and $B$ are kept exactly equal to atmospheric pressure during the transfer of the gas.

One now watches the surface of the drop at $d$ with a lens to see whether or not any deposit is formed during ten minutes. The presence or absence of any visible precipitate will decide whether the amount of gas taken from the respiratory chamber contained enough carbon dioxide to give a visible deposit. With this apparatus we have repeatedly introduced accurately known quantities of carbon dioxide of very high dilution into the left chamber and found with remarkable regularity that $\mathrm{I} .0 \times \mathrm{IO}^{-7} \mathrm{~g}$. of carbon dioxide is the minimum amount which will cause a formation of detectible precipitate of barium carbonate during ten minutes. Smaller amounts of the gas than this will give no precipitate for a long time, while larger amounts give it more quickly and it appears in larger quantities. There is a sharp line of demarkation at $\mathrm{I} .0 \times 10^{-7} \mathrm{~g}$., no matter how large a space this amount of gas is occupying with the air. 
Thus in order to determine the concentration of carbon dioxide in question, one must first determine how many cubic centimeters of the gas must be introduced before we can obtain the precipitate in ten minutes; this volume must contain then $1.0 \times \mathrm{IO}^{-7} \mathrm{~g}$. Since we know the volume of the original respiratory chamber from which this known amount of gas is withdrawn, we can easily determine how much total carbon dioxide is present at the time of analysis. That is to say, the original capacity of chamber $B$ divided by this minimum quantity of the gas which gave the precipitate, multiplied by $\mathrm{I} .0 \times \mathrm{IO}^{-7} \mathrm{~g}$., corresponds to the total amount of the carbon dioxide given by the known weight of the tissue for the known period of time.

The following example will make the details of the method and calculation clear:

We took Io $\mathrm{mg}$. of the sciatic nerve of a frog and after ten minutes of respiration we drew I c.c. from the respiratory chamber into the left chamber, and found no precipitate visible within ten to fifteen minutes. Instead of now taking more gas from the respiratory chamber, we should take another fresh nerve, and, after it has respired ten minutes or longer, draw, say, I. 5 c.c. to the analytic chamber. As will be noticed, we have three variables which we can choose from, namely, the weight of the nerve, the time of respiration, or the amount of gas withdrawn from the respiratory chamber at the time of analysis. To estimate the carbon dioxide production from the isolated tissues it is far better to keep the time constant and vary the other two, for in many cases the rate of respiration varies as the time elapses. As far as the weight of the tissue is concerned, we cannot but 
vàry it, for it is not only a waste of time to try to get exactly the same amount of the tissue for each experiment, but in many cases such an attempt will lead to a number of physiological errors. Of course there is a time when we must select the same weights of the tissues for a particular experiment, such, for instance, as when we are to test the relation of the sizes of the tissue and rate of the carbon dioxide production.

The quantitative experiments, therefore, consist in determining the least volume of the gas necessary to give the precipitate for a known weight of the tissue for a known period of time. This can be found by experimenting on several tissues of different weights (too much variation of the weight should be avoided), i.e., by obtaining two sets of results, namely, the one which does not give the precipitate and the other which gives the precipitate.

These results are calculated on the standard unit, so that we can compare them with each other. We have usually taken Io $\mathrm{mg}$. and ten minutes as units. An example will explain: $\mathrm{I}_{4} \mathrm{mg}$. of the nerve for fifteen minutes of respiration did not give a precipitate when we took but I c.c. from the respiratory chamber. Therefore this nerve for Io $\mathrm{mg}$. for ten minutes' respiration will not give any precipitate when we take $2 . x$ c.c. from the chamber. In another case we took $13 \mathrm{mg}$. of the nerve, which after ten minutes' respiration produced so much carbon dioxide that 2 c.c. gave a precipitate; thus 2.6 c.c. will give precipitate for Io $\mathrm{mg}$. of the nerve for ten minutes' respiration. In this way a series of experiments with several fresh nerves was conducted in order to approximate both the minimum volume which 


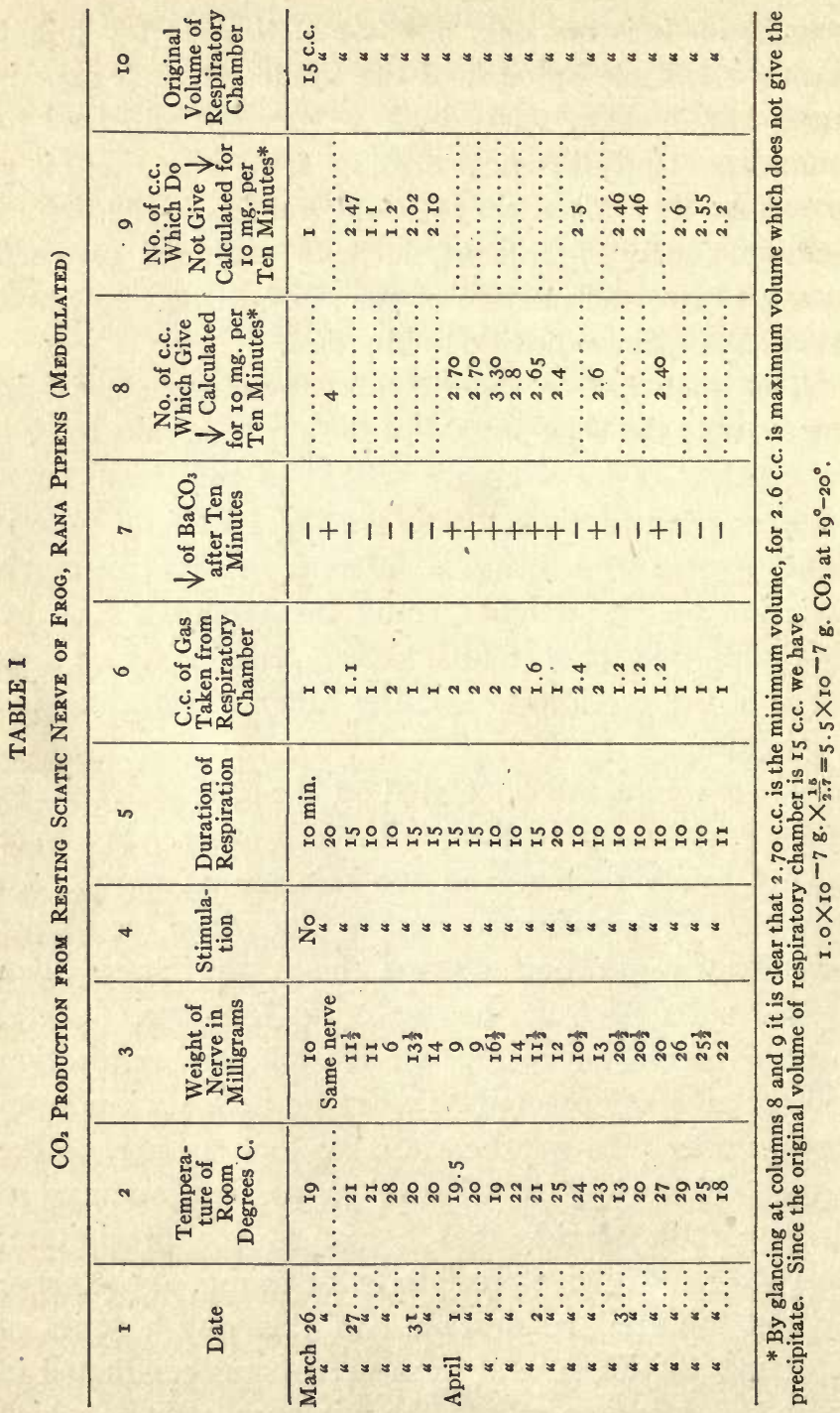


will precipitate and the maximum volume which does not give a precipitate for a definite time and weight. In Table I columns 8 and 9 refer to these columns calculated from the experiments for ten minutes' respiration by ro $\mathrm{mg}$. of the nerve. Since we know that the minimum volume which gave a precipitate must contain a definite amount of carbon dioxide, i.e., I.OX $\mathrm{IO}^{-7} \mathrm{~g}$., and since we had ${ }_{5}$ c.c. of original volume of the respiratory chamber, we can calculate the total amount of the gas given off by the sciatic nerve of the frog.

\section{APPARATUS III}

Although the use of the biometer is perfectly satisfactory for almost all micro-metabolic analyses, and sometimes is indispensable for a quick quantitative comparison of two different rates of carbon dioxide production from the different tissues, yet it is extremely inconvenient for a complete determination of carbon dioxide production from a single tissue, the metabolic rate of which is constantly changing and the availability of which is not very great. The necessity for a new device to meet this difficulty was keenly felt when we were studying the metabolic changes before, during, and after the cleavage of a single fish egg.

The new feature of this special apparatus is a device by which the air after a definite period of respiration by the tissue can be withdrawn into a tube from the respiratory chamber for subsequent complete analysis. With the new arrangement, therefore, one can make not only a complete analysis with a single tissue, but also several duplicate determinations. 
Description of Apparatus III.-As shown in Fig. 5, the main part of this apparatus consists of only one glass bulb $A$, which serves the combined purposes of respiratory and analytical chambers of the biometer. Its capacity is about 30 to 40 c.c., but can become smaller by introducing mercury in the same way as we managed in the other apparatus. The barium hydroxide tube $d$ is inserted through its wall, and the three-way stopcock 4 is attached to the bottom of the chamber. Just opposite the top of the barium hydroxide tube $d$ there is another three-way stopcock 2, one arm of which is connected to the nitrometer $C$ and the other arm of which is connected to tube $B$, into which the respired air is to be drawn for a subsequent analysis. This tube $B$ is attached to a mercury burette $G$, by which the pressure in the tube and the chamber can be adjusted. The similar mercury burette $H$ is attached to the chamber proper for the same purpose as well as for the means of driving air into the tube $B$. The remaining parts of the apparatus are exactly the same as in the biometer and are shown in the figure with dimensions.

Method for quantitative determination of carbon dioxide with apparatus III.-The detailed method is as follows: Open stopcocks 2 and 3 in such a way as to connect the chamber $A$ and the tube $B$ only. Fill the tube $B$ with mercury by raising the mercury burette $G$. Close stopcock 2 when a little excess of mercury is pushed over into the space in the capillary tube between the chamber $A$ and the tube $B$ and when the tube $B$ is known to be absolutely free from any bubble of air. The closing of the stopcock must be done in such a way that there is a connection made between the chamber $A$ and 


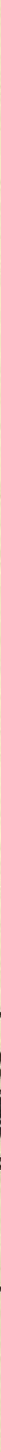


the nitrometer $C$. Increase the pressure inside of the nitrometer $C$ by raising the safety bottle $D$ above the level of the alkali in the nitrometer, and then open stopcock $I$. In this way the excess of mercury left in the capillary tube will be pushed over into the chamber $A$ and flow through stopcock 4 into a receiving vessel.

If stopcocks 2 and 3 are absolutely air-tight, there should be no air bubble present in the tube $B$ on standing. This being assured, a known amount of mercury is introduced into the chamber $A$ by means of mercury burette $H$, thus making the capacity of the chamber what was desired. Tissue is introduced into the chamber in the usual manner, the glass stopper is replaced, the chamber is sealed with mercury, and the nitrometer is filled with air free from carbon dioxide. After evacuation of the chamber and introducing pure air several times, stopcock 5 is closed and the time is recorded, the pressure is adjusted, and stopcock 2 is turned $45^{\circ}$. At the end of the desired period of respiration any portion of the air, say Io or 15 c.c., from the chamber can be driven into tube $B$. This is accomplished by raising the right-hand mercury burette $H$ and by simultaneously opening stopcocks 2 and 4 and gradually lowering the left-hand mercury burette $G$. Stopcock 2 is now closed and the pressure of the air in $B$ is made equal to that of the atmosphere and is kept under this condition, having the mercury burette $G$ at the proper height.

Remove mercury from the stopper $S$ and unstop the chamber, take away the tissue, and lower the mercury burette $H$ so that all the mercury in the chamber will flow back into the burette. The little excess of mercury 
now left in the chamber $A$ can be withdrawn through stopcock 4 into a receiving vessel. In order now to analyze the air in the tube $B$, it is better to clean the apparatus once more with water and dry it, as directed elsewhere.

The chamber is now filled with mercury so that the remaining volume of it will be as little as possible, say I5 c.c. (the exact volume need not be known here), the apparatus is sealed with mercury as usual, and then washed several times with air free of carbon dioxide, and then clear barium hydroxide is introduced into the usual tube inside of the chamber, forming a hemispherical drop at the top of $d$. If no deposit of barium carbonate forms on the surface of the drop within ten or fifteen minutes, we are sure that ordinarily the air we use is free from carbon dioxide and that the apparatus is in perfect condition. This point established, a small portion of the gas is driven from the tube $B$ into this chamber $A$. This is done by withdrawing a desired amount of mercury from the chamber $A$ into a receiving cylinder and adjusting the pressure in the chamber and tube $B$ by means of mercury burette $G$. Close stopcock 2 by turning it $45^{\circ}$.

The surface of the drop at $d$ should now be watched with a lens, as usual, for a deposit of carbonate. If no deposit appears within ten minutes, we should introduce more air from the tube, with usual care, until we get the first visible precipitate detectible with a lens during ten minutes' standing. It is very important that we should give about ten minutes of time for the reaction after each withdrawal of the air from the tube $B$ into the chamber $A$. 
The following calculation will make the method clearer:

The original volume of the respiratory chamber is 3 I. 4 c.c., to which 6.4 c.c. of mercury are introduced, making the remaining volume exactly 25 c.c. Ten milligrams of the tissue are used and are allowed to respire in the chamber for ten minutes. Then about Io to I5 c.c. of the gas are withdrawn into the tube $B ; 0.5$ c.c. of this gas gave no precipitate during the first ten minutes; 0.5 c.c. more of the same sample gave no deposit in another interval of ten minutes. Thereupon 0.5 c.c. more, a total of I. 5 c.c., was run into the chamber. A marked evidence of a precipitate appeared in ten minutes. Therefore $\mathrm{I} .5$ c.c. of this gas must contain $\mathrm{I} .0 \times 1 \mathrm{O}^{-7} \mathrm{~g}$. of carbon dioxide.

The apparatus is then cleaned and dried and a clear drop of barium hydroxide is again introduced upon the top of the tube $d$; and after making sure that the air is free from any carbon dioxide by waiting, I c.c. of the sample gas which has been left undisturbed in the tube $B$ is introduced into the chamber; no precipitate will be found to have formed within ten minutes; 0.25 c.c. more of the sample will not produce any precipitate; but if 0.25 c.c. more is taken, crystals of barium carbonate appear after ten minutes. It follows that I. 5 c.c. of the respired gas must contain $1.0 \times \mathrm{IO}^{-7} \mathrm{~g}$. of carbon dioxide.

From these duplicates it becomes certain that I. 5 c.c. of 25 c.c. capacity of the chamber now contain $\mathbf{I} .0 X$ $\mathrm{IO}^{-7} \mathrm{~g}$. of carbon dioxide. Therefore the total amount 
of carbon dioxide produced by Io $\mathrm{mg}$. of the tissue during ten minutes will be

$$
\text { I. } 0 \times 10^{-7} \mathrm{~g} . \times \frac{25}{\mathrm{I} .5}=\mathrm{I} 6.6 \times 10^{-7} \mathrm{~g} \text {. }
$$

of carbon dioxide.

In order to test the accuracy with which our new method can be used for the estimation of the exceedingly minute quantities of the carbon dioxide, a series of determinations was made on the samples whose concentrations were unknown to the experimenters at the time of analysis.

The results are given in Table II:

\section{TABLE II}

\begin{tabular}{|c|c|c|}
\hline \multirow{2}{*}{$\begin{array}{l}\text { VoLUME OF SAMPLE } \\
\text { REQUIRED TO GIVE A } \\
\text { PRECIPITATE }\end{array}$} & \multicolumn{2}{|c|}{ WeIGHT OF $\mathrm{CO}_{2}$ IN I C.C. } \\
\hline & Found & Taken \\
\hline 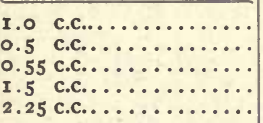 & $\begin{array}{l}1.0 \times 10^{-7} \mathrm{~g} . \\
2.0 \times 10^{-7} \mathrm{~g} . \\
1.82 \times 10^{-7} \mathrm{~g} . \\
0.67 \times 10^{-7} \mathrm{~g} . \\
0.45 \times 10^{-7} \mathrm{~g} .\end{array}$ & $\begin{array}{l}0.92 \times 10^{-7} \mathrm{~g} . \\
2.3 \times 10^{-7} \mathrm{~g} . \\
1.83 \times 10^{-7} \mathrm{~g} . \\
0.62 \times 10^{-7} \mathrm{~g} . \\
0.45 \times 10^{-7} \mathrm{~g} .\end{array}$ \\
\hline
\end{tabular}

One disadvantage of this apparatus III is that we must take into consideration temperature and pressure variation, which was entirely unnecessary for the biometer proper. If the respiration and analysis are carried out at different temperature and pressure, the ratio between the minimum volume which gives the first precipitate and the original volume of the chamber will not be rigid. In that case the minimum volume should be translated to the volume at the temperature and pressure at the time of respiration. Such correction, however, will not be necessary if the 
analysis is done immediately after the respiration, during which the variation in temperature and pressure will not affect the results beyond experimental errors, as is shown in the following calculation:

Let us suppose that Io mg. of the tissue respire for ten minutes at $18^{\circ} \mathrm{C}$. under $760 \mathrm{~mm}$. of pressure in 25 c.c. of the chamber, and suppose I. 5 c.c. of the air at $22^{\circ} \mathrm{C}$. and $730 \mathrm{~mm}$. of pressure gave the first precipitate. We shall then obtain the following results:

a) Without correction we get

$$
\mathrm{I.0} \times \mathrm{IO}^{-7} \mathrm{~g} . \times \frac{25}{\mathrm{I} .5}=\mathrm{I} 6.6 \times \mathrm{IO}^{-7} \mathrm{~g} \text {. }
$$

b) With a correction,

$$
1.0 \times 10^{-7} \mathrm{~g} . \times \frac{25}{\frac{1.5 \times(270+18) \times 730}{(270+22) \times 760}}=17.6 \times 10^{-7} \mathrm{~g} \text {. }
$$

This shows a little over 5 per cent error, which will be the maximum and almost an impossible variation, considering the ordinary weather in the laboratory for a short interval of time. Besides, we are dealing with a very small sample of moist tissue, the weight of which may easily vary within 5 per cent. 


\section{INDEX}

Note.-References give the number of the page on which the matter referred to begins.

Acid, 23; production in eggs, 4I; in muscle, $4 \mathrm{I}$; in nerves, 25 .

Action current, I3.

Aërobic tissue, 15 .

Afferent fiber, 58 .

Air, pure, 23.

Algae, red, 92.

Alkali, Greenbank, II4.

Anaërobic tissue, 15 .

Anesthesia: partial, on local excitability, 58; on conductivity, 58. See also Carbon dioxide production.

Anesthetics, 25, 6I; on refractory period, 48. On carbon dioxide production see Carbon dioxide. See also Ether, Urethane, Chloral hydrate.

Animal heat: discovery of nature of, II ; source of, II, 5 I.

Apparatus, for carbon dioxide determination. See Biometer; Apparatus III.

Apparatus III, I29; description, I30; diagram, I3I; method, I30.

Arachnid, 80.

Arbacia, 4I.

Asphyxiation: on refractory period, 48; as cause of anesthesia, 60 .

Astacus, 30.

Atmospheric oxygen. See Oxygen. Automatic ganglion. See Ganglion.

Axis cylinder, 50, 51 .

Bacterial decomposition, 27, 28 .

Banana fly, Iro.
Barium carbonate: detection of, III; precipitation of, I6, I9; solubility of, 15; stages of granulation of, diagrams, 123 .

Barium hydroxide, I5, I9, 20, 89, 94, IIO, II4, II5, II8, I2 I, I30, I33.

Bayliss, 29, 33, 45, note I, I8.

Bicycle, compared to life-process, I07.

Biometer, 6, I5, I7, I9; accuracy of, 135; bubbles in, 123; calculating results, 127, 128; calibrating volume of, Ir 8 ; carbon dioxide, free air for, II6; cleaning of, II 5 ; description of, III; diagram of, II3; photograph of, I7, II2; principles of, I IO; qualitative use of, I20; quantitative use of, I23; quick quantitative comparison with, I22; sensitiveness of, III; setting up, II4; testing purity of air in, II 7; uses of, rog.

Blaze current, 5, 88, ror. See also Electrical signs of life.

Blood supply, $\mathbf{1 6 .}$

Brain, 16, 59; increased metabolism in, 36; ring, 76 .

Brown, Horace, 87 .

Burch, 47 .

Cancer, pagurus. See Carbon dioxide production.

Carbohydrate, Io.

Carbon dioxide production: by life process, 22; comparison of, in nerve and other tissues, 29; in different animals: crabs, cancer pagurus, 30; crayfish, astacus, 30; Crustacea, 3o; dog, 
3o; frogs, Rana esculenta, and temporaria, 30; in ganglion, Limulus polyphemus, 32; in muscle, frog, Rana temporaria, 3o; lobster, Homarus vulgaris, 30 ; man at rest, 30 ; in different parts of nerve, 76,77 ; in hydrogen, 26, 43; in "inexcitable" nerves, 65; in killed nerves, 24; in nerves: carp, $R$. lat. vag., and $R$. lat. acc., 79; catfish, $R$. lat. vag., and $R$. lat. acc., 79; chloral hydrate, 65 ; dog, anterior root, posterior root, hypoglossal, 79; frog, Rana pipiens, sciatic, vesting, and stimulated, 32 ; guinea pig, 22; hypoglossal, 79; "inexcitable," 62; Limulus, claw nerve, $32 ;$ mouse, 22 ; optic nerve (whole) proximal and distal, 32; rabbit, 22; rat, 22; 6 skate, Raia erinecia, and Raia ocallata, optical, olfactory, oculomotor, 22; spider crab, Libinia canaliculata, claw nerve, whole, proximal, distal, 32; squiteague, cynoscion regalis, 22; stimulated, non-stimulated, under treatment of different concentrations of ethyl urethane, 62; turtle, 22; under anesthesia, 25; in resting nerves, I9, 22, 32; in stimulated nerves, at successive time intervals, 65 ; under anesthesia, 25, 6r.

Carbon dioxide: as a measure of metabolism, I2; as end product of metabolism, I I, 34; gradient, 79 ; increment of, on stimulation as sign of life, 87 , chap. v; influence on electrical change, I4; method of analysis of, see Biometer; method of detecting, in nerve, 16, 20; sources of, 23.

Carbon dioxide free air, II6.

Carbonate, 23.

Carp. See Carbon dioxide production.
Cat fish. See Carbon dioxide production.

Chemical energy, 84 .

Chemical processes, various, in the living matter, Io.

Chemical sign of life, algae, 93; in Australian pine, 92 ; in common glass, 92 ; in corn, 91 ; in Japanese ivy, 92; in Lincoln oats, $9 \mathrm{I}$; in mustard seeds, $9 \mathrm{I}$; in nerve, 34,55 ; in rice, $9 \mathrm{I}$; in Swedish selected oats, $9 \mathrm{I}$; in wheat, 89.

Chemical stimulation. See Stimulation.

Chemical transformation, I2.

Child, 74, 8r.

Chloral hydrate, 6r. See also Carbon dioxide production.

Chloroform, 6r.

Chlorophyll, 2.

Claude Barnard, 48.

Claw nerve. See Nerve.

Cold-blooded animals, 22.

Conducting medium, 18.

Conduction: as phenomenon of living matter 4; also chap. iv.

Conductivity, 6. See also Conduction.

Connective tissue, $16,18,46$.

Contractility, 8.

Crab. See Cancer pagurus.

Crayfish. See Astacus.

Crocker, 92.

Crustacea. See Carbon dioxide production.

Current of action. See Action current.

Cyanide. See Potassium cyanide. Cynosion regalis. See Carbon dioxide production.

Daniel cell, 52 .

Death, rapidity of, 73 . 
Dèndrite, 77; metabolic gradient in sensory, 78 .

Dextrose, 82.

Diphasic current, 13 .

Dog, metabolism in. See Carbon dioxide production.

Drugs, on refractory period, 48 .

Dry seed. See Seed.

Dyer, Thistleton, 87 .

Efferent fiber, 58; gradient in, see Metabolic gradient.

Eggs, production of acid in, 4I.

Ehrlich, 37.

Electrical changes: as functional change, 4; discovery of, 4; as sign of passage of nerve impulse, 23; influence of carbon dioxide on, 13; See also Blaze current; Electrical sign of life.

Electrical current, 37 .

Electrical resistance, changes in, after stimulation, ror.

Electrical sign of life. See Blaze current; Electrical resistance.

Electricity: measure of, 3; velocity of, 8.

Electrodes, I2, I3, 40.

Electromotive force, in nerve, 35 . Electropositive, 58 .

Energy, source of, in living matter, 9, II.

Ether, 25, 6r; for effect of, on carbon dioxide production, see Carbon dioxide production.

Ethyl urethane, 25, 63. See also Carbon dioxide production.

Excitability: degree of, 59; depression of, see Anesthetics; its relation to conductivity, 57 , chap. iv; its relation to metabolism, 59; three criteria of, 59; transmission of, 41. See also Irritability.

Faraday, 3.

Fat, ro.
Fatigue: as metabolic sign, 49; lack of, in nerve, 8,46 .

Fermentation, 10, 23, 25, 27.

Film, of barium hydroxide, ${ }_{5}$, 16 .

Fletcher, 30, 41.

Forgetting, phenomenon of, 35 .

Frog. See Carbon dioxide production.

Fröhlich, 45 .

Functional changes, $4 ;$ in the nerve impulse, 7; invisible, 4; See also Electrical changes; Chemical changes.

Fundulus hectroclitus, 1 ro.

Galen, Ir.

Galvani, 5, 13 .

Galvanometer, 3, 5, 13, 23.

Ganglion, 3I; comparison with metabolism of nerve fiber, $3 \mathrm{r}$; heart ganglion, 32. See also Carbon dioxide production.

Glass plate, 20, 37; diagram, 38 .

Gotch and Burch, 47.

Gradient: metabolic, 79; in afferent fiber, 76 ; in efferent fiber, 72; in sensory dendrite, 77 ; relation of, to direction of impulse, 78, 80; structural, 75 .

Green pigment, 2.

Growth, ro, 35 .

Guinea-pig. See Carbon dioxide production.

Haberlandt, 54 .

Heart, 3 r.

Heat coefficient, 52 .

Heat formation: in brain, 36 ; in nerve 7,49 ; its relation to metabolism, 5 .

Helmholtz, $5 \circ$.

Herrick, 7 r.

Hill, 30; on heat formation, 50.

Homarus vulgaris. See Carbon dioxide production.

Hopkins, 4r. 
Horseshoe crab. See Limulus polyphemus.

Hydrogen, 26, 60; decreased metabolism in 44 ; lack of increased metabolism in, 44 .

Hydrolysis, 52.

Hypoglossal nerve. See Nerve.

Impulse: in plant, 2; nerve, see Nerve impulse.

Inhibition: by heat, 58 ; nontransmissibility of, 58 .

Injury, 4I, 9I.

Insect, wings of, 47 .

Invertebrate, I8.

Irritable response, 103.

Irritability: definition of, 4; metabolic condition - for, 85 ; nature of, 104; origin of physical theory of, 9 ; relation of, to conductivity, 57 ; relation of, to metabolism, I04; two phases in protoplasmic, 57 .

Katabolism, 48.

King crab. See Limulus polyphemus.

Lateral line nerve. See Nave.

Lavoisier, II.

Learning, phenomenon of, 35 .

Lens, I5, 16.

Libinia canaliculata. See Carbon dioxide production.

Life: chemical sign of, chap. v; definition of, 95; quantity of, I07.

Light, 35 .

Limax, 22.

Limulus. See Limulus polyphemus.

Limulus polyphemus. See Carbon dioxide production.

Living process, I03; material changes in, 3 ; physical state of, I05.

Living things: property of, 3 ; two signs of, 4 .

Lobster. See Homarus vulgaris.
Man. See Carbon dioxide production.

Mathews, 35, 4I.

Mayer, 82.

Mayow, I I.

Medullary sheath, 5I, 58; function of, 18.

Medullated nerve, I8, 21. See also Carbon dioxide production.

Memory, 35 .

Metabolic gradient. See Gradient.

Metabolism: function of, 85 , ro4; increased, on stimulation, 34 ; in different tissues and organisms, see Carbon dioxide production; indirect evidence for, in nerve, I 2; its meaning, 50, I04; method of study of, in nerve, see Biometer; relation to behavior, $8 \mathrm{I}$; resting, 33,89 .

Methylene blue, 37 .

Motor nerve. See Nerve.

Mouse, 22.

Muscle: acid production in, $9 \mathrm{I}$; contraction of, as sign of nerve impulse, 23; increased metabolism of contracting, 35; smooth, 5 I; voluntary, I8.

Narcosis. See Anesthesia.

Narcotics. See Anesthetics.

Negative phase, 13 .

Negative response, influence of carbon dioxide, I4.

Nerve: afferent, 58; claw, I8; efferent, 58; hypoglossal, 79; lateral line, 22; motor, 2I; oculomotor, $2 \mathrm{I}$; olfactory, $2 \mathrm{I}$; optic, 22; sciatic, 2I, 22, 67; sensory, 22, 58; nerves of different animals. See also Carbon dioxide production.

Nerve fibers: Changes of weight under anesthesia, 62, 65; chemical change in, chaps. ii and iii; chemical sign of, 55 ; different 
kinds of, 58 ; electrical changes in, $5,12,13$; function of, 6 ; functional changes in, 7 ; heat formation in, 7, 50; lack of visible sign of vitality in, 7 ; longevity of isolated, 24; metabolic gradient in, 72 ; metabolism on stimulation, 55 ; oxygen consumption by, 53; physical changes in, $7 ;$ production of acid in, 25; property of, 6; resting metabolism in, 22; structural changes, 7 ; structural gradient in, 75 ; use of isolated, 23.

Nerve impulse, 6; direction of, 72 ; direction of, and metabolic gradient, 77; effect of salt on, 82 ; effect of temperature on, 83 ; nature of, 85 ; nature of material basis of, Io7; velocity of, 8 ; velocity of, and resting metabolism, 80 .

Nitrogen, electrical response in, 45.

Non-medullated nerve, I8.

Nucleus, cell, on oxidation, I6.

Oculomotor nerve. See Nerve.

Olfactory nerve. See Nerve.

Optic nerve. See Nerve.

Organic compounds, 22.

Osterhout, 92.

Oxidation: measure of, see Metabolism; rôle of nucleus on, I6.

Oxygen: as essential to life, II; atmospheric, 15; consumption by brain, 36 ; consumption by linseed oil, 35 ; consumption by nerve fibers, 53 ; consumption by stimulated nerve, 50,53 ; consumption under anesthesia, 60 ; deficiency of, on nerve metabolism, 27; discovery of, II; rôle of, on excitability, 54, 60; rôle of, in salt stimulation, 26.

Painting, chemical process in, 34 . Peas, 31 .
Permeability, 8I, I03.

Plants: differentiation from animals, 2; electrical response in, 5; resemblance to animals, 2; response in, 2. See also Seed.

Pneumatic spirit, I I.

Positive phase, $\mathbf{1} 3$.

Positive response, influence of carbon dioxide on, $\mathbf{I} 4$.

Potassium chloride, 42.

Potassium cyanide, 75 .

Priestly, I I.

Propagation, of excitability. See Nerve impulse.

Proteins, Io.

Protoplasm, 48; physical condition in, 8.

Protoplasmic respiration, 35 .

Psychic change, 3 .

Psychic life, evolution of, 2; in child, 2 ; in seed, 3 ; physical basis of, 3 .

Psychic process, physical process, accompanying, 4 .

Psychism, 3; indirect measure of, 6.

Psychometer, 3.

Rabbit. See Carbon dioxide production.

Raia erinecia. See Carbon dioxide production.

Raia ocallata. See Carbon dioxide production.

Ramus lateralis accessorius. See Nerve.

Ramus lateralis vagis. See Nerve.

Rana esculenta. See Carbon dioxide production.

Rana pipiens. See Carbon dioxide production.

Rana temporaria. See Carbon dioxide production.

Rat. See Carbon dioxide production. 
Red pigment, 2.

Refractory period, 48; absolute phase of, 48; conditions affecting, 48; relative phase of, 48 .

Respiration, definition of, Io; as fundamental to vital process, II.

Respiratory metabolism, how to study, I5.

Resting metabolism. See metabolism.

Riggs, 42.

Ringer's solution, 28.

Rolleston, 50.

Salts: permeability of, to nerve, 8 ; effects on nerve impulse, 82 ; Ringer's solution, 28; sodium, on metabolism, 43.

Sciatic nerve. See Nerve.

Secretion, 8.

Seeds: blaze current in, 5,88 ; chemical signs in, 88; deterioration of, 87 ; effect of anesthetics on, 9I; electrical sign in, 5, 88; increased metabolism of, on injury, 90 ; invisible response in, 4; metabolism in killed, 9r; old Egyptian, 88; psychic life in, 3; vitality of, at low temperature, 87.

Sensory dendrite. See Dendrite.

Sensory nerve. See Nerve.

Sheath. See Medullary sheath.

Sisyphus, 84 .

Skate. See Raia.

Smooth muscle. See Muscle.

Snyder, 5 I.

Sodium chloride, 42.

Spider Crab. See Carbon dioxide production.

Squiteague. See Carbon dioxide production.
Staircase, I4.

Stewart, 50.

Stimulation: Chemical, 40; effect of repeated, on electrical changes I4; electrical, 37 ; injury as, $9 \mathrm{I}$; mechanical, 4I, 9I ; other stimulations, 39 .

Stomata, 92.

Surface tension, 8.

Tait, 48.

Turtle, 22.

Temperature: effect on nerve impulse, 82 ; effect on nerve metabolism, 83 .

Thörner, 45 .

Transmission, of excitability. See Nerve impulse.

Twelfth dynasty, 88 .

Universe, 2.

Unstable equilibrium, I05.

Urethane. See Ethyl urethane.

Velocity: its relation to resting metabolism, 80; of the nerve impulse, different salt concentration on, 82 ; of various crustacean nerves, $8 \mathrm{I}$; temperature on, 83 .

Vertebrates. See Carbon dioxide production.

Viscera, nerve to, 18.

Voluntary muscle. See Muscle.

Waller, II; metabolism of nerve, I 2; on blaze current, 5 ; on changes of electrical resistance, IOI; on longevity of nerve, 24 ; on protoveratrin, 48 ; on staircase, $\mathrm{r} 3$.

Water, as end product of metabolism, I I.

Weston cell, 52 .

Yohimbin, on refractory period, 48. 
THIS BOOK IS DUE ON THE IAST DATE STAMPED BELOW

AN INITIAL FINE OF 25 CENTS WILL BE ASSESSED FOR FAILURE TO RETURN THIS BOOK ON THE DATE DUE. THE PENALTY WILL INCREASE TO 50 CENTS ON THE FOURTH DAY AND TO $\$ 1.00$ ON THE SEVENTH DAY OVERDUE.

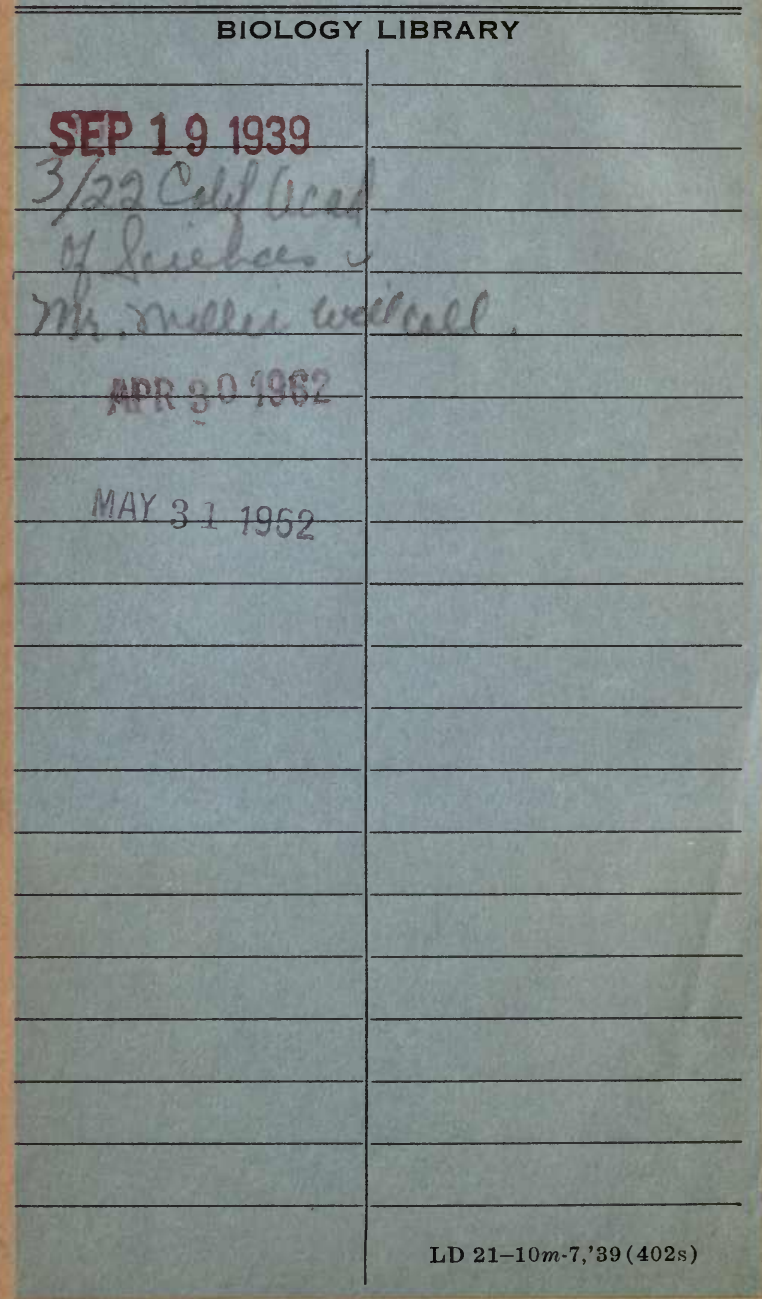




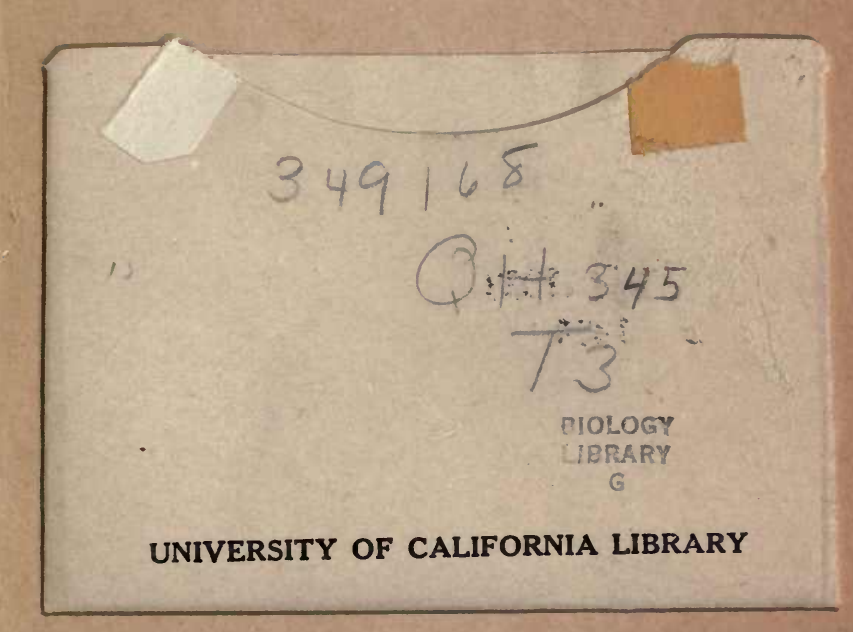


